\title{
UNHCR and partner practices of community-based protection across sectors in the East and Horn of Africa and the Great Lakes Region [Arabic]
}

Charles Mballa

Josephine Ngebeh

Machtelt De Vriese

Katie Drew

Abigayil Parr

See next page for additional authors

Follow this and additional works at: https://knowledgecommons.popcouncil.org/departments_sbsr-rh How does access to this work benefit you? Let us know!

\section{Recommended Citation}

Mballa, Charles, Josephine Ngebeh, Machtelt De Vriese, Katie Drew, Abigayil Parr, and Chi-Chi Undie. 2020. "UNHCR and partner practices of community-based protection across sectors in the East and Horn of Africa and the Great Lakes Region," report in Arabic. Nairobi: UNHCR and Population Council. 


\section{Authors}

Charles Mballa, Josephine Ngebeh, Machtelt De Vriese, Katie Drew, Abigayil Parr, and Chi-Chi Undie 


\section{مهارسات المفوضية السامية للأمم المتحدة لشؤون}

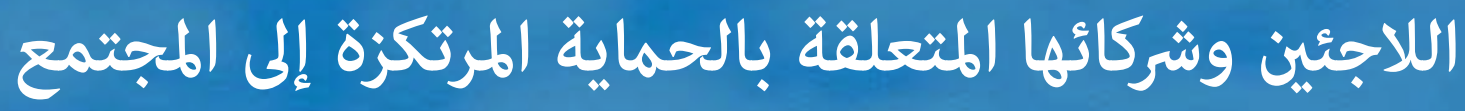

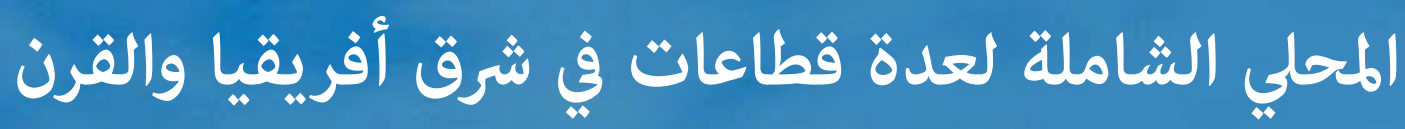

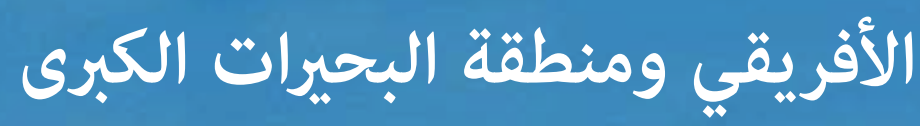

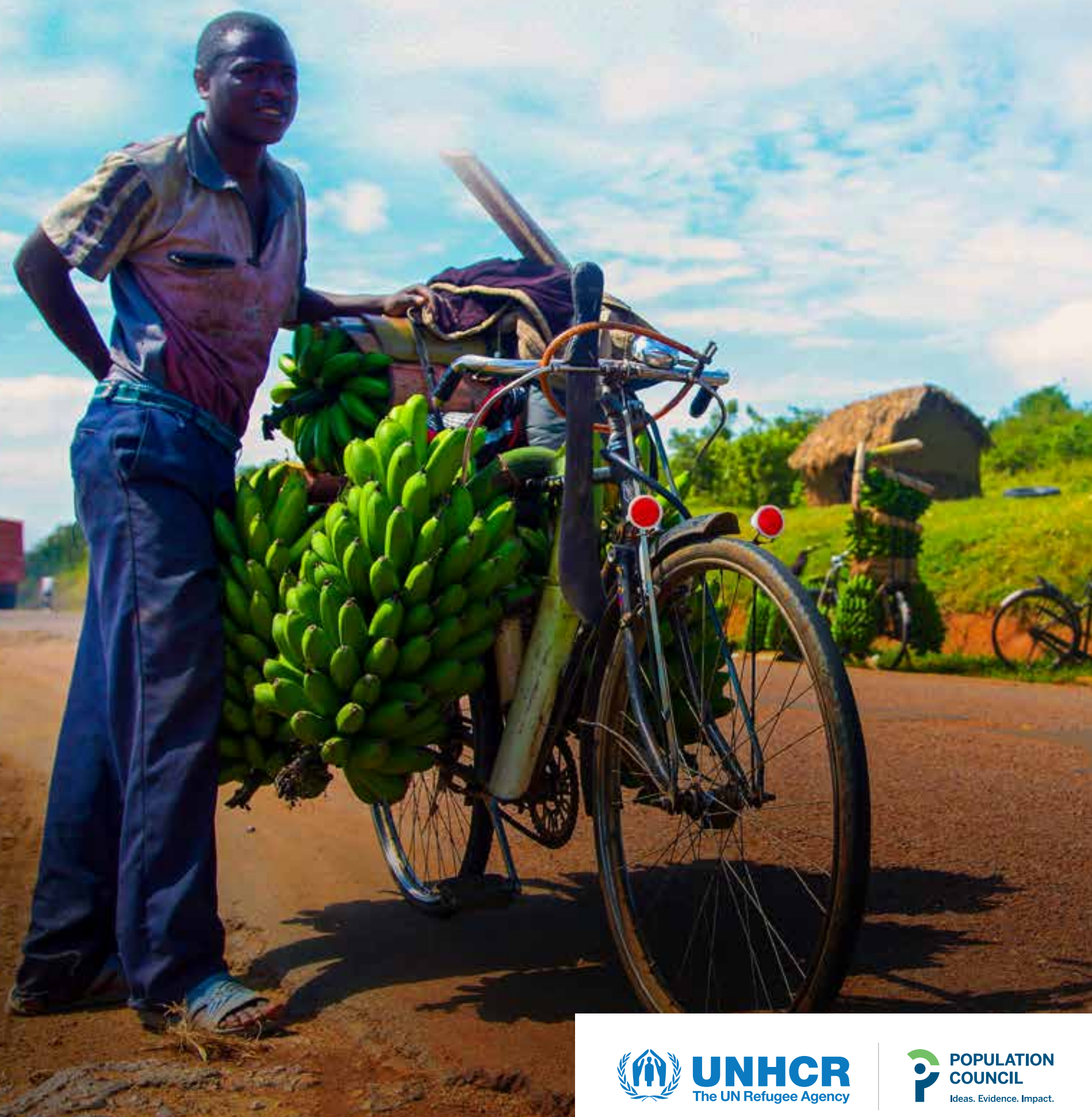




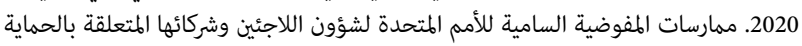

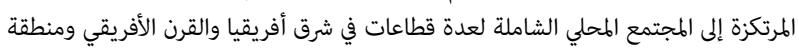
البحيرات الكبرى. المفوضية السامية للأمم المتحدة لشؤون الماعي اللاجئين ومجلس السكان. 
2

3

4

5

7

9

9

9

15

26 3. 2 3. العنف الجنسي والجنساني/التخفيف من المخاطر/الاستجابة

28 المحارسات غير المرتبطة بكوفيد

28

35

3. المساواة بين الجنسين

51

4. العنف الجنسي والجنساني/التخفيف من المخاطر/الاستجابة

55 


\section{أوائل حروف الكلمات والاختصارات}

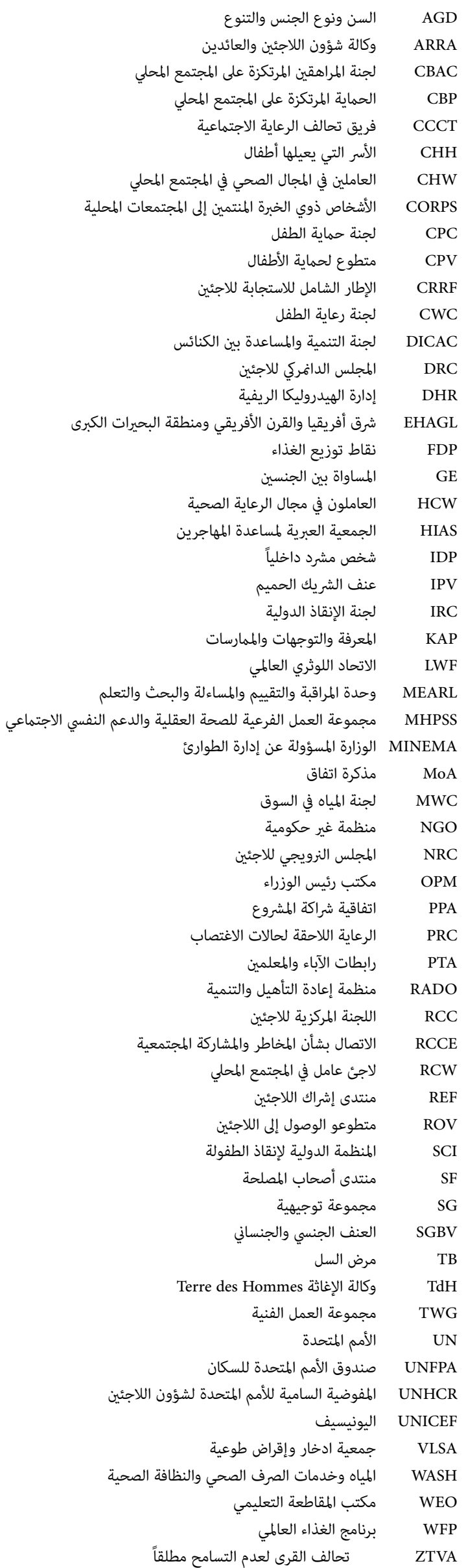




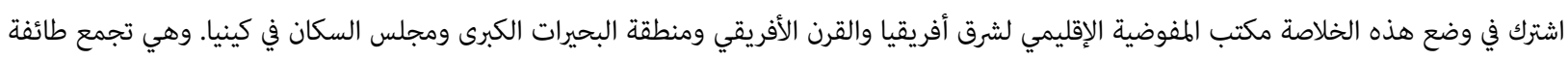

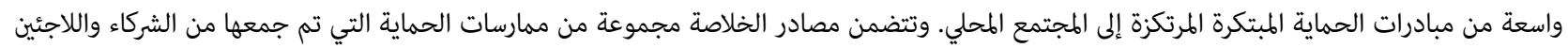

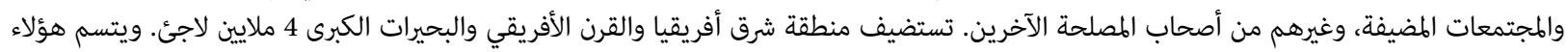

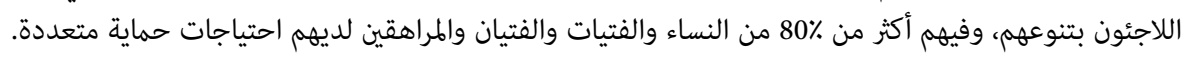

وانطلاقاً من روح نهج المجتمع بأكمله الذي يدعم الميثاق العالمي للاجئين، جاءت الخلاصة كنتيجة شراكةٍ طويلة الأمد بين المكتب الإقليمي للمفوضية ومجلس

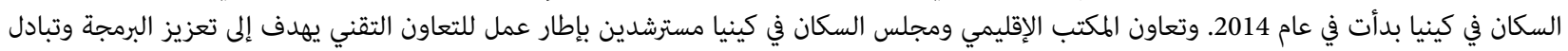
المعلومات فيما يخص أوضاع اللاجئين.

وتشهد الخلاصة على التصميم الذي أظهرته كلتا المؤسستين لتفعيل إرشادات الحماية المؤسساتية، بما يتضمن سياسة ونُهُج السن ونوع الجنس والتنوع (2018)؛

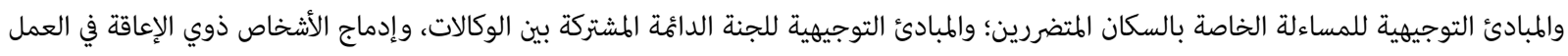

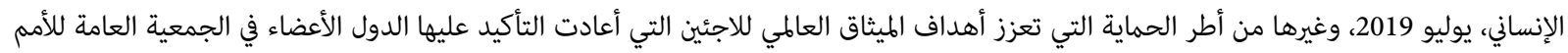

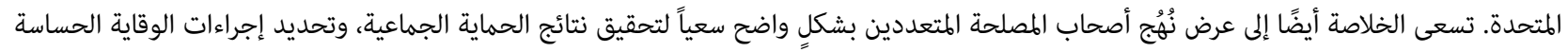

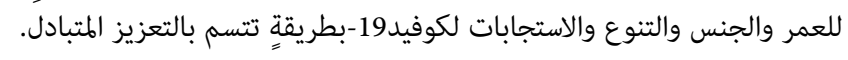

ويحدونا أملُ صادق في أن تكون هذه الخلاصة الوافية بمثابة أداة عملية لأصحاب المصلحة لتعزيز توفير الحماية؛ وتعزيز المشاركة المباشرة للمجتمعات المضيفة

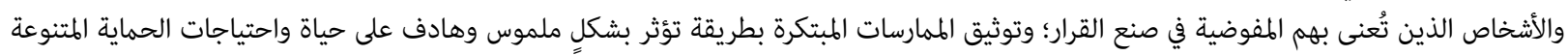
كلايين اللاجئين في المنطقة الذين تعنى

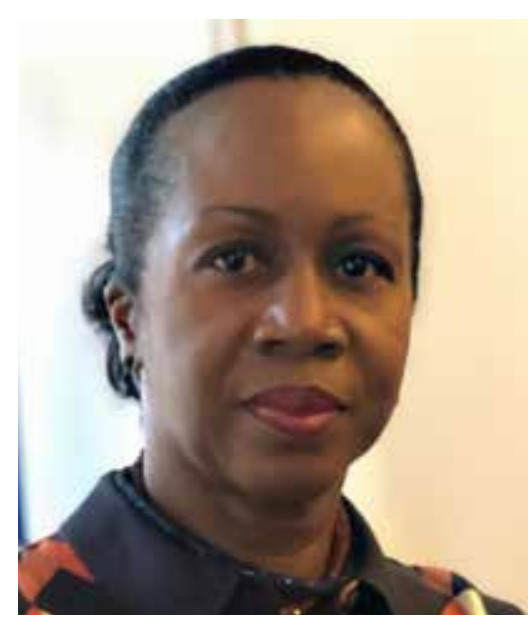

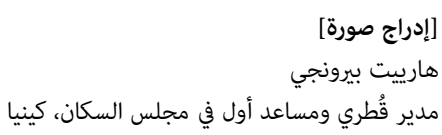

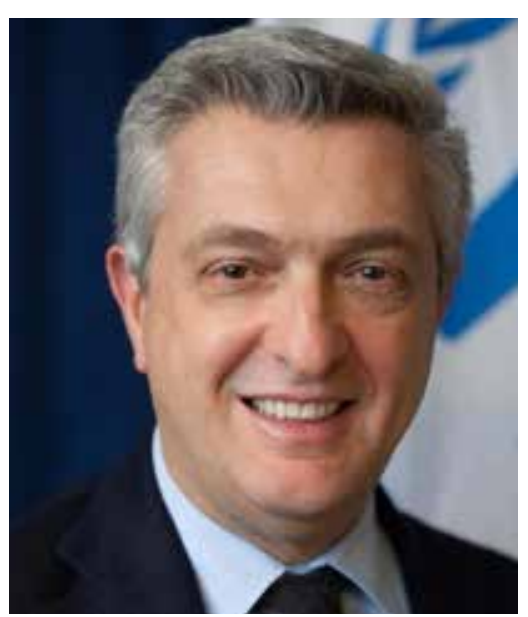

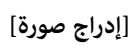
فيليبو غراندي المفوض السامي للأمم المتحدة لشؤون اللاجئين

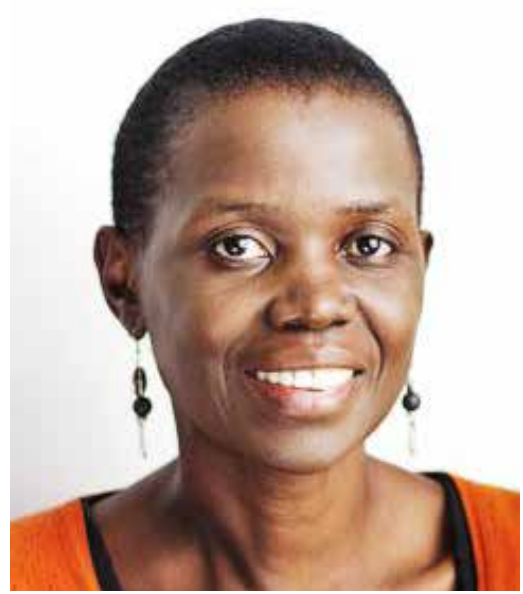

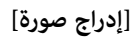
كليمنتين أو نكويتا سلامي

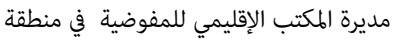
شرق أفريقيا والقرن الأفريقي والبحيرات الكبرى 


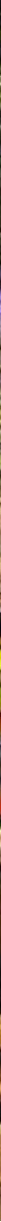

\section{مقدمة}

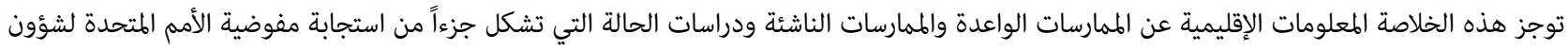

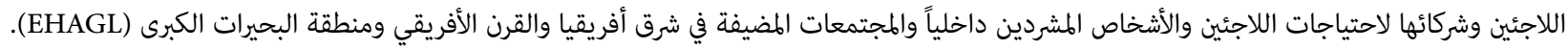

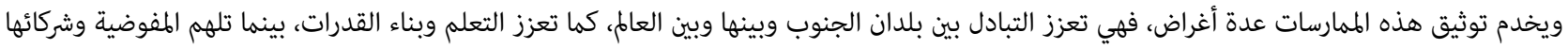

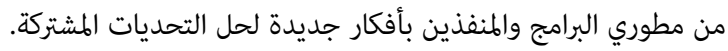

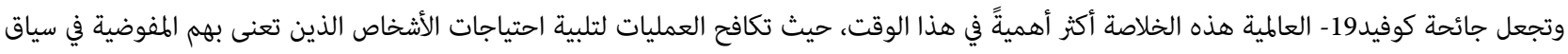

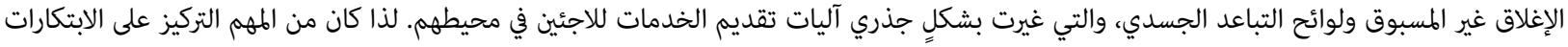

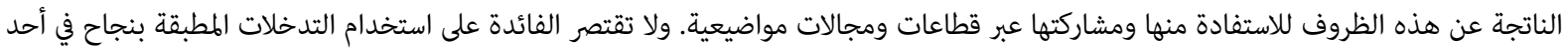

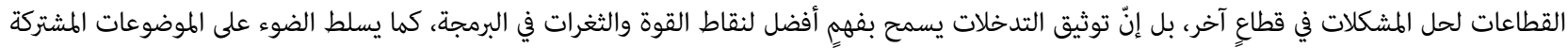
داخل وعبر العمليات القُطرية.

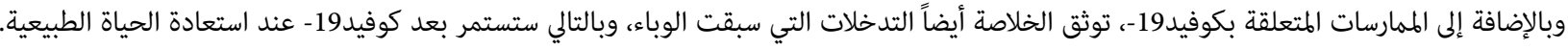

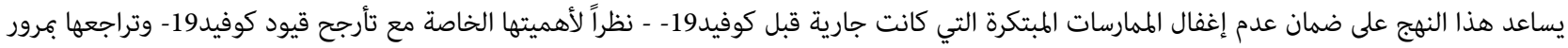

الوقت.

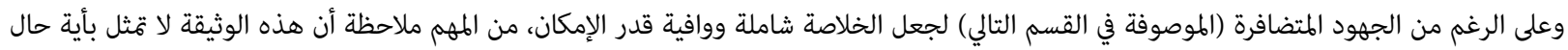

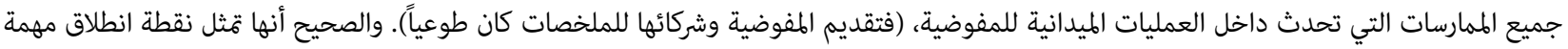

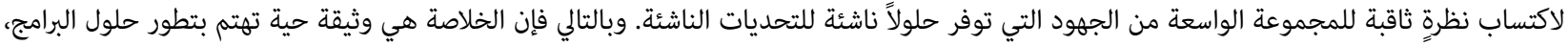

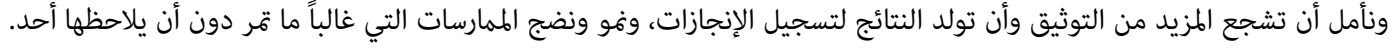

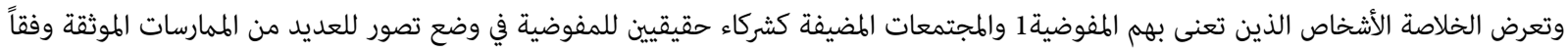

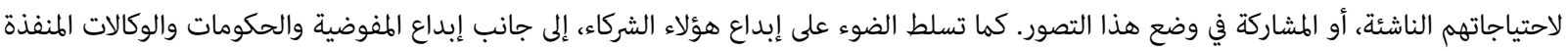

1 This includes refugees, asylum seekers, Internally Displaced People (IDP), returnees and statelesss persons. 


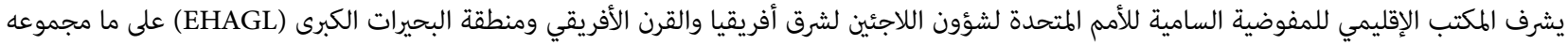

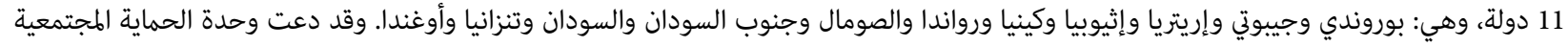

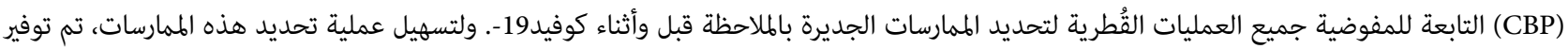

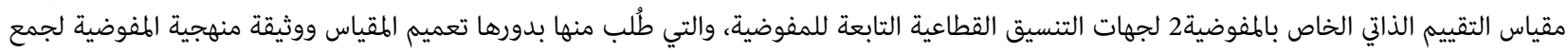

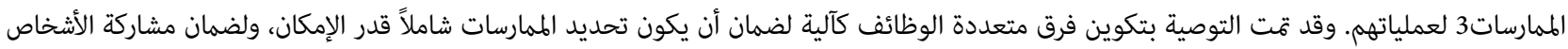

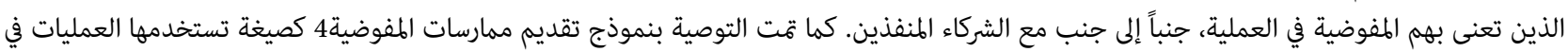

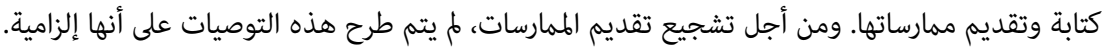

تحدد وثيقة منهجية المفوضية السامية للأمم المتحدة لشؤون اللاجئين لجمع المهارسات ثلاث فئات لتصنيف المهارسات على أرض الواقع، وهي المهارسات الواعدة،

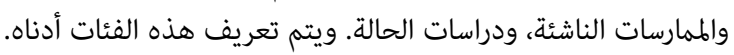

\begin{tabular}{|c|c|}
\hline التعريف & الفئة \\
\hline 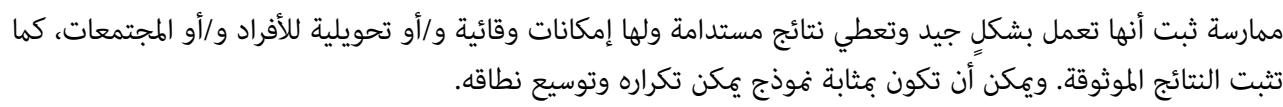 & 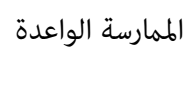 \\
\hline ممارسة تُظهر مؤشرات مبكرة على تحقيق نتائج إيجابية لتغيير حياة الأفراد و/أو المجتمعات بشكلٍ إيجابي. & الممارسة الناشئة \\
\hline 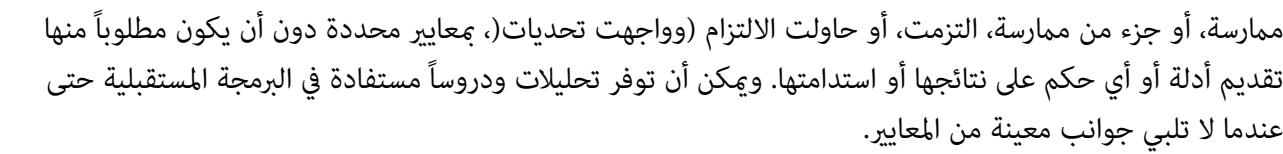 & دراسة الحالة \\
\hline
\end{tabular}

على النحو المبين في وثيقة منهجية المفوضية،

”المهارسات الواعدة هي تلك التي تفي بكعايير أعلى وتثبت بالأدلة، وستخضع لزيد من التدقيق. الممارسات الناشئة هي تلك التي تظهر بعض العلامات أو أو إمكانية

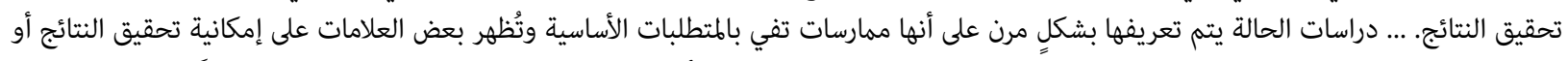

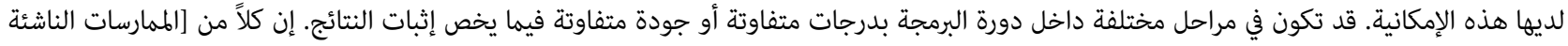

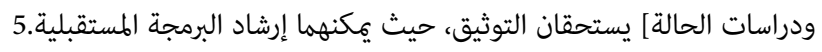

وعُقد اجتماعان افتراضيان مع جهات التنسيق القطاعية في المفوضية لتوضيح الغرض من الخلاصة الوافية، وتعزيز أهميتها، وزيادة التقديم الخاص بالعمليات القُطرية.

2 UNHCR (2019). Methodology and Background Document: Collecting Practices and Case Studies - Child Protection, Community-Based Protection, Gender Equality, Sexual and Gender-Base Violence, pp. 12-18.

3 Ibid.

4 Ibid., pp. 16-17.

5 UNHCR (2019). Methodology and Background Document: Collecting Practices and Case Studies - Child Protection, Community-Based Protection, Gender Equality, Sexual and Gender-Base Violence, p. 7. 
وفي سبتمبر 2020، قام فريق مراجعة مكون من ثلاثة أشخاص6 بتقييم كل طلب تقديم بشكلٍ مستقل، وتم تصنيف الطلبات وفقاً لتحقيقها للتعريفات المذكورة

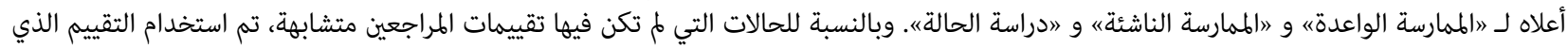

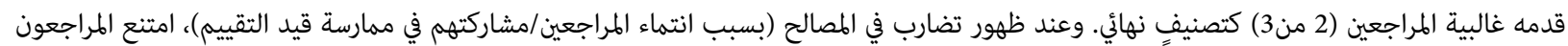

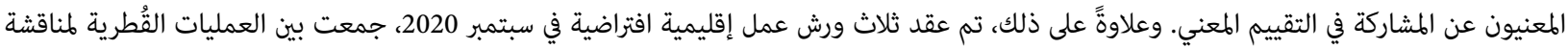

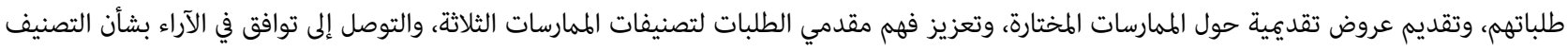

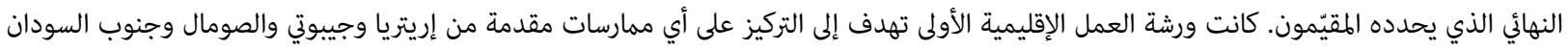

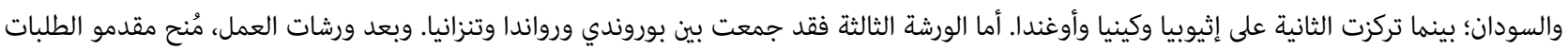

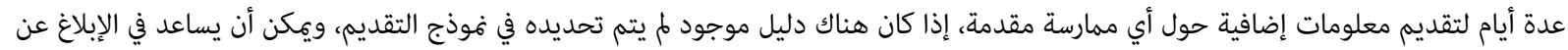

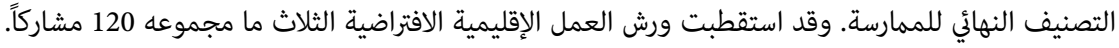

وقد تم النظر في جميع الطلبات، سواءً تم استخدام فهوذج التقديم لتقديم المهارسات أم لا (كانت الاستثناءات الوحيدة هي الطلبات التي حاولت تسجيل

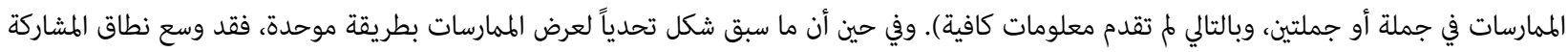

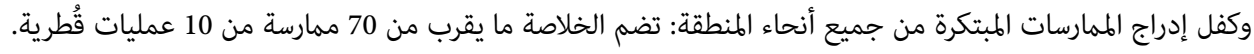

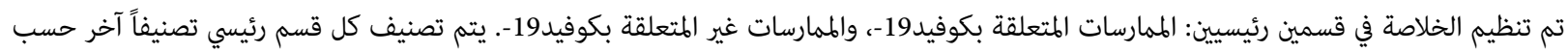

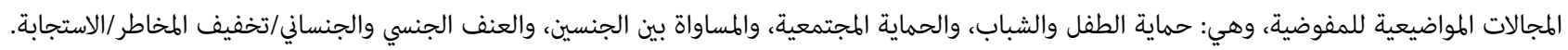

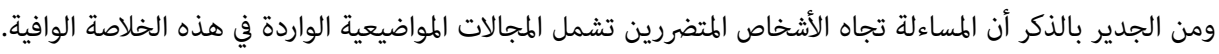

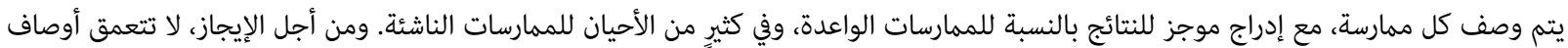

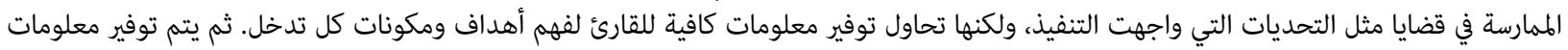

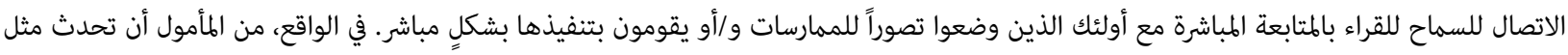

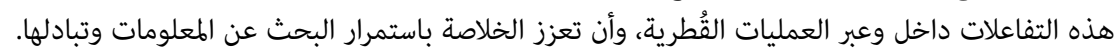

إن التداخل بين المجالات الموضوعية جديرٌ بالملاحظة، ويؤدي إلى تصنيفات للممارسات ليست خالية من الأخطاء بالضرورة في جميع المجالات. ومع ذلك، فإن هذا الواقع يوضح الترابط بين المجالات المواضيعية، وهو أمرٌ مناسب.

6 Two Innovation Officers, with the UNHCR EHAGL Bureau, and with the Innovation Service (Global), respectively; and a Population Council Senior Associate. All reviewers were based in Nairobi, Kenya. 


\section{المواضيعية الواردة في هذه الخلاصة الوافية.}

ينتهي هذا القسم التمهيدي من الخلاصة بإبراز المهارسات الواعدة التي تم تحديدها في المنطقة بناءً على التقارير الطوعية من أصحاب المصلحة، ويركز على

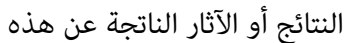

الممارسات. كما يرد وصفُ أكثر تفصيلاً لكل ممارسة تم تقديمها لإدراجها في الخلاصة (بما في ذلك جميع المارسات الواعدة) في الجزء المتبقي من الوثيقة. ممارسة واعدة من إثيوبيا: تقييم التعليم والبرمجة ونهج المشاركة المجتمعية

ال أدى هذا النهج منذ اعتماده في عام 2015 إلى تحسين الحضور والبقاء على مستوى المدارس.

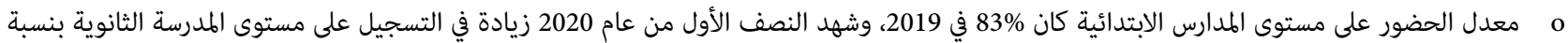
والمجتمعات المضيفة مجتمعةً. $53 \%$ في مدارس اللاجئين

ممارسة واعدة من رواندا: مجموعة عمل النظافة المجتمعية والجهود المشتركة للمجتمع في الوقاية من كوفيد19-، بما في ذلك الموسيقيون المحليون

النتائج

o

o

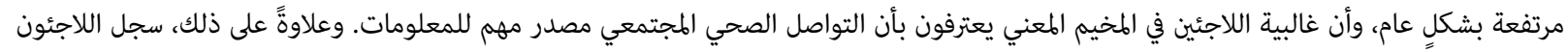

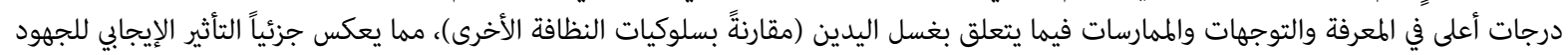

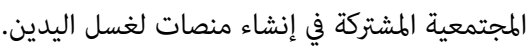
o

ممارسة واعدة من رواندا: جمعيات الادخار والقروض الطوعية (VSLAs)

النتائج

o ي يحتوي مخيم ماهاما للاجئين حالياً على 15 جمعية ادخار وقروض قروية تتكون أساساً من أشخاص ذوي إعاقة، على الرغم من أن المشاركة مفتوحة لجميع أفراد المجتمع.

o انضم أعضاء المجتمع، مبا في ذلك القادة، إلى جمعيات مدرة للدخل أنشأها الأشخاص ذوي الإعاقة. تتكون كافة جمعيات الادخار والقروض الطوعية مجتمعةً

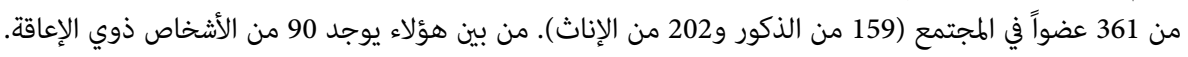
o

o

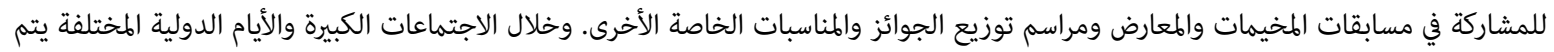

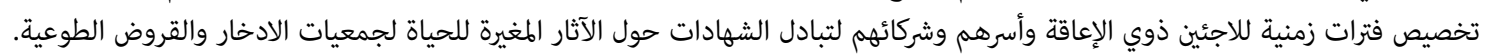
o تشهد المجتمعات أن اللاجئين ذوي الإعاقة لديهم أيضاً القدرة والقوة لدعم عائلاتهم والمجتمع ككل.

ممارسة واعدة من رواندا: تحديد الناجين والاستجابة من خلال الفحص

النتائج

o

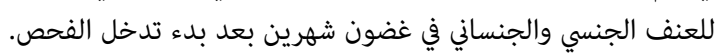

o

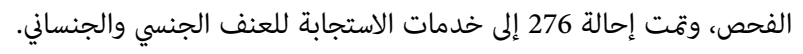

o

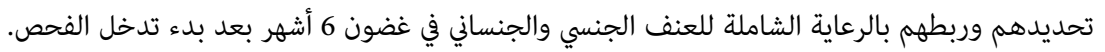

o مفاجئة في الحالات المستلمة، والتي يُعتقد أنها تتعلق بالزيادة الكبيرة في اكتشاف الناجين من العنف الجنسي والجنساني والحصول على الرعاية. تشير البيانات 


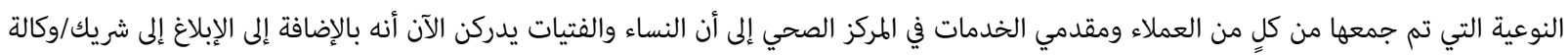

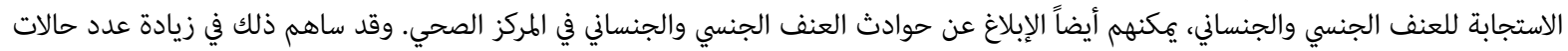
العنف الجنسي والجنساني المكتشفة.

o o

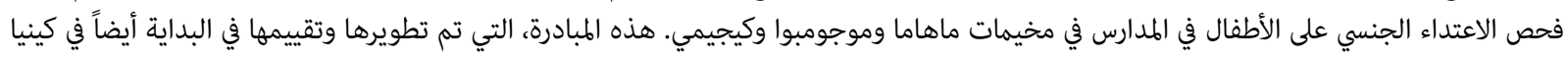
من قبل مجلس السكان ومستشفى كينياتا الوطني، معلقة بسبب كوفيد19-.

ممارسة واعدة من أوغندا: "تحالف القرى لعدم التسامح مطلقاً "ZTVA)

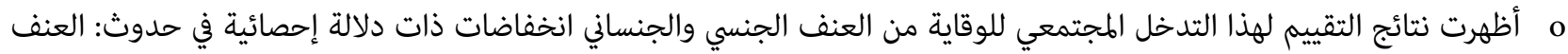

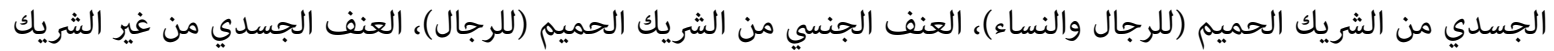

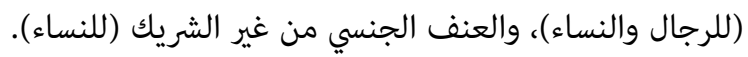
o

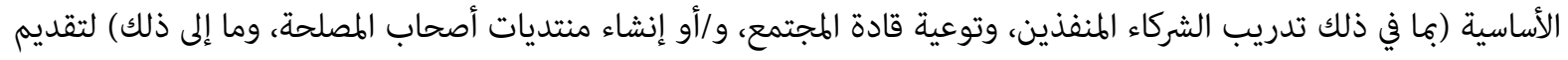
التدخل في نهاية المطاف في محيط اللاجئين في جيبوتي وإثيوبيا وزامبيا 


\section{خلاصة وافية للممارسات \\ الممارسات المتعلقة بجائحة كوفيد}

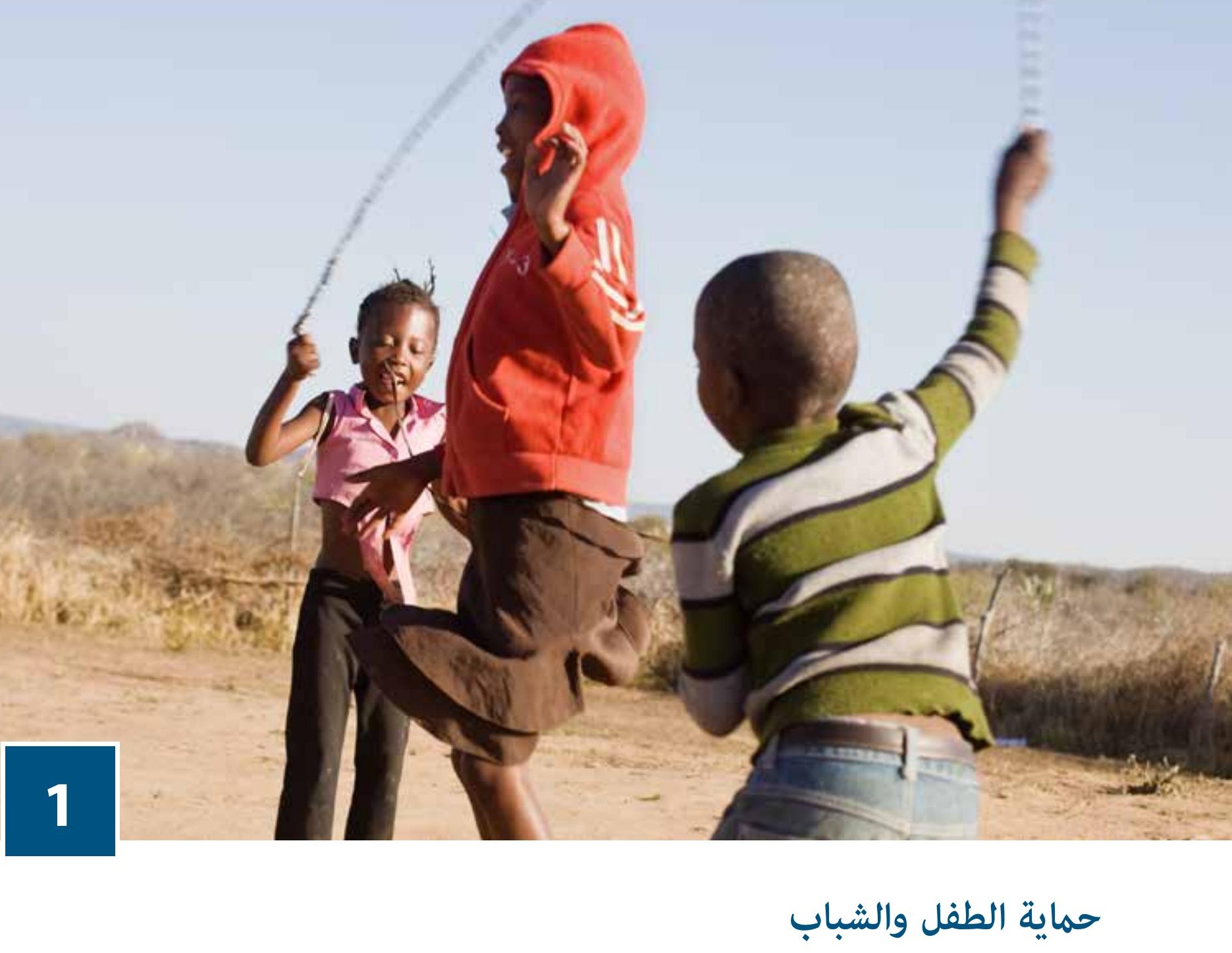

ممارسة ناشئة من جيبوتي: إدارة حالات حماية الطفل عن بعد باستخدام العاملين بحوافز وأعضاء الحماية المرتكزة على المجتمع المحلي أدى اكتشاف حالات كوفيد19- في مخيمات اللاجئين إلى إغلاقات فرضتها الحكومة قمنع دخول اللاجئين إلى هذه المواقع والخروج منها، وكذلك الأمر بالنسبة لشركاء

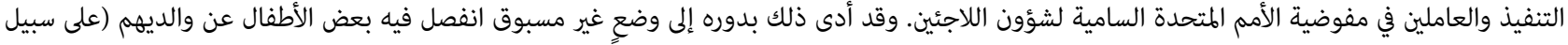

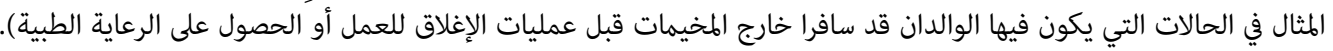

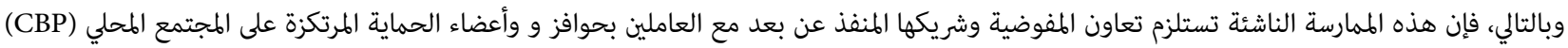

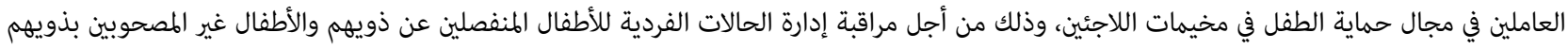
والأطفال المعرضين للخطر والأطفال المهملين أو المتخلى عنهم.

وفيما يلي تفاصيل مكونات هذا التدخل - وهي الزيارات المنزلية، والتوعية، وجمع بيانات إدارة الحالة الخاصة بحماية الطفل:

الزيارات المنزلية

o o o تحديد الأطفال المهملين والمتخلى عنهم والمفصولين عن بعضهم وغير المصحوبين بذويهم والأيتام 
o

$$
\text { o رفع الوعي المجتمعي بتدابير الحماية من فيروس كورونا المرتكزة على المجتمع المحلي }
$$

جمع البيانات

o

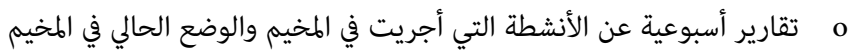

o

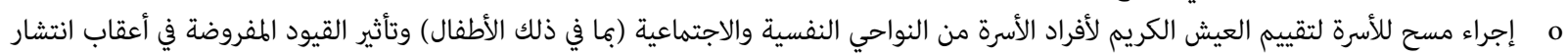

كوفيد19- على الحياة اليومية للاجئين

النتائج

تم تحديد ما مجموعه 41 طفلاً ناجياً من خلال هذا التدخل في فترة الأشهر الأربعة الأولى التالية لظهور كوفيد19-. الناجون مسجلون في برنامج إدارة الحالة

الجاري.

الشريك/الشركاء: شبكة العمل الدولية للأطفال

لمزيد من المعلومات، اتصل ب:

desomer@unhcr.org لورا دي سومر باتص من المعات

أرنو نتاهومباغازي: هيلين تشيج وانجوي:

ممارسة ناشئة من تنزانيا: راديو اللجتمع الهحلي للتعليم أثناء كوفيد19-

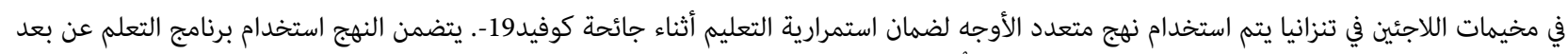

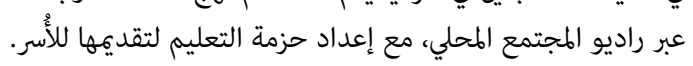

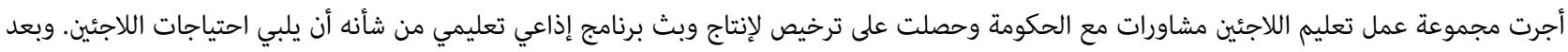

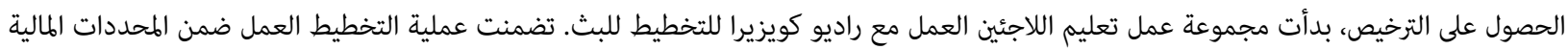

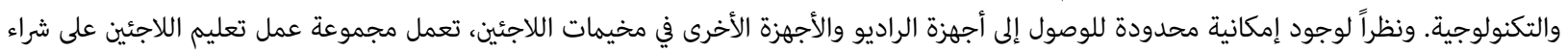

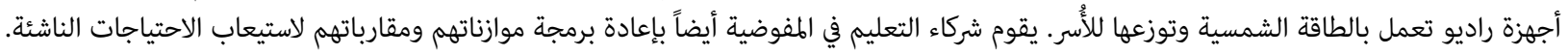

بالإضافة إلى ذلك يتم إعداد حزم التعليم في المنزل، بما في ذلك تصوير نسخ من الكتب المدرسية المرتكزة على المناهج الدراسية، لأغراض التعلم في المنزل، والتي تستهدف بشكل رئيسي طلاب المدارس الثانوية.

$$
\begin{aligned}
& \text { الشريك/الشركاء: } \\
& \text { مجموعة عمل تعليم اللاجئين } \\
& \text { راديو كويزيرا } \\
& \text { لمزيدٍ من المعلومات، يرجى الاتصال بـ: } \\
& \text { تامار جوانيان: joanian@unhcr.org }
\end{aligned}
$$




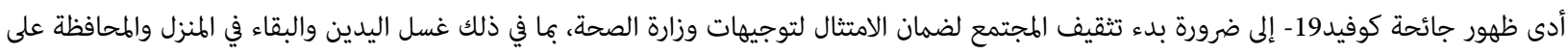

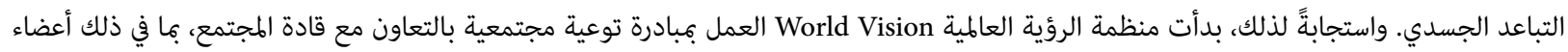

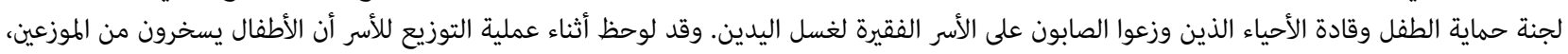

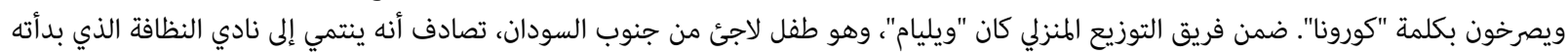
World Vision

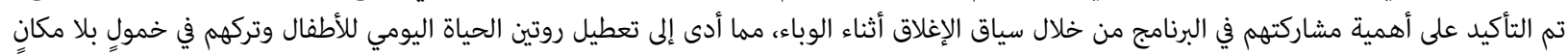

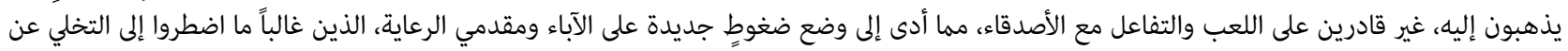
العمل، أو إيجاد خيارات جديدة لرعاية الأطفال.

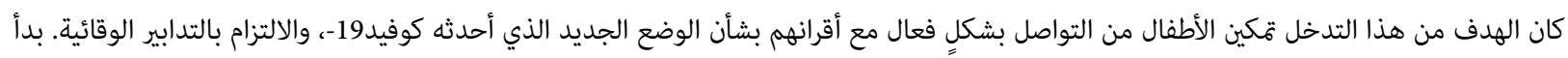

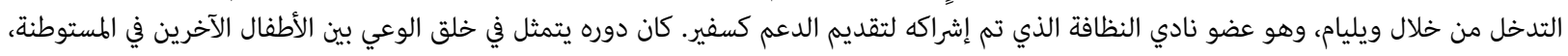

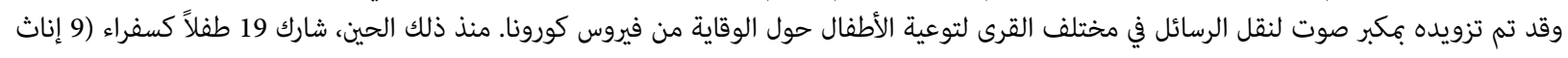

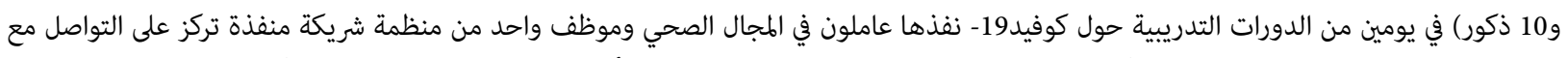

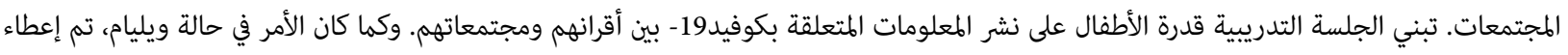

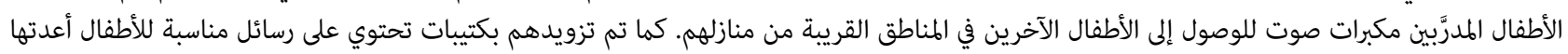

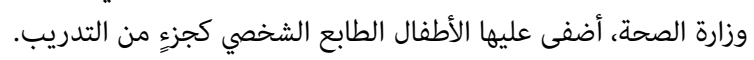
النتائج

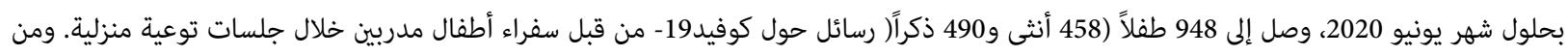

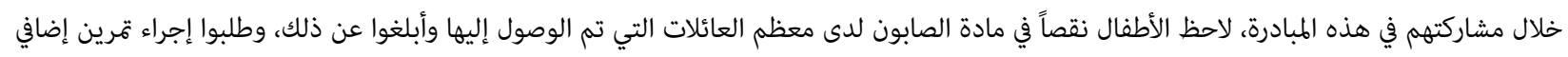

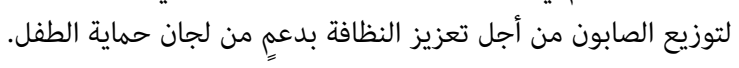

$$
\text { منظمة الرؤية العالمية الدولية }
$$

فيرونيك نجو: بروبئ مادرارا بريندا أدراكو مادرارا: Britimorenda@gmail.com ؛Brenda_Madrara@wvi.org

دراسة حالة من جنوب السودان: الاستفادة من الطلاب في إرسال رسائل بخصوص كوفيد19- في المناطق الحضرية

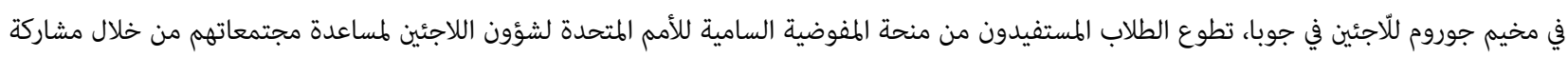

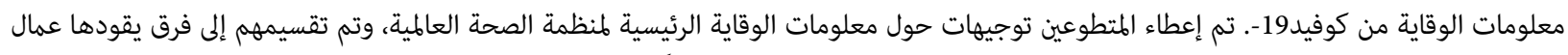

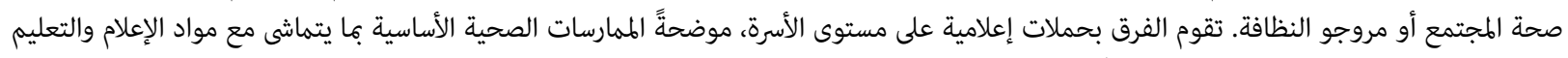
والاتصالات الموصى بها. تقوم فرق الطلاب أيضاً بإحالة الحالات الطبية الفردية إلى الشركاء في مجال الصناء الصحة.

الشريك/الشركاء: متعددون

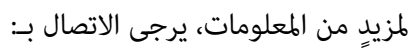
زامار جوانيان: joanian@unhcr.org 
ممارسة ناشئة من جنوب السودان: "ميكن للجميع إحداث فرق؛ كل عمل مهم"

في مخيم دورو للاجئين، يوجد في كل قرية ممثل للشباب (رئيس) يشارك في لجنة شباب المخيم. تم تحديد ثمانية أعراق مختلفة بين اللاجئين، ولكل منها لهاجاتها

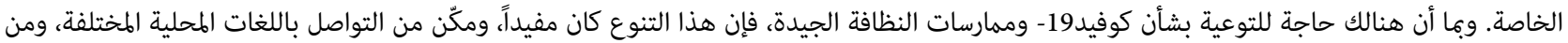
أجل النجاح فإن وضع رسائل كوفيد19- الرئيسية في سياق المخيم المحلي أمرٌ مطلوب.

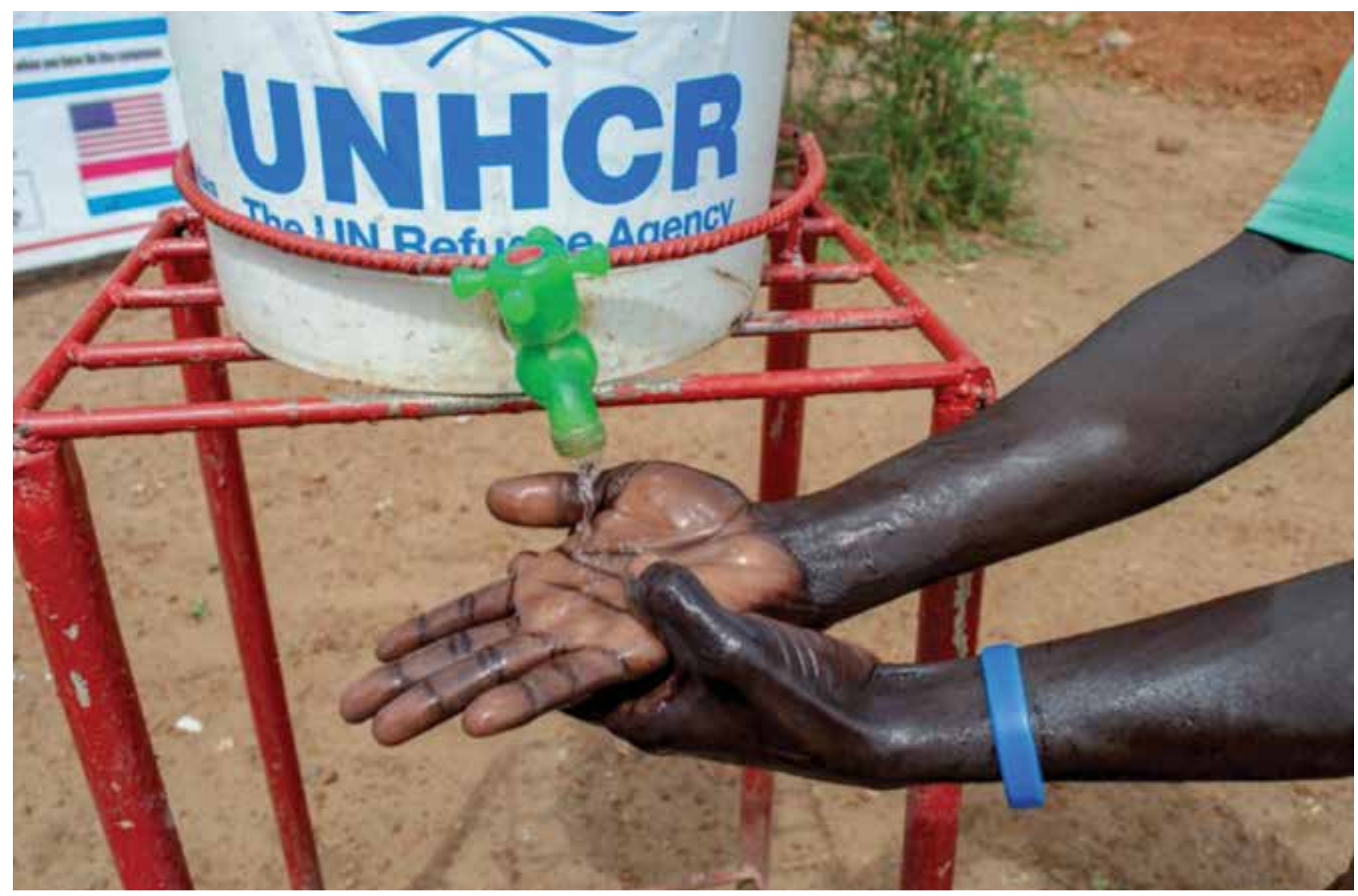

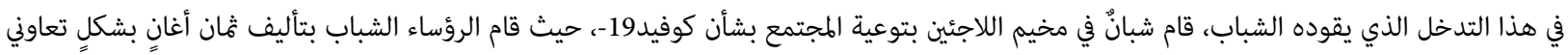

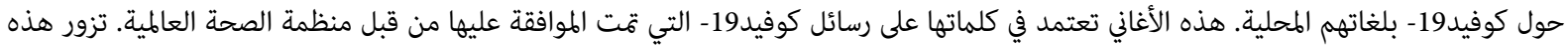

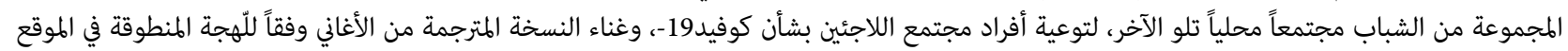
الفرعي المحدد.

تؤكد المجموعة على التباعد الجسدي طوال أدائها، إلى جانب غسل اليدين بشكلٍ مناسب، والأغاني المؤلفة مبنية على رسائل كوفيد19- الرئيسية التي قتت الموافقة عليها من قبل منظمة الصحة العالمية.

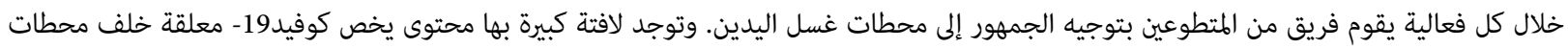

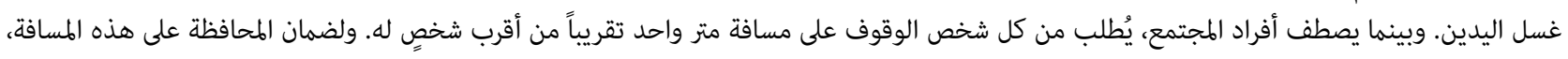

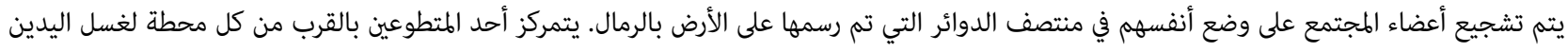
لتعليم تقنيات غسل اليدين الموصى بها للنساء والرجال والأطفال.

الكراسي المخصصة للجمهور موزعة بتباعد متر واحد فيما بينها، ويتم تشجيع كل من يختار الجلوس على الحصائر على الحفاظ على نفس المسافة. وعندما قتملئي

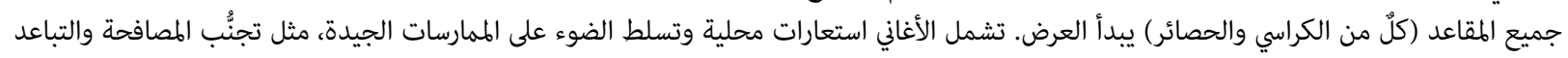

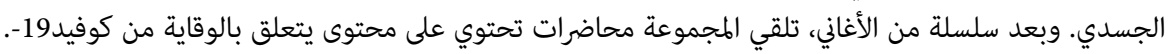

توثق لجنة الشباب عدد المناطق التي قتت زيارتها، وعدد جلسات الأداء التي تم إجراؤها، وعدد الأشخاص الذين تم الوصول إليهم. وفي يوليو 2020، ومن خلال

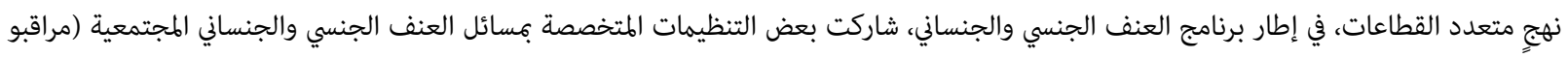

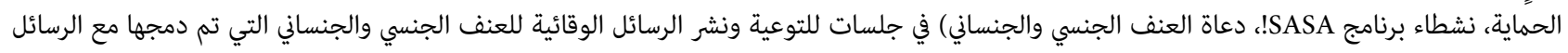



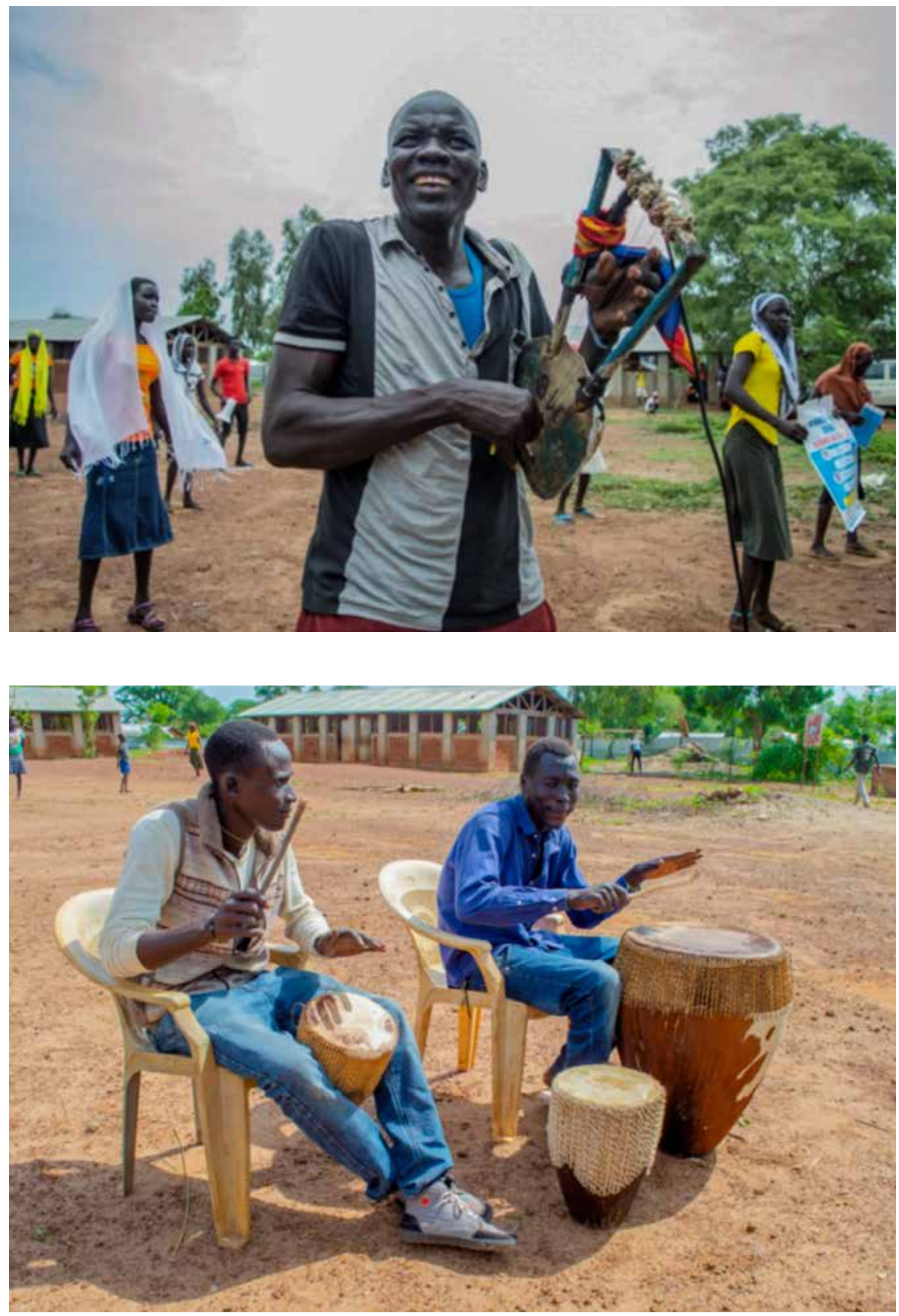


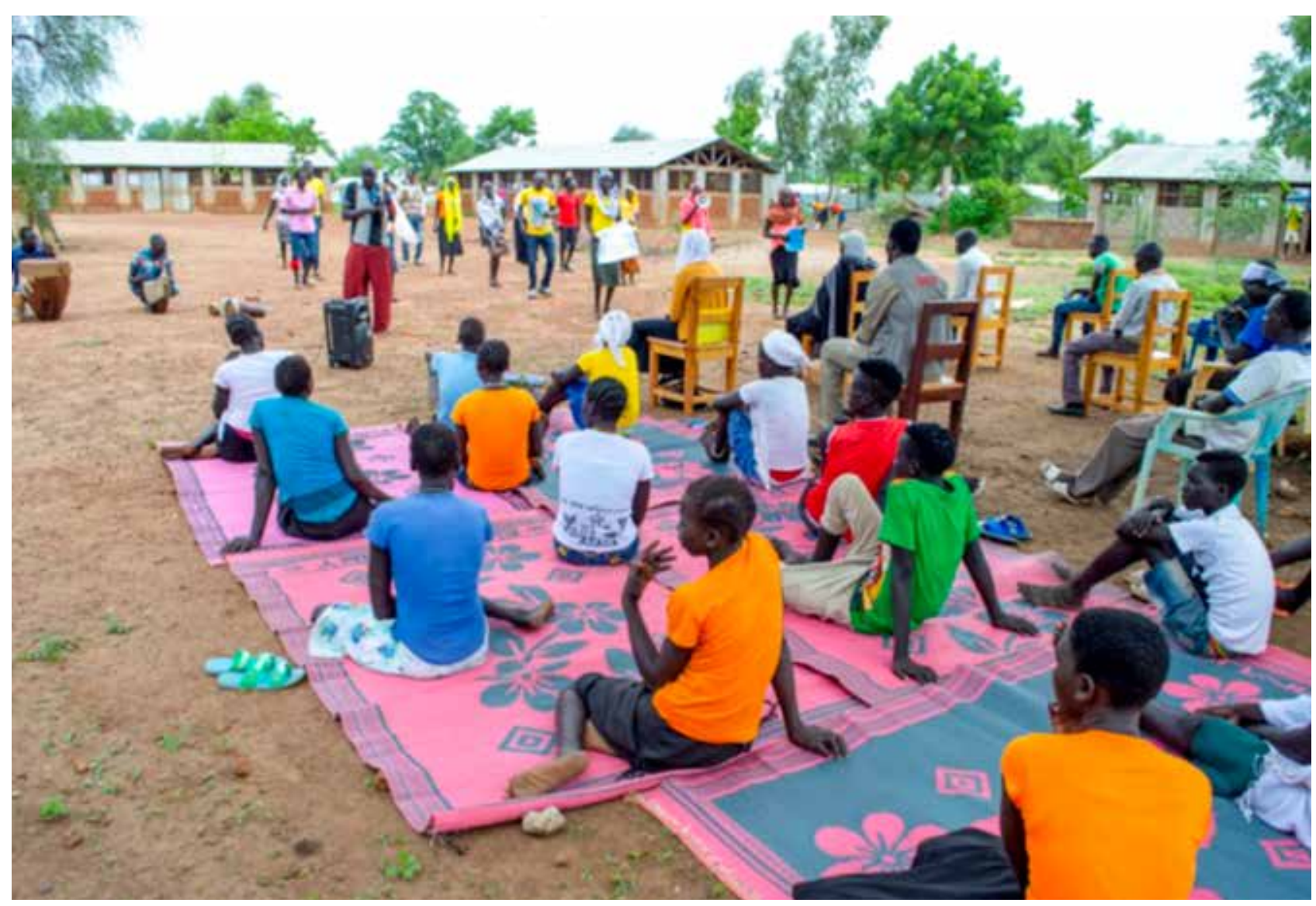

الوقائية لكوفيد19-. وقد تم الوصول إلى إجمالي 4,899 فرداً من أفراد المجتمع (2,092 من الذكور و2,807 من الإناث).

بدأت هذه المجموعة الشبابية المبادرة من تلقاء نفسها، لكنها بحاجة إلى دعم الجهات الفاعلة الإنسانية لاستمرار أنشطتها. يمكن لمثل هذه المبادرات المحلية أن توفر منصة مؤثرة لنقل الرسائل الهامة المعدلة لتناسب السياق المحلي والأعراف.

$$
\begin{aligned}
& \text { الشريك/الشركاء: إ: } \\
& \text { مفوضية شؤون اللاجئين } \\
& \text { المجلس الدافركي للاّجئين } \\
& \text { لمزيٍٍ من المعلومات، يرجى الاتصال بـ: }
\end{aligned}
$$

petros@unhcr.org د. جبريوولد بيتروس يوهانس توماس جون هيذر، رئيس لجنة الشباب، مخيم دورو للاّجئين ألور كول، نائب مدير المخيم في جمهورية الكونغو الديمقراطية، مخيم دورو للآلّئين 



$$
\text { لشزيد من المعلومات، يرجى الاتصال بـ:الشركاء: المعلومات غير متوفرة }
$$

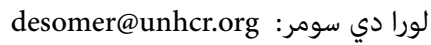

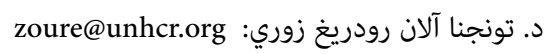
أوبه عبدي حسن: تونجا الان روديغ زوري:

دراسة حالة من إثيوبيا: مجموعات WhatsApp لقادة مجتمع اللاجئين ومتطوعي التواصل مع اللاجئين في أديس أبابا

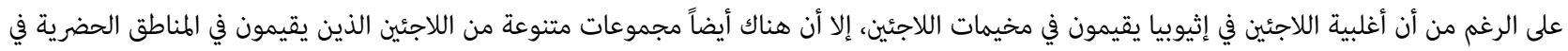

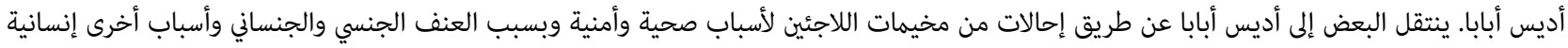

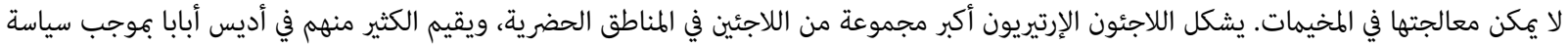

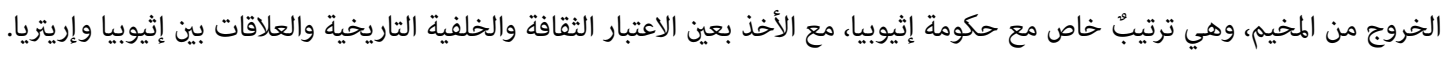

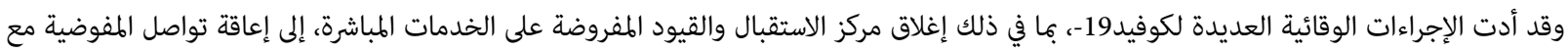

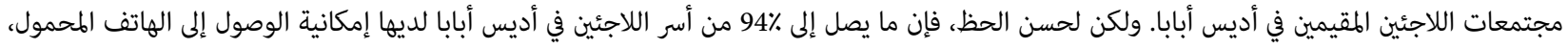

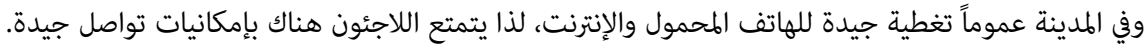

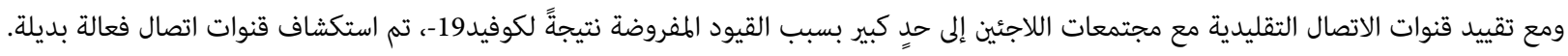

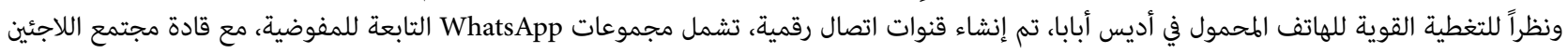
والمتطوعين في مجال التوعية.

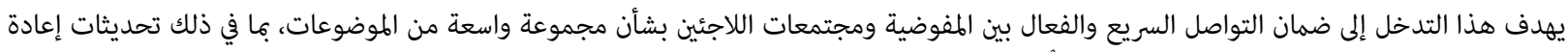

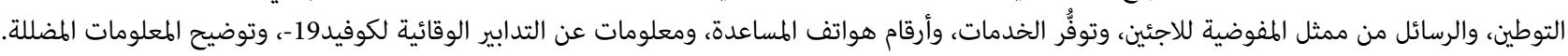

أنشأت المفوضية ثلاث مجموعات عبر WhatsApp لقادة مجتمع اللاجئين (15-120 عضواً في كل مجموعة)، تمثل جميع الجنسيات الرئيسية في أديس أبابا،

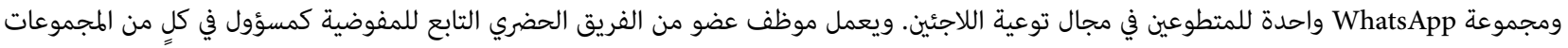
الأربعة، حيث ينشر المعلومات ذات الصلة ويجيب على الاستفسارات.

يتعين على أعضاء مجموعات WhatsApp الالتزام بإرشادات معينة، بما في ذلك الامتناع عن مناقشة الحالات أو مشاركة معلومات حساسة أو شخصية عن اللاجئين.

مَكّن مجموعات WhatsApp قادة اللاجئين من الوصول إلى المعلومات ذات الصلة، وهم مكلفون بدورهم بنقل المعلومات لمجتمعاتهم، وخاصةً المجموعات التي لديها احتياجات خاصة. ويشكل هذا الاتصال ثنائي الاتجاه أداةً لتعزيز التمكين وتعزيز الشراكة التهات الأفقية بين قادة اللاجئين والمفوضية.

لمزيد من المعلومات، يرجى الاتصال بـ: الشريك/الشركاء: المعلومات غير متوفرة أوتا هلينوماز: hlinomaz@unhcr.org نونو عليي: aliyi@unhcr.org 


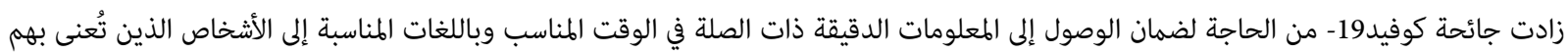

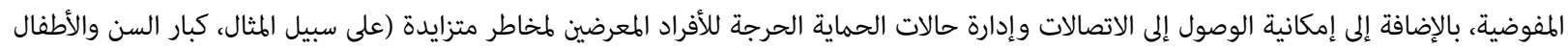

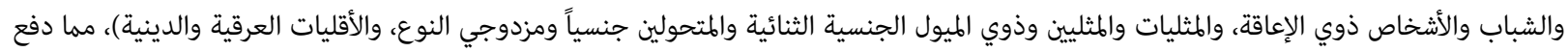

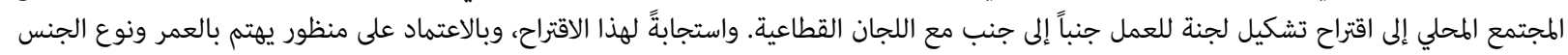

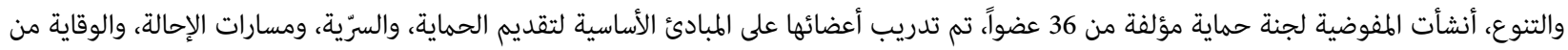

جائحة كوفيد19-/التخفيف من حدتها

ومع بداية انتشار الجائحة تم تقليص أعداد الحضور/الموجودين في المخيمات من قبل المفوضية وشركائها، على الرغم من استمرار العمل عن بعد من خلال الرمال

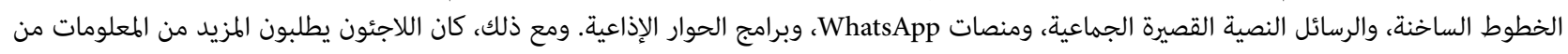

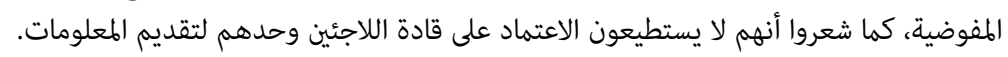

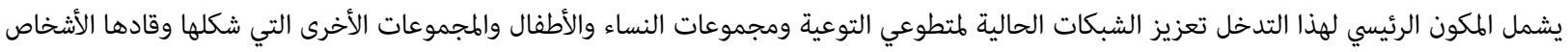

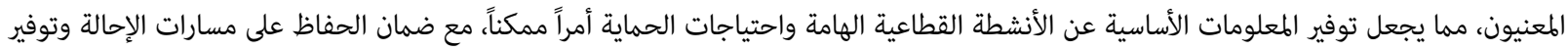

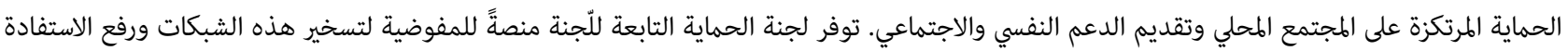

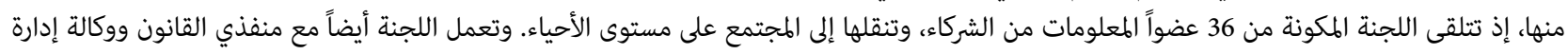
المخيم لضمان وضع جميع الوافدين الجدد في مركز الحجر الصحي، كما تقوم بالاتصال مع لجان المعان من اللاجئين القطاعية الأخرى.

ومن الأدوار الأخرى للّجنة:

o إجراء الزيارات المنزلية للأسر وتقديم المعلومات الأساسية حول الخدمات المتوفرة والأمور الناشئة الأخرى

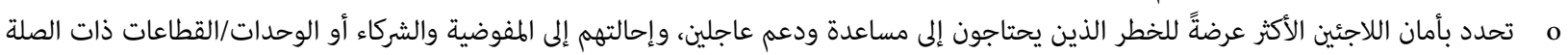
إنوفير الاستجابة الفورية o o

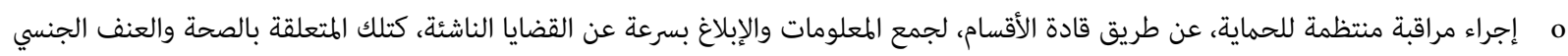

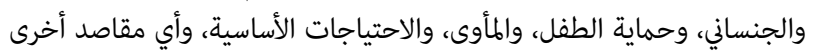
o

توفر مفوضية الأمم المتحدة السامية لشؤون اللاجئين والطجلس النرويجي للاجئين أوقات بث عبر الهاتف المحمول لأعضاء اللجنة لضمان توفُر الاتصال ثنائي الاتجاه وتسهيل توفير تقارير حالة أسبوعية.

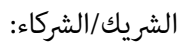

$$
\begin{aligned}
& \text { المجلس النرويجي للاجئين } \\
& \text { أمانة شؤون اللاجئين } \\
& \text { لمزيدٍ من المعلومات، يكنكم الاتصال بـ: } \\
& \text { لينا كوكي: } \\
& \text { نيكولاس ميديو: midiwo@unhcr.org لينا }
\end{aligned}
$$


أدت القيود المفروضة على الحركة خلال جائحة كوفيد19- إلى دفع المفوضية ووكالة كير إلى الاعتماد بشكلٍ كبير على اللاجئين العاملين في المجتمع (RCWs)

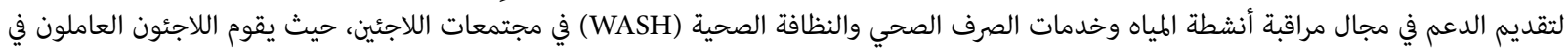

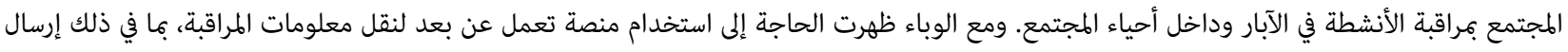

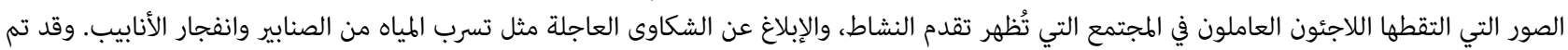

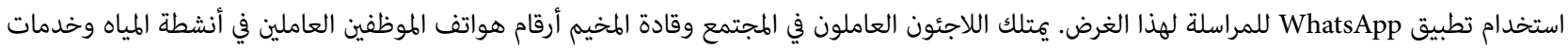

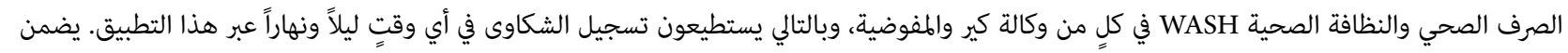

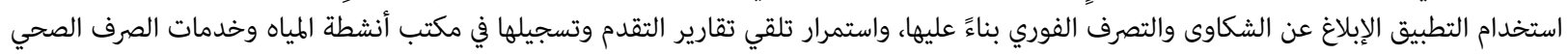
والنظافة الصحية WASH في وكالة كير.

$$
\begin{aligned}
& \text { الشريك/الشركاء: } \\
& \text { وكالة كير } \\
& \text { لمزيدٍ من المعلومات، يرجى الاتصال بـ: } \\
& \text { عثمان يوسف أحمد: ahmedos@unhcr.org }
\end{aligned}
$$

ممارسة واعدة من رواندا: مجموعة عمل النظافة المجتمعية والجهود المشتركة للمجتمع في الوقاية من كوفيد19-، بما في ذلك الموسيقيون

$$
\text { المحليون }
$$

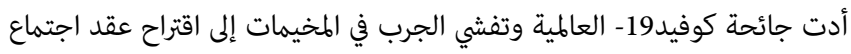

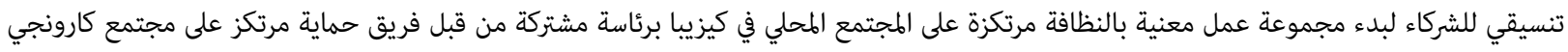

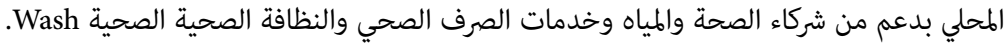

كانت الأهداف المحددة لهذه الممارسة هي: التقييم الشامل لحالة النظافة (المعرفة والطمارسات والبنية التحتية) في المخيم من خلال تطوير أدوات التفتيش المهنية

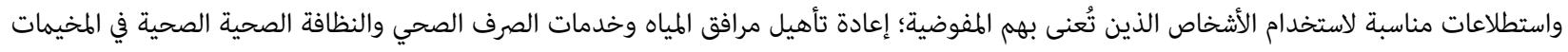

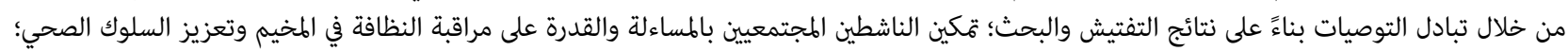

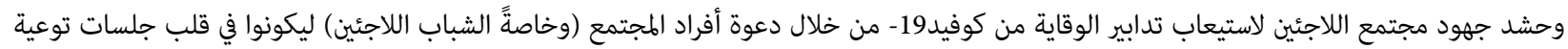
المجتمع وأنشطة التقييم الأخرى.

وفيما يلي المكونات الرئيسية للتدخل:

o

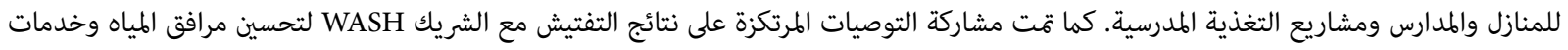

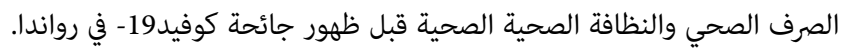

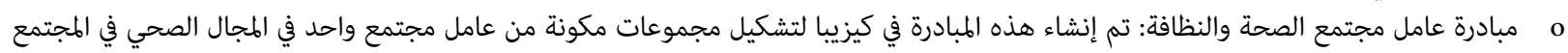

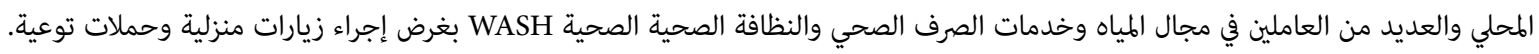
o ("DJ MC Orphans")

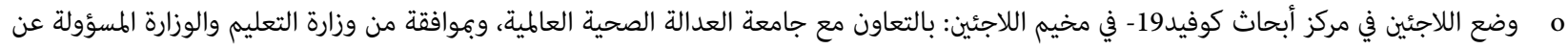

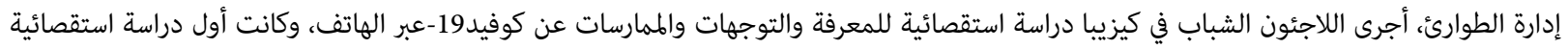

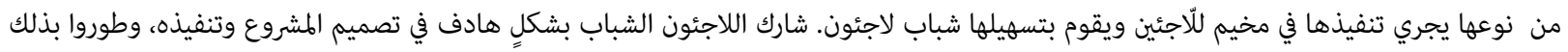
مهاراتهم وخبراتهم البحثية. 
o

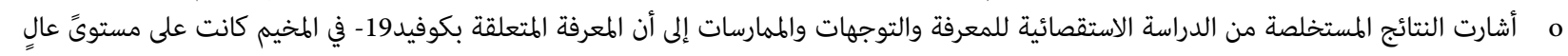

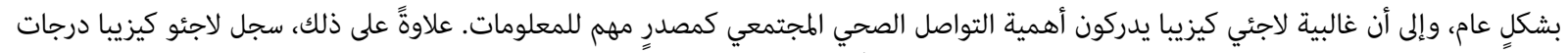

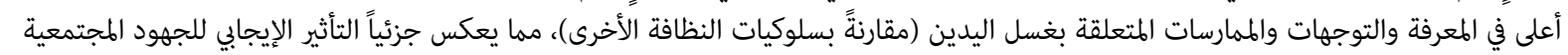
المشتركة في إنشاء منصات لغسل الغعات اليدين. س مجلت النساء درجات أقل من الرجال في المعرفة المتعلقة بكوفيد19-، بسبب الأمية ومحدودية الوصول إلى الهاتف/الراديو.

الشريك/الشركاء: منظمة العمل الإنساني الأفريقي Alight منظمة الإنظمة

كزيدٍ من المعلومات، يرجى الاتصال بـ: رويزي

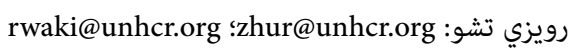
buwamari@unhcr.org ربيسيوس بو واماري تشو:

دراسة حالة من أوغندا: تعبئة الهجتمع من خلال مجلس لرعاية اللاجئين للوقاية من كوفيد19- والاستجابة له

تم إنشاء مجالس رعاية اللاجئين (RWCs) في مخيم إمفيبي للاجئين في عام 2017 لتعزيز التعبئة المجتمعية والتنسيق بين السكان اللاجئين. وتتمثل الأدوار

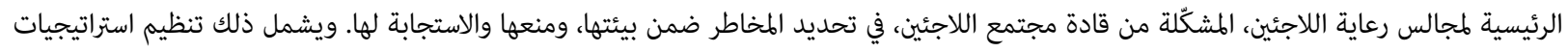

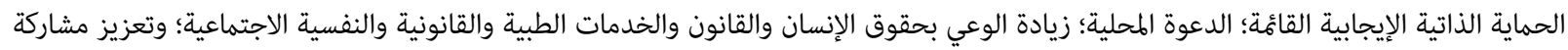
مجموعات مختلفة من مجموعات السن ونوع الجنس والتنوع في القرارات المتعلقة بالحماية.

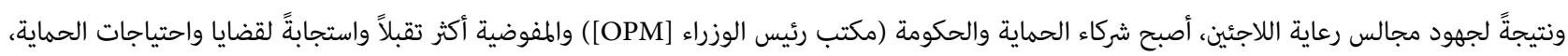

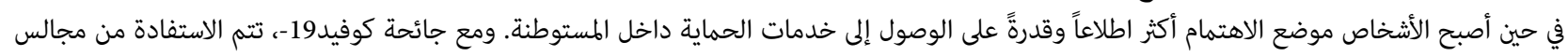

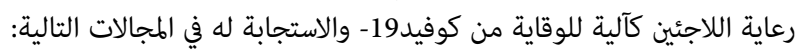

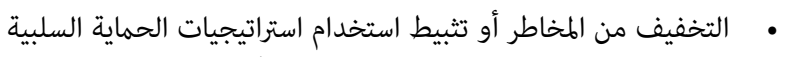

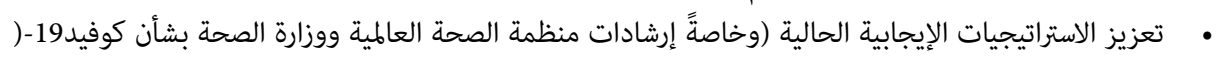

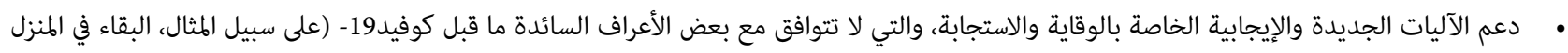
وغسل اليدين بالصابون بانتظام والتباعد الجسدي والإرتداء التداء الكمامات).

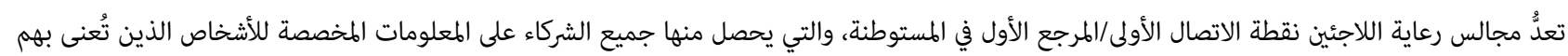

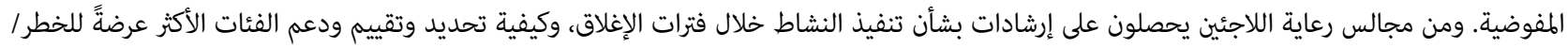

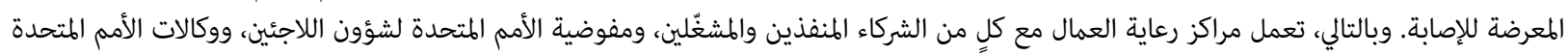

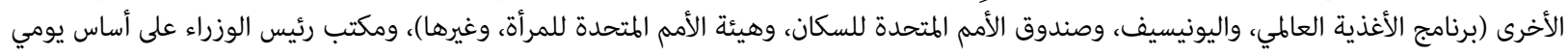

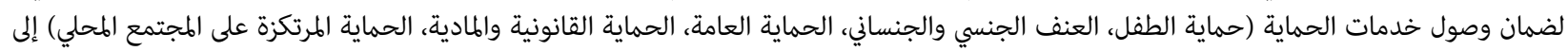

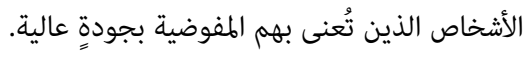

ومع عمل معظم الشركاء عن بعد خلال فترة وجود كوفيد19-، تم تعزيز التنسيق بين الشركاء والمجتمع من خلال مجالس رعاية اللاجئين التي تقدم تقرير

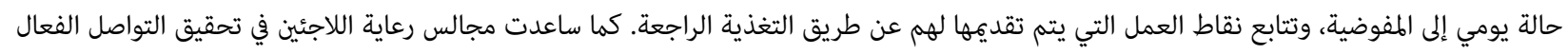

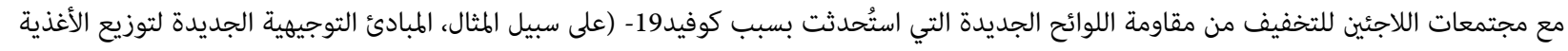
والمبادئ التوجيهية الوطنية للوقاية من كوفيد 19-1).

وعلاوةً على ذلك، كان للأدوار القيادية لججالس رعاية اللاجئين في الأنشطة المجتمعية آثارٍ إيجابية. فعلى سبيل المثال، نجحت مجالس رعاية اللاجئين في تعزيز نهج إنها

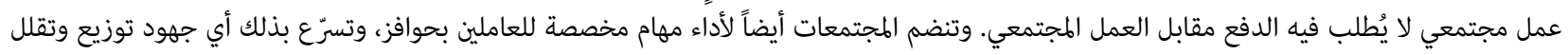

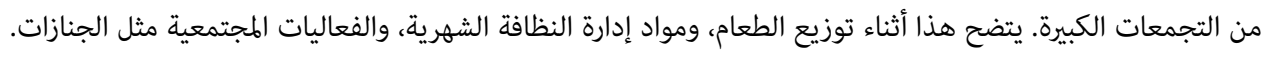




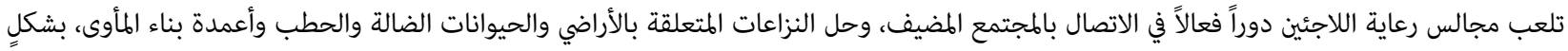

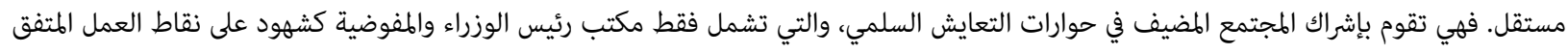

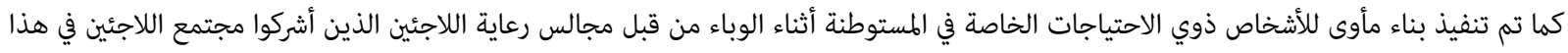

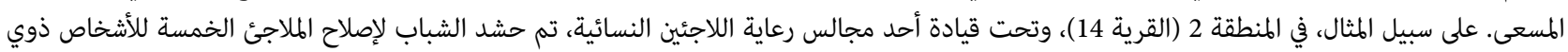
الاحتياجات الخاصة أثناء الجائحة.

$$
\begin{aligned}
& \text { الشريك/الشركاء: } \\
& \text { المجلس الدافركي للاّجئين } \\
& \text { مكتب رئيس الوزراء } \\
& \text { الشريك المنفذ للمفوضية } \\
& \text { ملزيٍٍ من المعلومات، يرجى الاتصال بـ: } \\
& \text { ويليان نجيزي: ngeze@unhcr.org } \\
& \text { فيث كامويو: kamoyo@unhcr.org }
\end{aligned}
$$

ممارسة ناشئة من أوغندا: تحالفات الرعاية المجتمعية

يواجه الأشخاص ذوو الاحتياجات الخاصة مثل الأشخاص ذوي الإعاقة، وأولئك الذين يعانون من حالات طبية خطيرة، والنساء

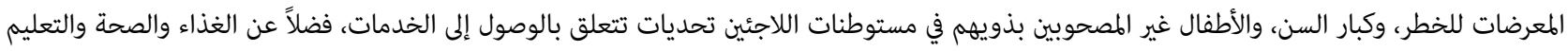

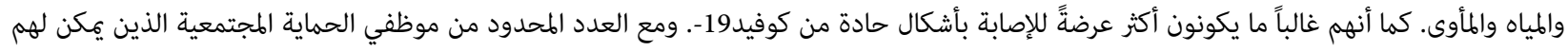

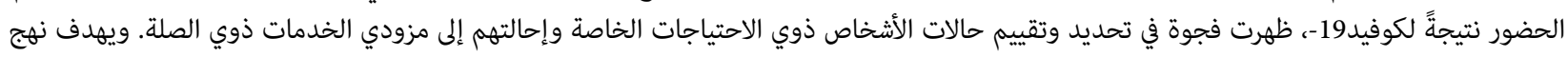
تحالف رعاية المجتمع الموضح أدناه إلى تحسين تقديم الخدمة ودعم الأشخاص ذويد الاحتيد الاحتياجات الخاصة.

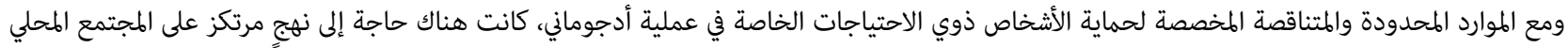

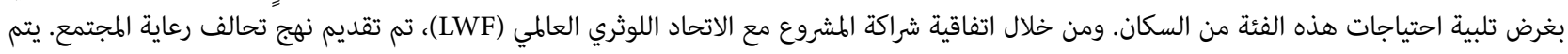

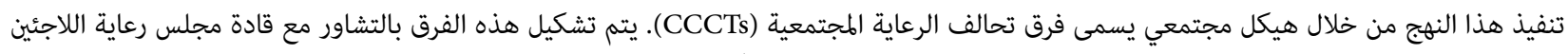

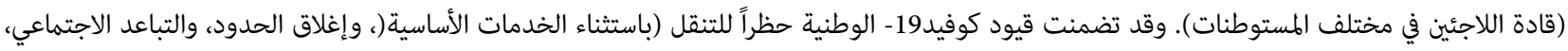

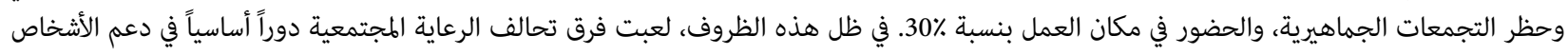

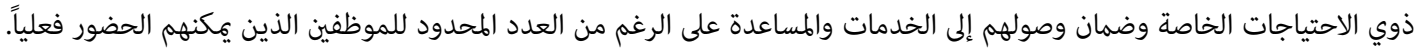

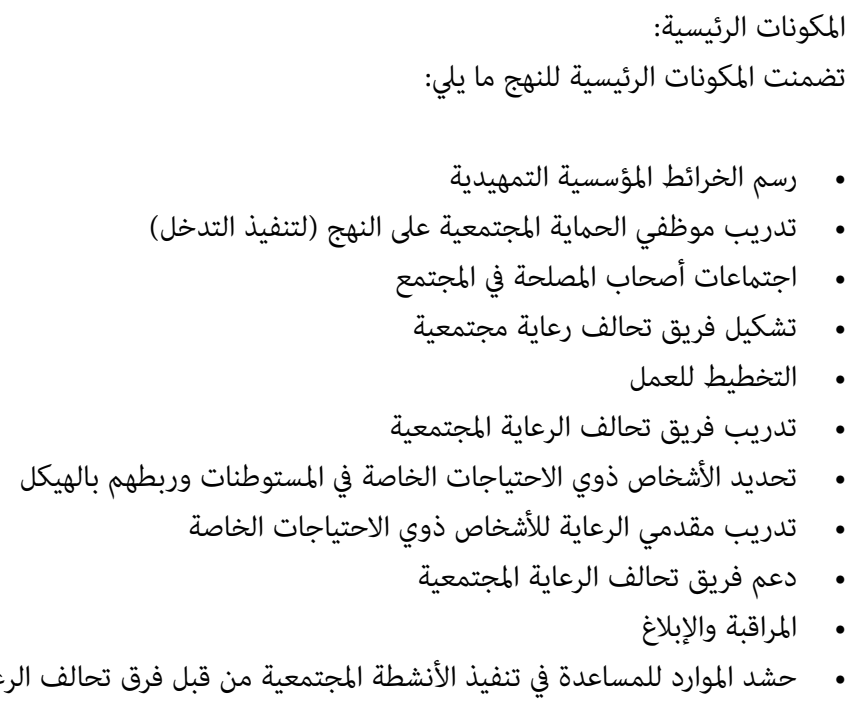




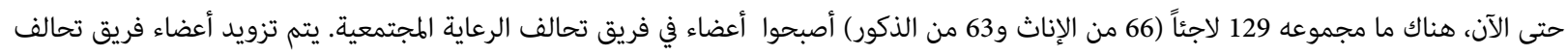

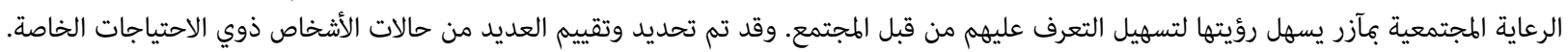

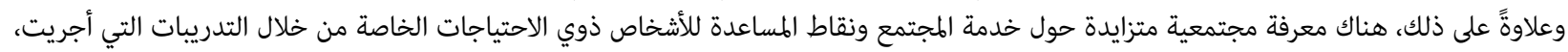

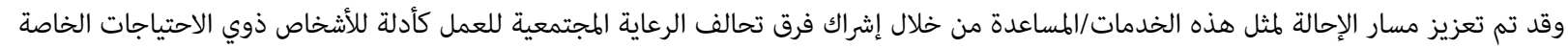

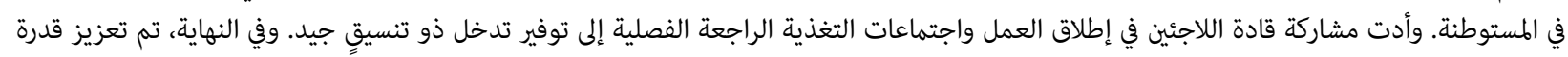

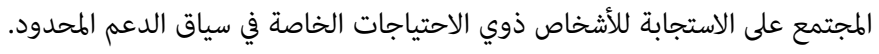

$$
\begin{aligned}
& \text { الشريك/الشركاء: - الشاء } \\
& \text { الاتحاد اللوثري العالهي } \\
& \text { لمزيدٍ من المعلومات، يرجى الاتصال بـ: } \\
& \text { إلفيرا ندانجا: ndangael@unhcr.org }
\end{aligned}
$$

إليزابيث كابويو: Elizabeth.kaboyo@lutheranworld.org أجافو باتريك: patrick.ajavu@lutheranworld.org ديوجراتياس أسيدري: بcidri@unhcr.org بروسكوفيا أشيرو: ديوجراتياسدي أبري

ممارسة ناشئة من أوغندا: دعم المأوى للأشخاص ذوي الاحتياجات الخاصة

أدى الإغلاق المؤقت لمركز استقبال كابازانا بسبب كوفيد19- إلى حالة استيطان طارئة لجميع الأشخاص الذين تُعنى بهم المفوضية الذين كانوا يقيمون في المركز.

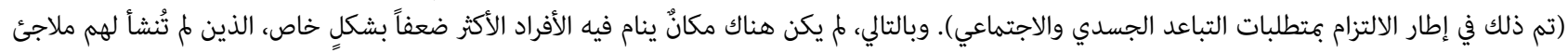

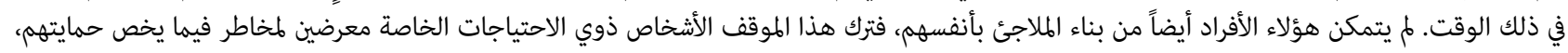

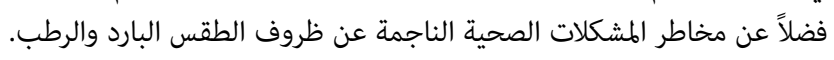

وكحلٍ لهذه المشكلة، تم تشييد ما مجموعه 74 مبنى مؤقت، وتم استخدامها لإيواء 65 من الأفراد المعرضين للخطر بشكلٍ خاص و9 أمهات عازبات. تم استخدام

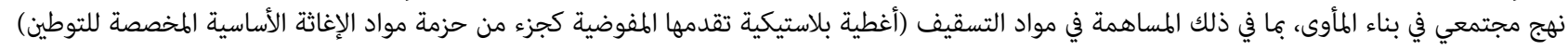

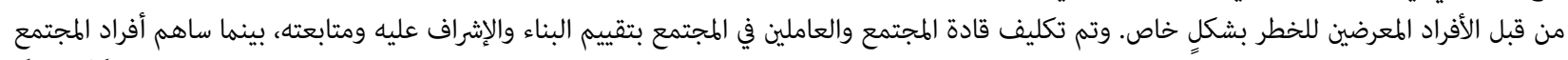

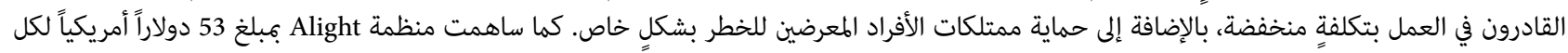
مأوى لشراء مواد مثل الأعمدة والقصب منغفة والطسامير، ولدفع أجور النقل والعمالة.

النتائج

كان للتدخل نتائج إيجابية من منظور الأشخاص ذوي الاحتياجات الخاصة وأعضاء المجتمع الآخرين. وعندما طُلب من أحسأ أحد المستفيدين إبداء رأيه بشأن دعم

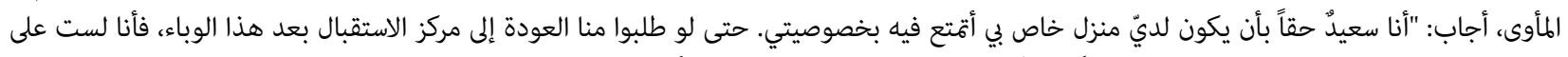

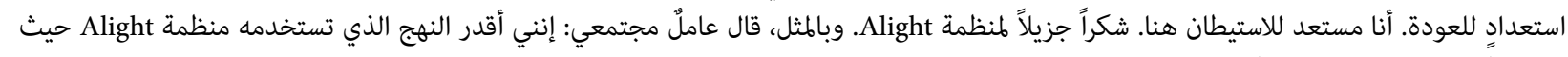

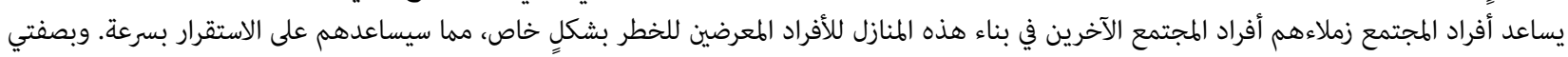

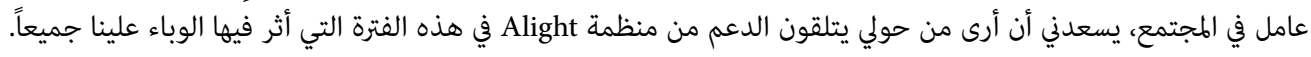

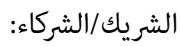

منظمة Alight

لميدٍ من المعلومات، يرجى الاتصال بـ:

ديفيس موغوميا: mugumya@unhcr.org

سيلفيا سامانيا: samanya@unhcr.org 


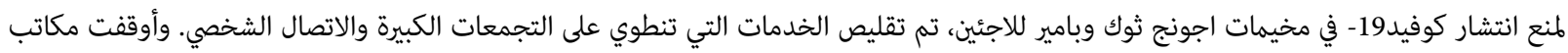

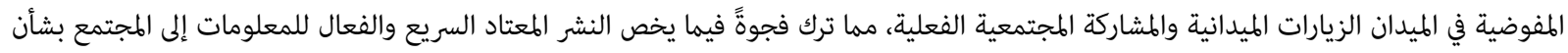

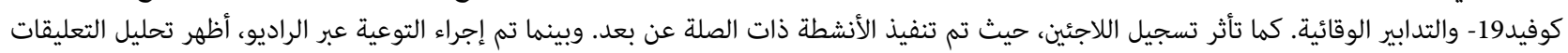
الواردة من الميدان أن العديد من اللاجئين كان لا يزال لديهم استفسارات.

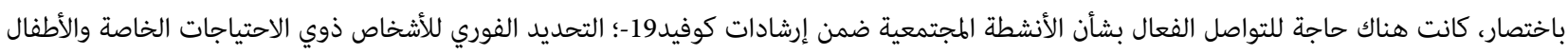

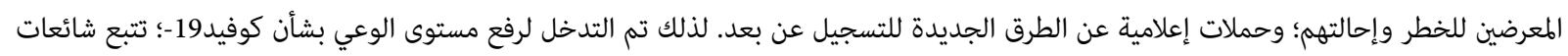

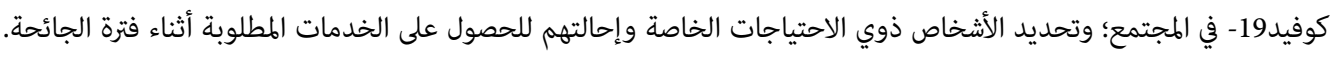

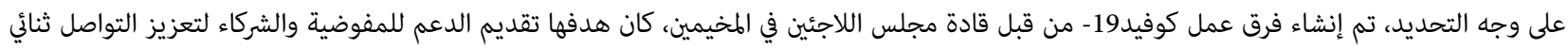

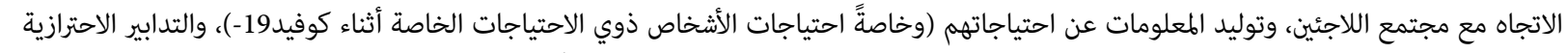

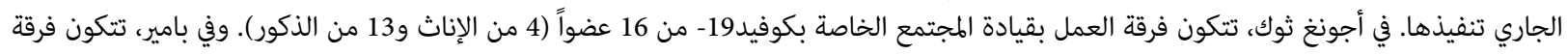

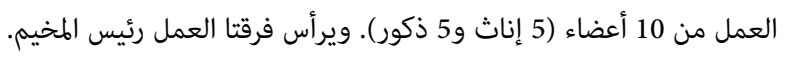

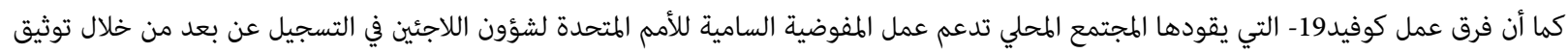

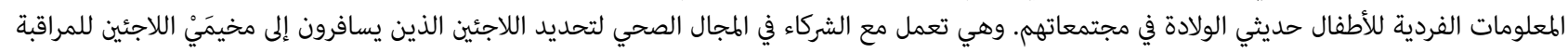

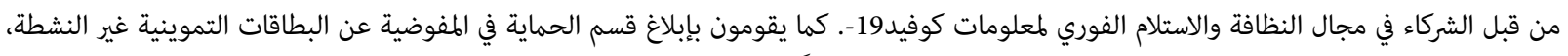

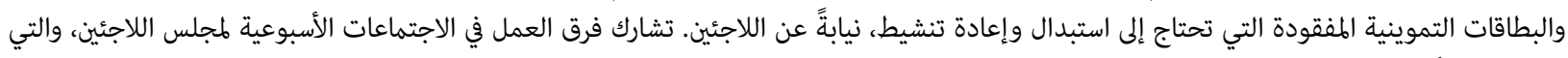

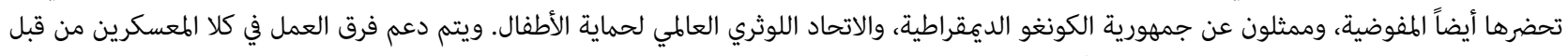

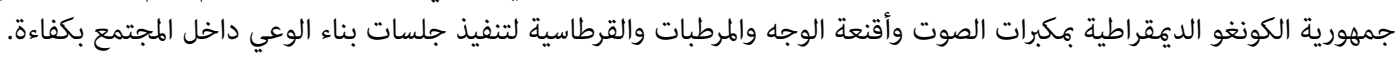

$$
\begin{aligned}
& \text { الشريك/الشركاء: } \\
& \text { المجلس الدافركي للاجئين } \\
& \text { الاتحاد اللوثري العالكي }
\end{aligned}
$$

لمزيدٍ من المعلومات، يرجى الاتصال بـ:

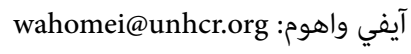

ريجينا خميس وودي: wude@unhcr.org أبراهام ميجوك أيويل داو: dau@unhcr.org

دراسة حالة من جنوب السودان: إنتاج الكمامات

بدأ المكتب الميداني للمفوضية في ملكال في إنتاج الكمامات بواسطة المشردين داخلياً والمجتمعات المضيفة كجزء من مبادرة لكسب العيش ونشاط بناء السلام

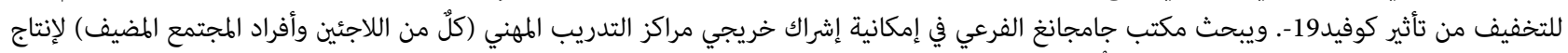

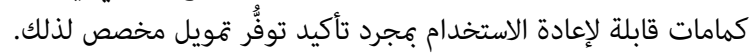

$$
\begin{aligned}
& \text { الشريك/الشركاء: المعلومات غير متوفرة } \\
& \text { فليدٍ من المعلومات، يرجى الاتصال بـ: } \\
& \text { في تران: tran@unhcr.org }
\end{aligned}
$$

دراسة حالة من جنوب السودان: محطة راديو المجتمع

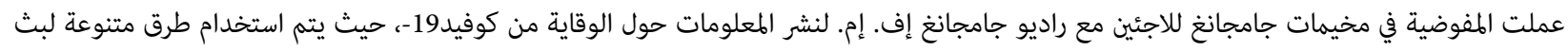

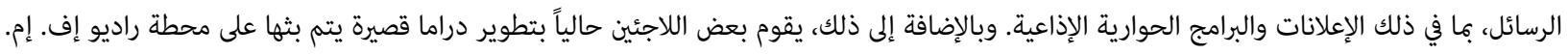

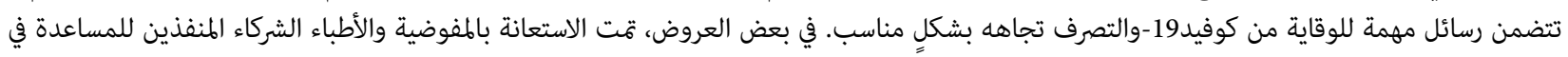


دحض الخرافات الشائعة حول الفيروس. وهناك خطط جارية لبث برنامج من شأنه الرد على الأسئلة والشائعات ومعالجة بعض المفاهيم الخاطئة للمجتمع حول

وهناك حاجة لضمان وصول المزيد من الأشخاص الذين تُعنى بهم المفوضية إلى أجهزة الراديو لتعزيز فرص تلقيهم للرسائل. الأجهزة المفضلة هي أجهزة راديو

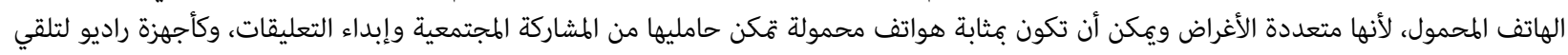

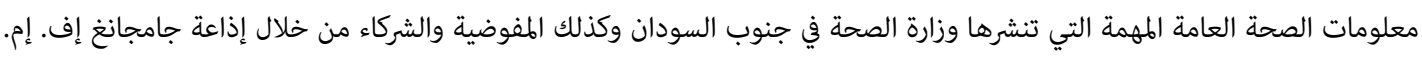

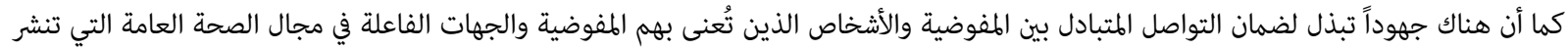

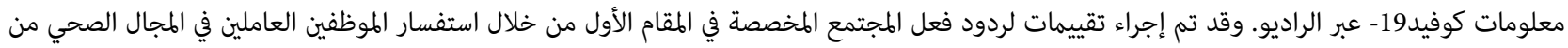

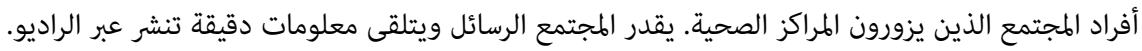

الشريك/الشركاء:

إذاعة جامجانغ إف. إم.

لمزيدٍ من المعلومات، يرجى الاتصال بـ:

joanian@unhcr.org تامار جوانيان

ممارسة ناشئة من جنوب السودان: التنسيق الإنساني للاستجابة لكوفيد19-

تم الاستشهاد بمجموعة عمل مابان للتواصل بشأن المخاطر وإشراك المجتمع المحلي (RCCE) في مناسبات عديدة من قبل مجموعة عمل جنوب السودان الفان الفنية

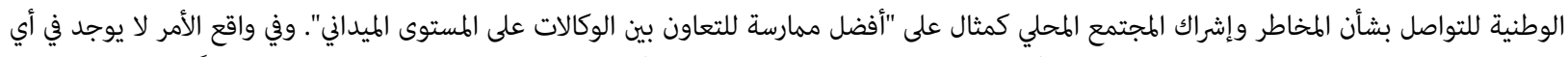

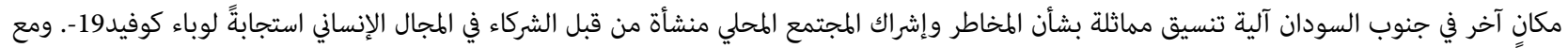

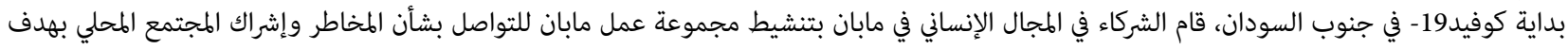

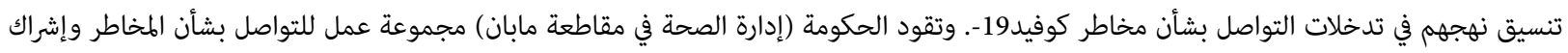

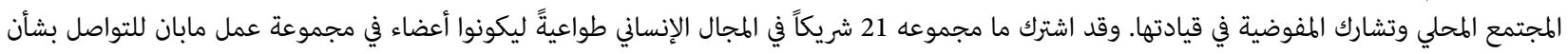
المخاطر وإشراك المجتمع المحلي، والتي تجتمع كل أسبوعين.

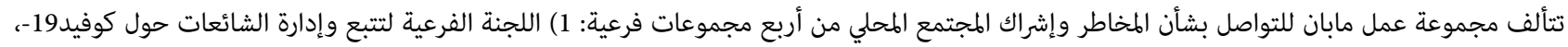

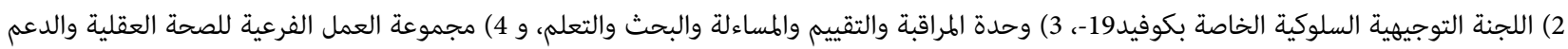

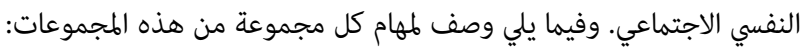

اللجنة الفرعية لتتبع وإدارة الشائعات حول كوفيد19-: بقيادة منظمة إنترنيوز، ويشارك في قيادتها المجلس الداثماركي للاجئين. o

o o o مشاركة التقرير مع اللجنة الفرعية الوطنية لتتبع الشائعات وإدارتها. o

اللجنة التوجيهية السلوكية الخاصة بكوفيد19-: بقيادة المنظمة الدولية لإنقاذ الطفولة وتشارك في قيادتها منظمة الإغاثة الدولية. o

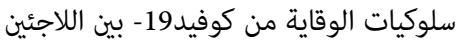
o لكوفيد19-. 


$$
\text { جمع بيانات رصد التواصل بشأن المخاطر وإشراك المجتمع المحلي }
$$

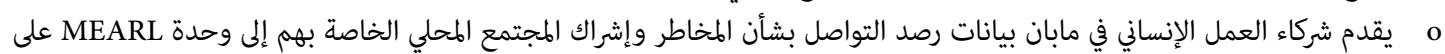

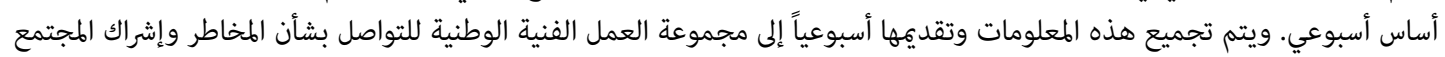

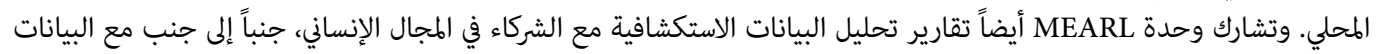
الخام الخاصة بالتواصل وتشارك

بشأن المخاطر وإشراك المجتمع المحلي. o

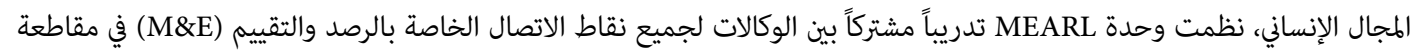
مابان، لبناء قدراتهم على استخدام أداة المراقبة المنسقة .

دعم المبادرات البحثية الخاصة بالتواصل بشأن المخاطر وإشراك المجتمع المحلي المشتركة بين الوكالات

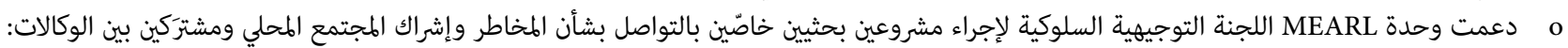

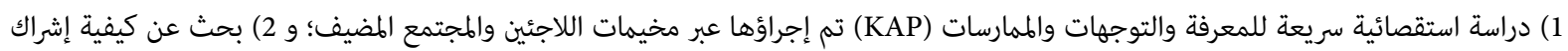

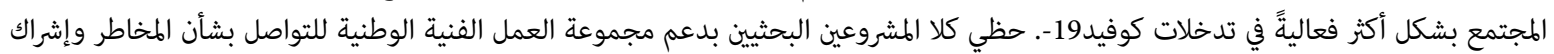
المجتمع المحلي وساهما في تشكيل سياسات الإرشاد الوطنية للتواصل بشأن المخاطر وإشراك كأ المجتمع المحلي في جنوب الماتين السودان.

مجموعة العمل الفرعية للصحة العقلية والدعم النفسي الاجتماعي (DHPSS): تقودها منظمة (DRS) (Jesuit Refugee Service (JRS) ويشارك في قيادتها المجلس

الدنماركي للاجئين (DRC).

o

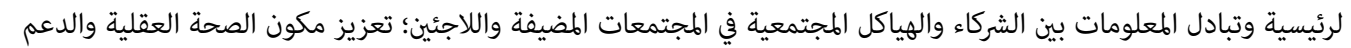

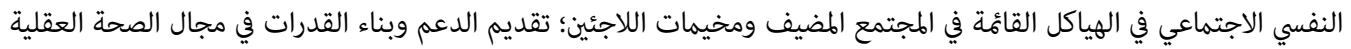

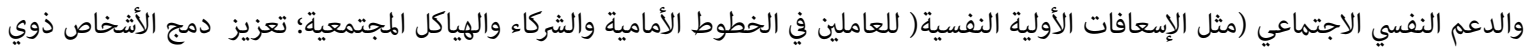

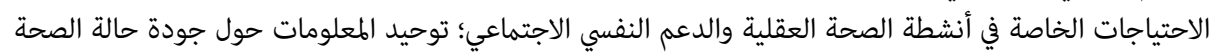

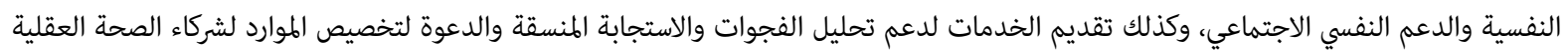

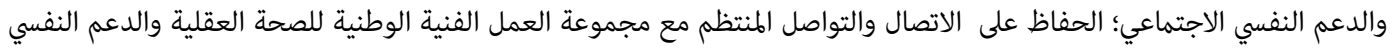

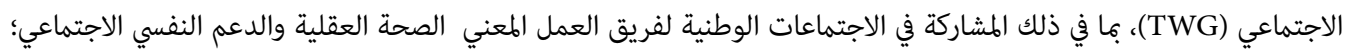

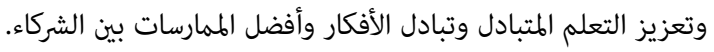
o مجموعة العمل الفرعية للصحة العقلية والدعم النفسي الاجتماعي في مابان ممثلة في مجموعة العمل الفنية الوطنية للصحة العقلية والدعم النفسي

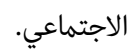

$$
\begin{aligned}
& \text { الشريك/الشركاء: } \\
& \text { المجلس الدافركي للاجئين } \\
& \text { منظمة انترنيوز }
\end{aligned}
$$

منظمة منظمة انترنيوز دائرة الصحة في مقاطعة مابان منظمة الإغاثة الدولية

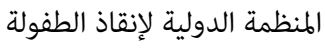
برنامج الغذاء العالمي

$$
\text { لمزيدٍ من المعلومات، يرجى الاتصال بـ: }
$$
د. جيبريوولد بيتروس يوهانس: petros@unhcr.org 
يشارك معلمو المجتمع في كردفان في المساعدة على ترجمة رسائل الوقاية من كوفيد19- إلى اللغات المحلية الرئيسية للاجئين لنشرها بمساعدة القادة المحليين.

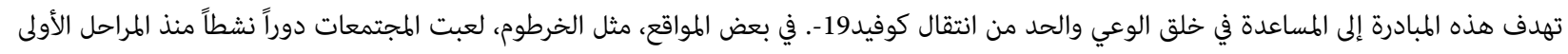
للاستجابة لكوفيد19-، ونشر ملصقات المعلواد الماعدات وتحديد المواقع لها في مناطقهم من خلال متطوعي التواصل المجتمعي والقادة المجتمعيين والدينيين والسلاطين.

الشريك/الشركاء: المعلومات غير متوفرة

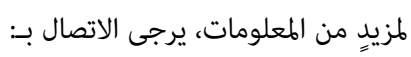
أنهيلي الضمّار: aldhamma@unhcr.org

دراسة حالة من السودان: المشاركة المجتمعية عبر الهاتف المحمول

في ولاية النيل الأبيض ومناطق أخرى، تم اختيار قادة اللاجئين والمجتمعات المضيفة وتدريبهم على مسار إحالة كوفيد

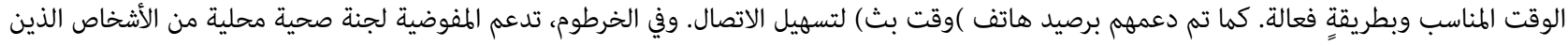

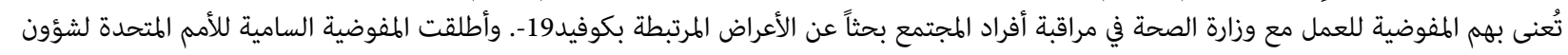

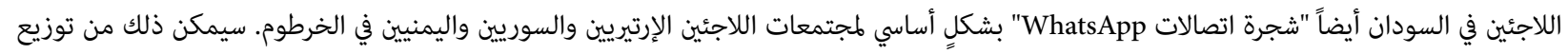

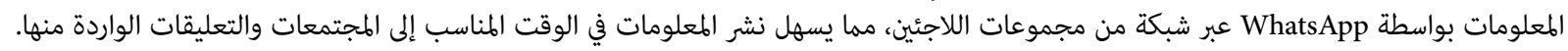

الشريك/الشركاء: المعلومات غير متوفرة

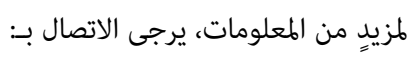
أنهيلي الضمّار: aldhamma@unhcr.org 


\section{العنف الجنسي والجنساني/التخفيف من المخاطر/الاستجابة}

3

دراسة حالة من بوروندي: الإحالات عن طريق الهاتف المحمول وإدارة الحالة للعنف الجنسي والجنساني

على الرغم من القيود المفروضة على الحركة في بوروندي أثناء جائحة كوفيد19-، قمكنت المفوضية من ضمان استمرارية الرعاية للناجين من العنف الجنائسي

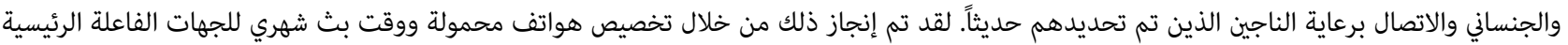

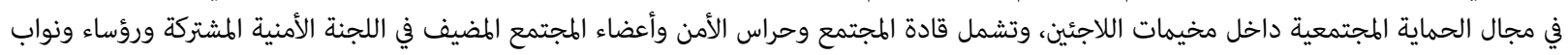

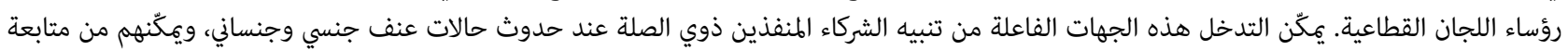

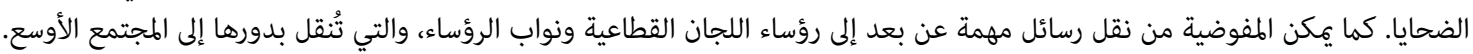

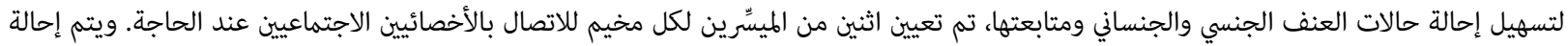

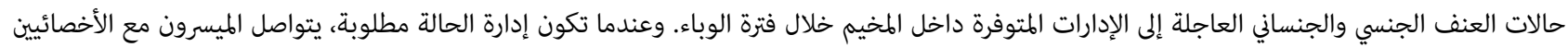

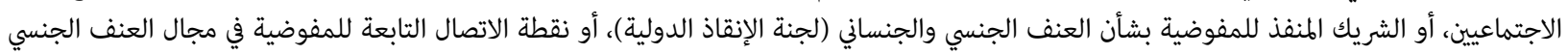

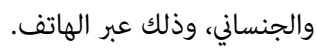

الشريك/الشركاء: لجنة الإنقاذ الدولية

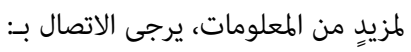

roeske@unhcr.org غويندولين رويسكي موكانغ إنو: eno@unhcr.org بريجيت موكانغا إينوين روسن كريستين إرامبونا: irambona@unhcr.org 
خلال إغلاق كوفيد19-، استمرت الحالات التي تتطلب الاهتمام بالظهور في مجتمعات اللاجئين، لكن بعض القادة والهياكل المجتمعية مل يكن لديهم المعرفة

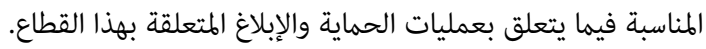

ونظراً لوجود الهياكل المجتمعية وقادة مجلس رعاية اللاجئين داخل مجتمعات اللاجئين، سعى هذا التدخل إلى الاعتماد على هذه الموارد المجتمعية للمساعدة في

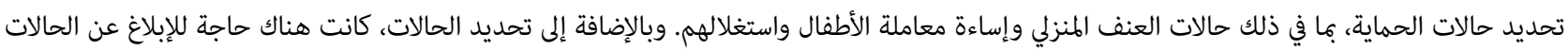
للشركاء المعنيين لكي يقوموا بالتدخل.

أدى هذا التدخل إلى تكين الهياكل المجتمعية من خلال تدريبهم على تحديد قضايا الحماية والمخاطر (العنف الجنسي والجنساني، وحماية الطفل، والطسائل

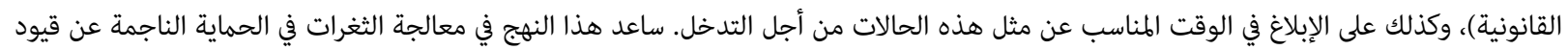
كوفيد19-، والتي حدت من وجود الشركاء في المجتمع.

الشريك/الشركاء: وكالة المساعدة الإنسانية وخدمات التنمية (HADS)

$$
\text { لمزيدٍ من المعلومات، يرجى الاتصال بـ: }
$$

ngeze@unhcr.org منيام نجيزي: buga@unhcr.org منصور بوقيام ذجي:

دراسة حالة من جنوب السودان: الإحالات عبر الهاتف الهحمول وجلسات الإرشاد النفسي والاجتماعي

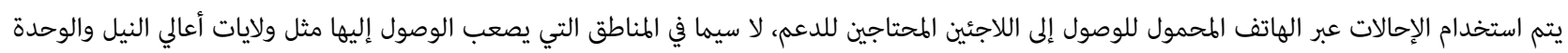

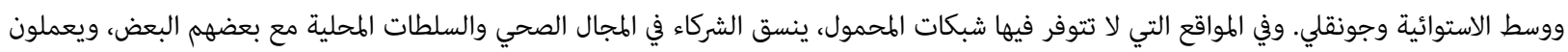

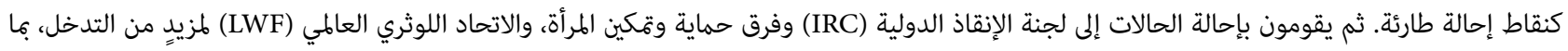

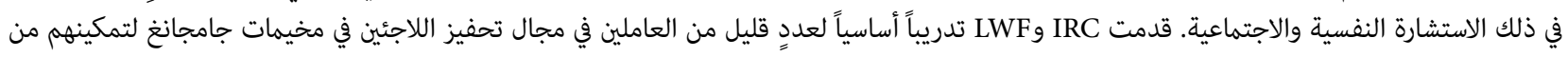

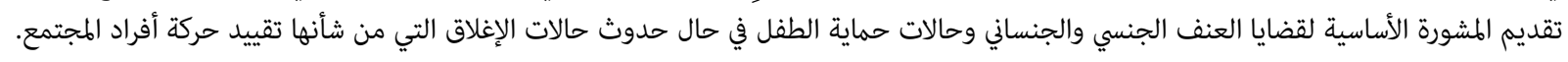

$$
\begin{aligned}
& \text { الشريك/الشركاء: } \\
& \text { لجنة الإنقاذ الدولية } \\
& \text { الاتحاد اللوثري العالمي الانقاذ الدلية } \\
& \text { لزيد من المعلومات، الاتصال: }
\end{aligned}
$$

tran@unhcr.org في تران 
o مشاركة ممثلي المجتمع في التقييمات المشتركة: القادة الدينيون، والجمعيات النسائية، واللجان المركزية للاجئين (RCCs)، وأعضاء آخرين يختارهم المجتمع

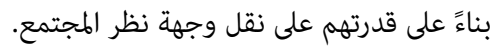

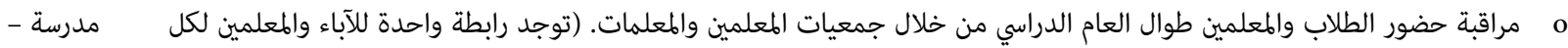

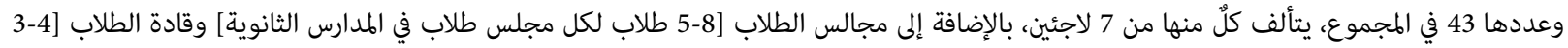

في كل مدرسة ابتدائية]).

o بناء قدرات رابطات الآباء والمعلمين. على سبيل المثال، بحلول منتصف عام 2020، تلقت 43 جمعية مدرسية تعليمية تدريباً على أدوارها ومسؤولياتها في المدارس.

o شكاوى العنف الجنسي والجنساني]). o تعزيز مشاركة الوالدين في الأنشطة المدرسية المصممة خصيصاً، مثل رواية القصص في مرحلة ما قبل المدرسة التي يقودها الآباء وجلسات الغناء التي تتمحور حول التراث الثقافي. تتم هذه الأنشطة على مدار الأنطة المدرية العمام لتعزيز مشاركة الوالدين.

يوفر التقييم المشترك منصة للمجتمع للتعبير عن مخاوفه، وتقديم اقتراحات فيما يتعلق بالبرامج، والمشاركة في عملية التخطيط التربوي. يتم توثيق نتائج التقييم

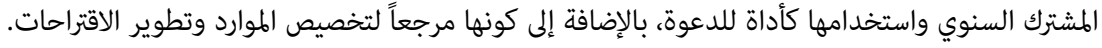

من الجدير بالذكر أن المفوضية قد أنشأت آلية تنسيق فعالة مع مكتب التعليم في المنطقة المحلية لتعميم العمل التعليمي للمفوضية ضمن نظام التعليم الوطني،

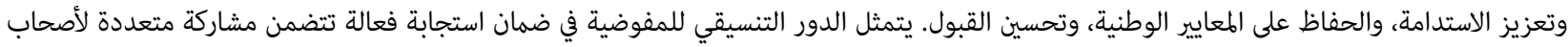

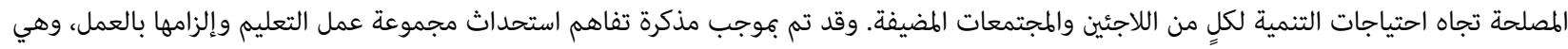

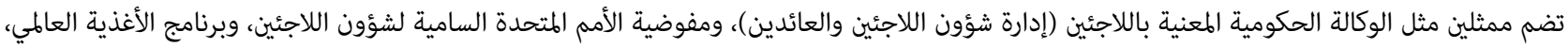

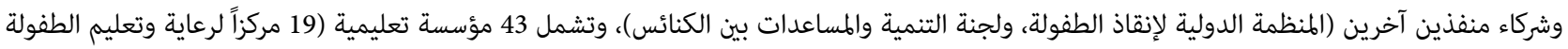
المبكرة [ECCE]، و 21 مدرسة ابتدائية، و3 مدارس ثانوية، وكلية تعليم المعلمين).

النتائج

أدى هذا النهج منذ اعتماده في عام 2015 إلى تحسين الحضور والبقاء على مستوى المدارس، فأصبح معدل الحضور على مستوى المدارس الابتدائية 83\% في

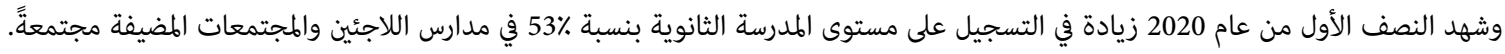

$$
\begin{aligned}
& \text { الشريك/الشركاء: - الشاء } \\
& \text { وكالة شؤون اللاجئين والعائدين } \\
& \text { لجنة التنمية والمساعدة بين الكنائس المأسن والعائدين } \\
& \text { المنظمة الدولية لإنقاذ الطفولة } \\
& \text { مكتب المقاطعة التعليمي } \\
& \text { برنامج الغذاء العالكي } \\
& \text { لمزيد من المعلومات، يرجى الاتصال بـ: }
\end{aligned}
$$




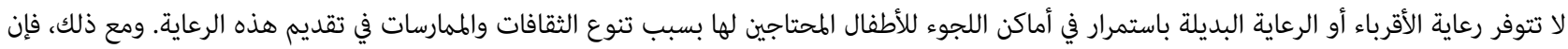

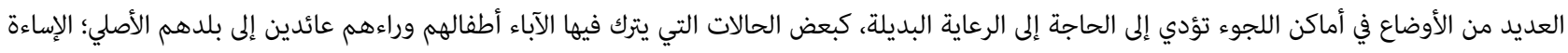

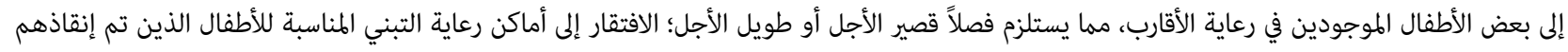

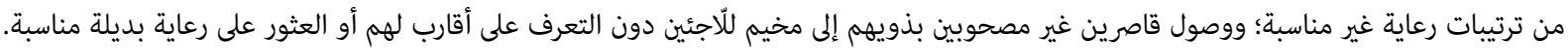

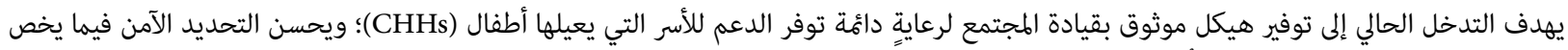

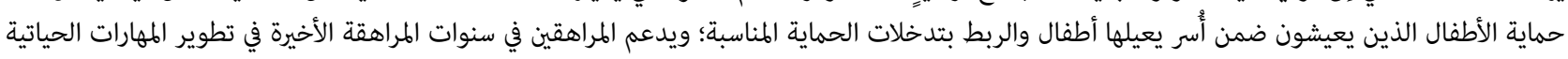
ومهارات التأقلم في مخيمات اللاجئين.

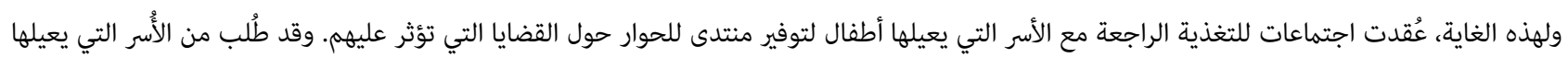

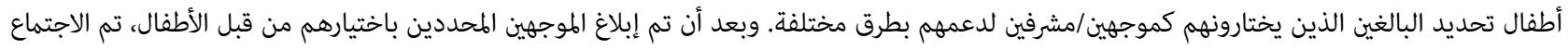

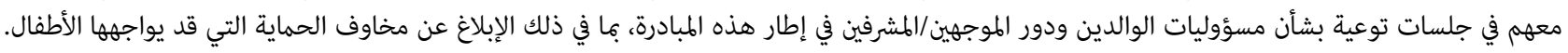

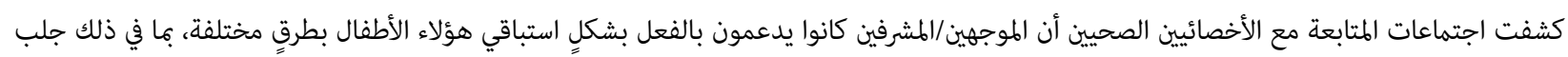

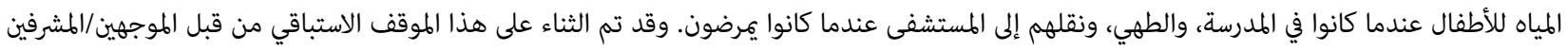
وقاموا بتشجيعه.

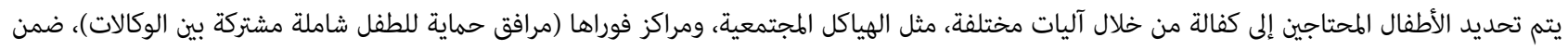

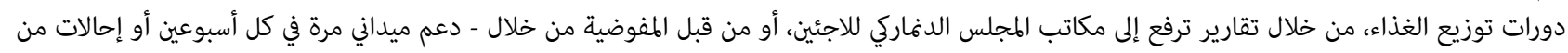

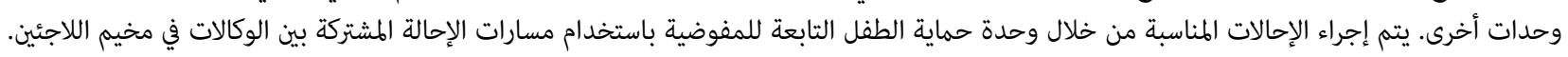

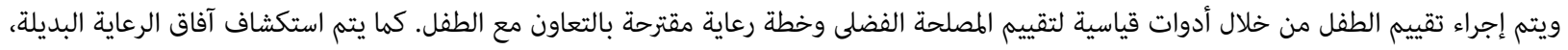

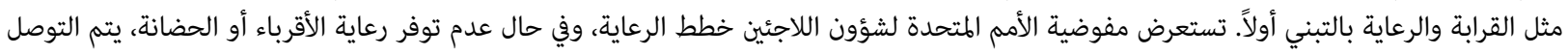

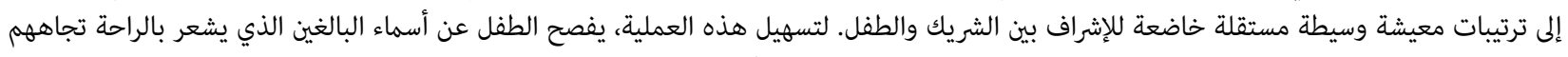
بالفعل لكي يعملوا كموجهين/مشرفين، ويتم توعيتهم لدعم الطفل كما هو موضح أعلان التها.

منذ بدايتها، تم تحديد ما مجموعه 50 موجهاً/مشرفاً (16 من الذكور و34 من الإناث) وتمت توعيتهم وربطهم بالأطفال.

$$
\text { الاتشريك/الشركاء: اللهاد اللوثري للاجئين }
$$

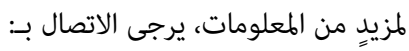
afridi@unhcr.org: أمين أفريدي من المعات برحيد novikau@unhcr.org الكسندر نوفيكاوي: إنطاوين إينا جويا: guyai@unhcr.org 


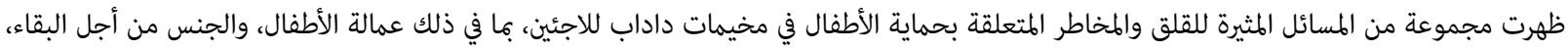

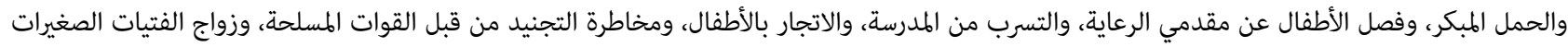

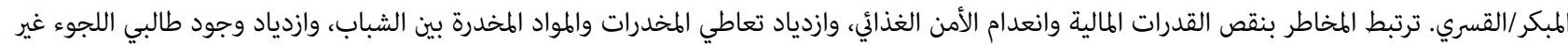
المسجلين، بما في ذلك الوافدون الجدد والذين عادوا إلى المخيم بعد عودتهم إلى الوطن.

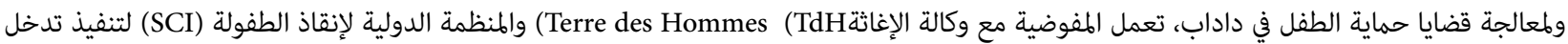

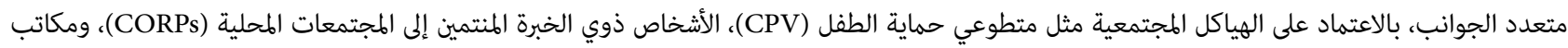

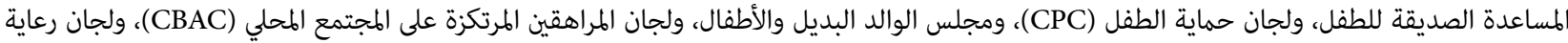

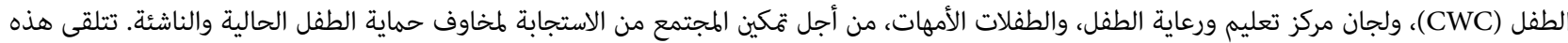

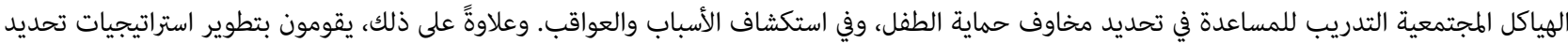

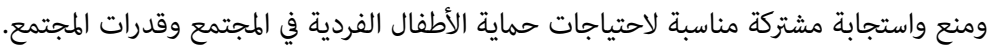

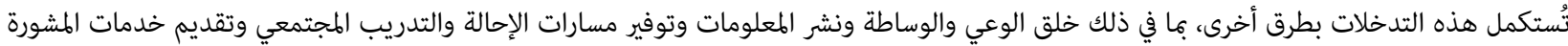

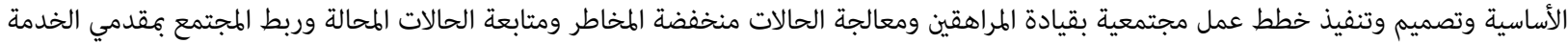

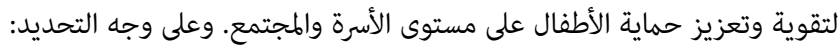

TdH إيداعاً مؤقتاً ودائًاً للأطفال تحت الرعاية البديلة في برنامجها للرعاية البديلة.

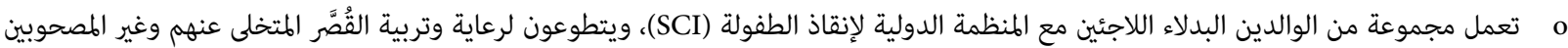

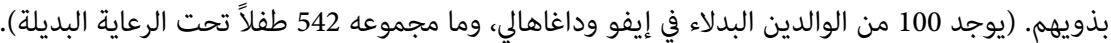
o الحالات. o

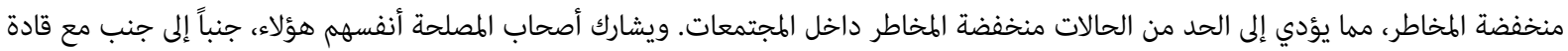

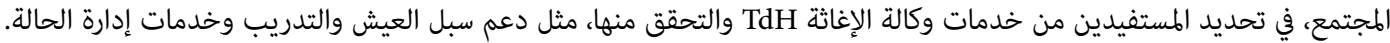

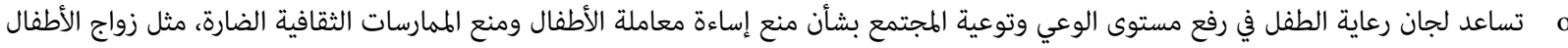

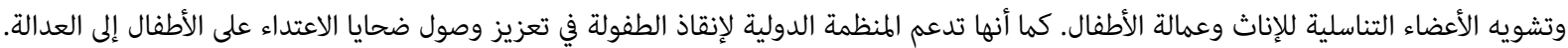

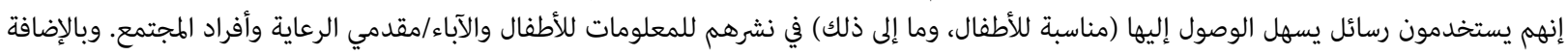

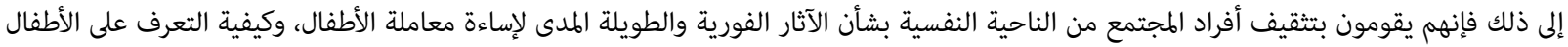

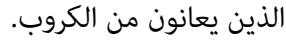
o يعقد أعضاء جمعية الأطفال جلسات مع الشركاء يتم خلالها طرح مخاوفهم والرد عليها من قبل الشركاء المعنيين. وبشكلٍ عام، تعمل الهياكل المجتمعية كآلية للإبلاغ عن التعليقات للمستفيدين والشركاء. 


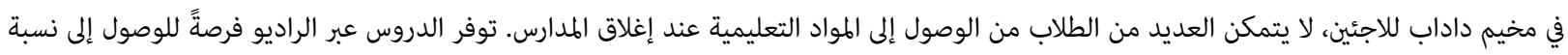

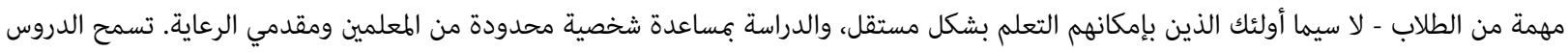

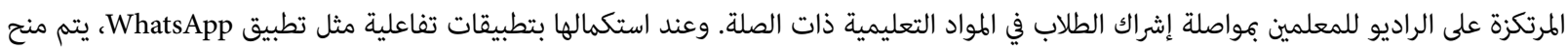

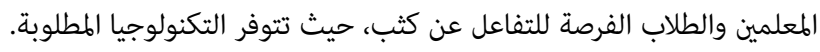

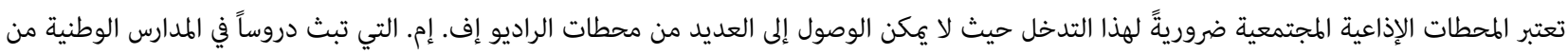

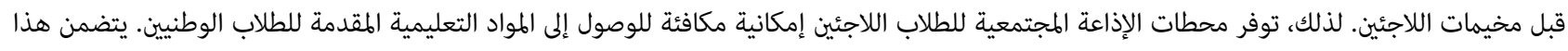

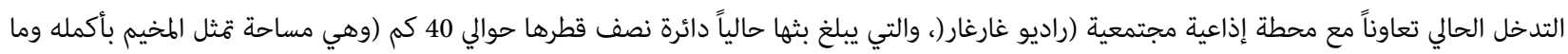

بعده).

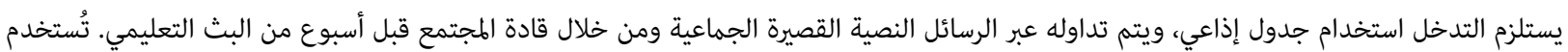

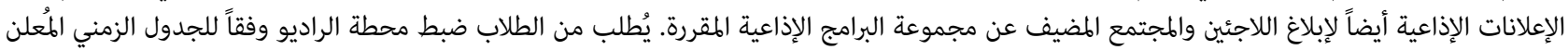

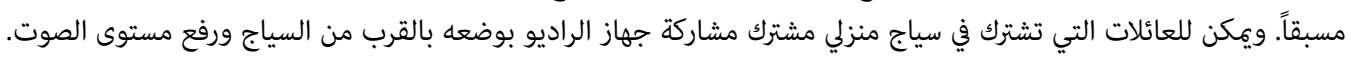

يتم إعداد البرامج النصية الإذاعية لكل موضوع بواسطة مدرسين مختارين في المادة ويتم طباعتها. كما يتم اختيار أحد المدرسين المشاركين في إعداد البرامج النصية

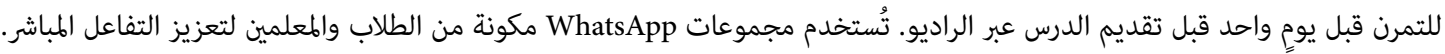

النتائج

الخطط جارية للحصول على محتوى تعليمي جاهز للبث من معهد كينيا لتطوير المناهج الدراسية. سيحل محتوى التعليم الوطني هذا محل نصوص الراديو

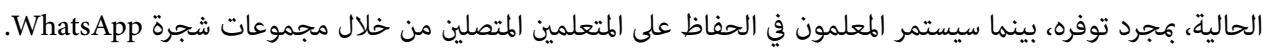

الشريك/الشركاء:

كزيدٍ من المعلومات ، يرجى الاتصال بـ: كلارا فان براغ: vanpraag@unhcr.org mwika@unhcr.org ألان مويكار

دراسة حالة من كينيا: إشراك أعضاء نادي WASH المدرسي

يتضمن تدخل المياه وخدمات الصرف الصحي والنظافة الصحية (WASH) التابع لججلس اللاجئين النرويجي (NRC) دمج الأطفال والشباب ونهج متعدد الأوجه

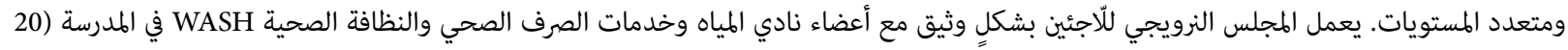

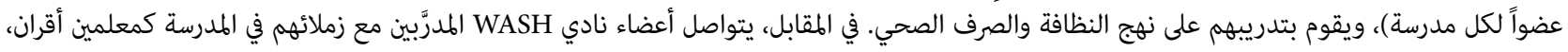

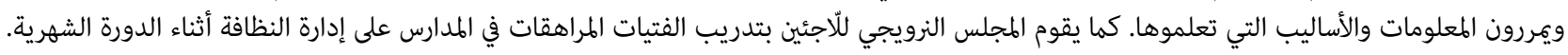

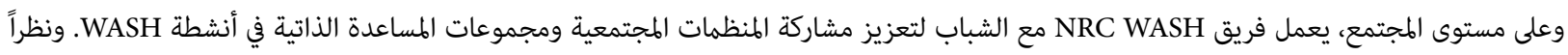

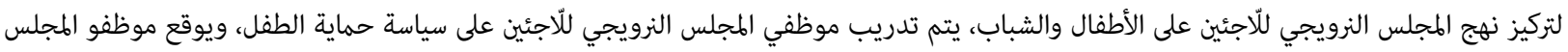
الوطني للّاجئين على هذه السياسة كجزءٍ من توصيف وظائفهم.

$$
\text { الشريك/الشركاء: المّلس النرويجي للاجين }
$$

كزيدٍ من المعلومات، يرجى الاتصال بـ:

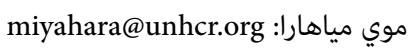
أوسكار نابيسوا: nوي ميارا: nabiswa@unhcr.org جون ناغاتشا بيرتون: burtonj@unhcr.org 


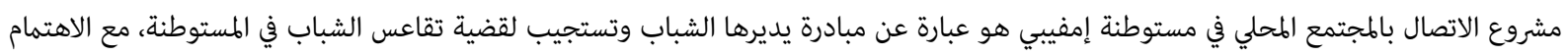

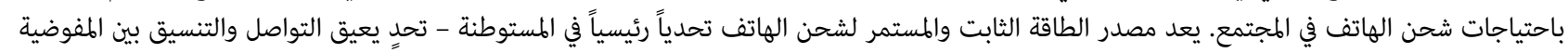

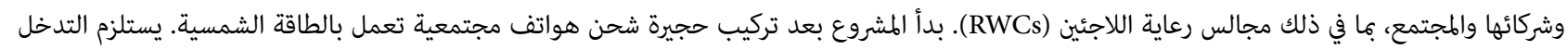

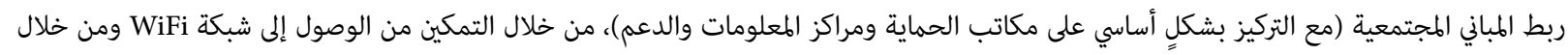

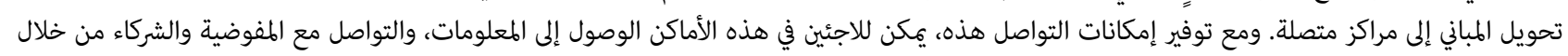

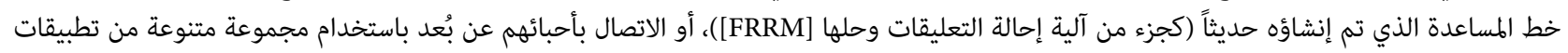

المراسلة/امكامات الصوتية.

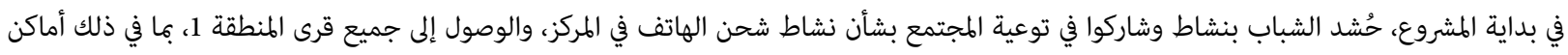

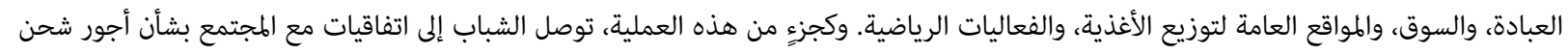

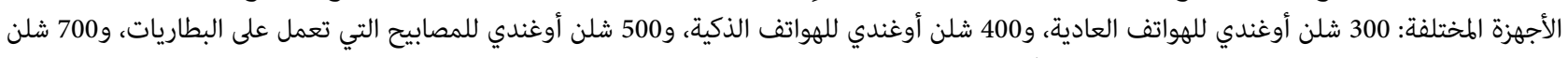

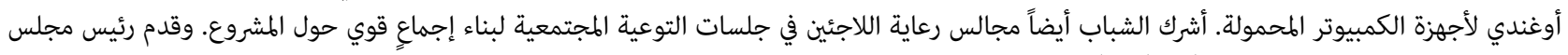

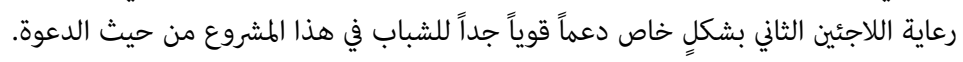

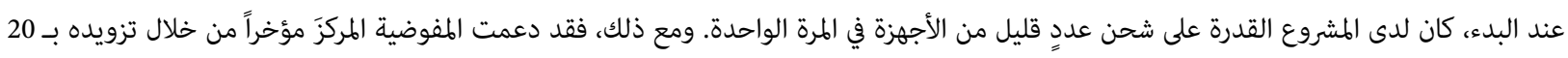

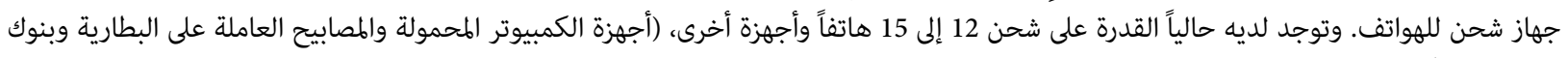
الطاقة) يومياً.

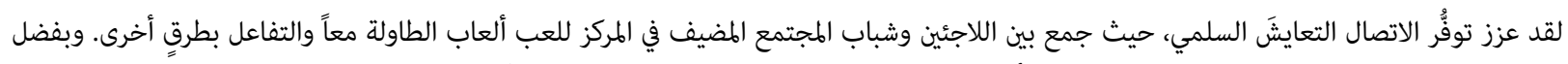

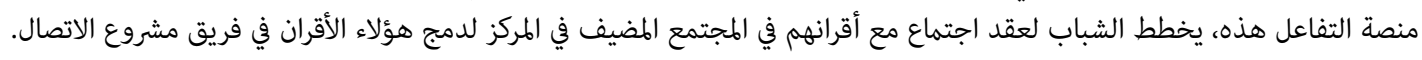

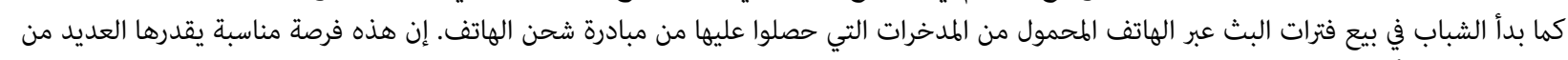

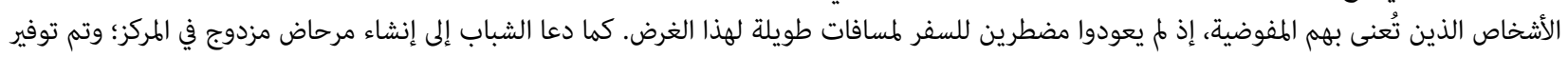
ذلك في النهاية من قبل لجنة الإنقاذ الدولية، حيث ساهم الشباب مغطر من خلال حفر حفرة المرحاض.

تتحمل مفوضية الأمم المتحدة لشؤون اللاجئين ومكتب رئيس الوزراء المسؤولية الكاملة عن المشروع، في حين أن شريك الحماية ومجالس رعاية اللاجئين مسؤولون عن المراقبة اليومية لنتائج المشروع.

$$
\begin{aligned}
& \text { الشريك/الشركاء: } \\
& \text { المجلس الدافركي للاجئين } \\
& \text { مكتب رئيس الوزراء } \\
& \text { لمزيٍٍ من المعلومات، يرجى الاتصال بـ: } \\
& \text { وليام نجيزي: ngeze@unhcr.org } \\
& \text { فيث كامويو: kamoyo@unhcr.org }
\end{aligned}
$$




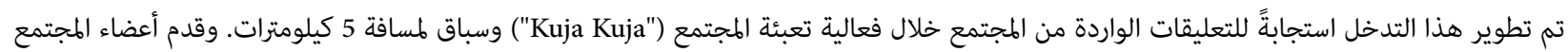

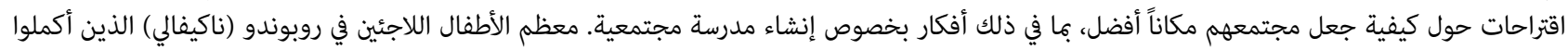

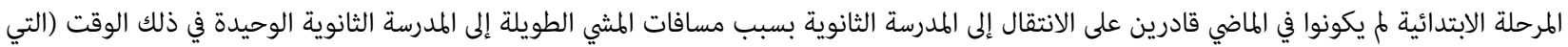

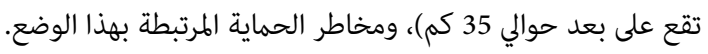

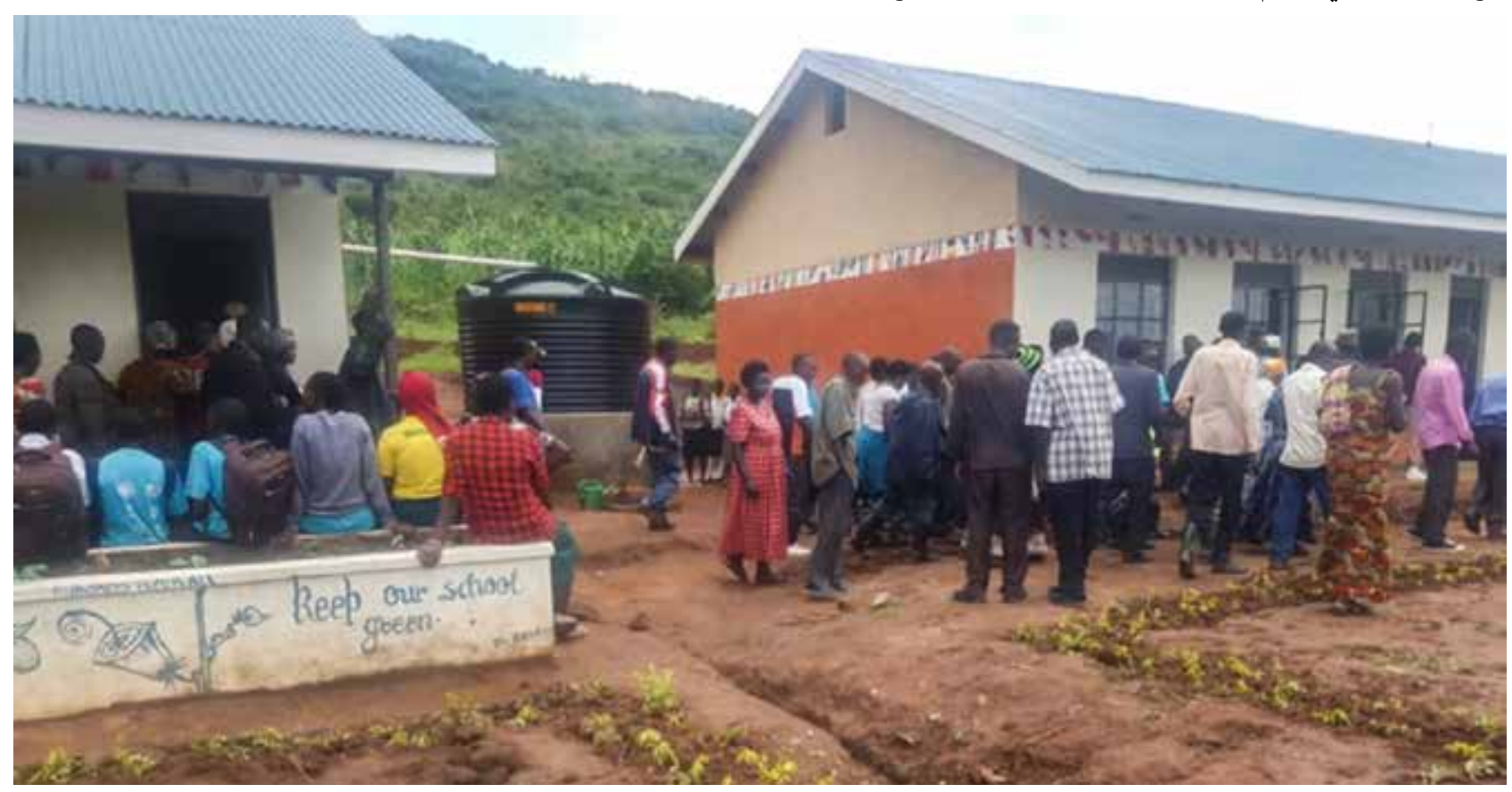

يقود جهود التدخل أفراد المجتمع، الذين يحشدون جميع الآباء والمجتمع المضيف، ويشجعونهم على إرسال أطفالهم إلى المدرسة. ويواصل أعضاء المجاجتمع أيضاً

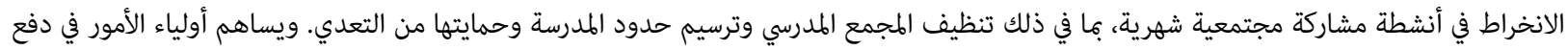
رسوم مدرسية بقيمة 100,000 شلن أوغندي (حوالي 27 دولاراً أمريكياً) لكل فصلٍ دراسي لتسهيل إدارة المدرسية المدرسة، مها في ذلك دفع رواتب المعلمين.

النتائج o زاد الالتحاق من 76 طالب (منهم 32 طالبة) في نهاية عام 2019 إلى 110 طلاب (منهم 52 طالبة) في شهر مارس 2020، قبل إغلاق المدارس بسبب جائحة كوفيد19-.

o o

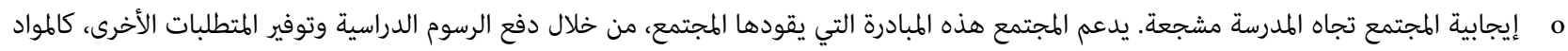
الدراسية والزي المدرسي.

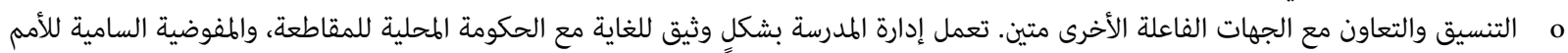

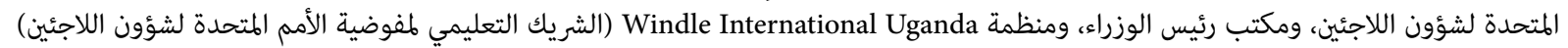
ومنظمة Alight، الشريك الذي يدعم تطويرها. o

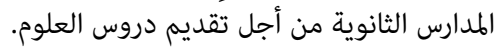

الشريك/الشركاء:

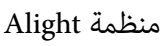
حكومة المنطقة المحلية مكتب رئيس الوزراء منظمة منب رئيس الوزراء كليدٍ من المعلومات، يرجى الاتصال بـ: ديفيس موغوميا: mugumya@unhcr.org سيلفيا سامانيا: samanya@unhcr.org 


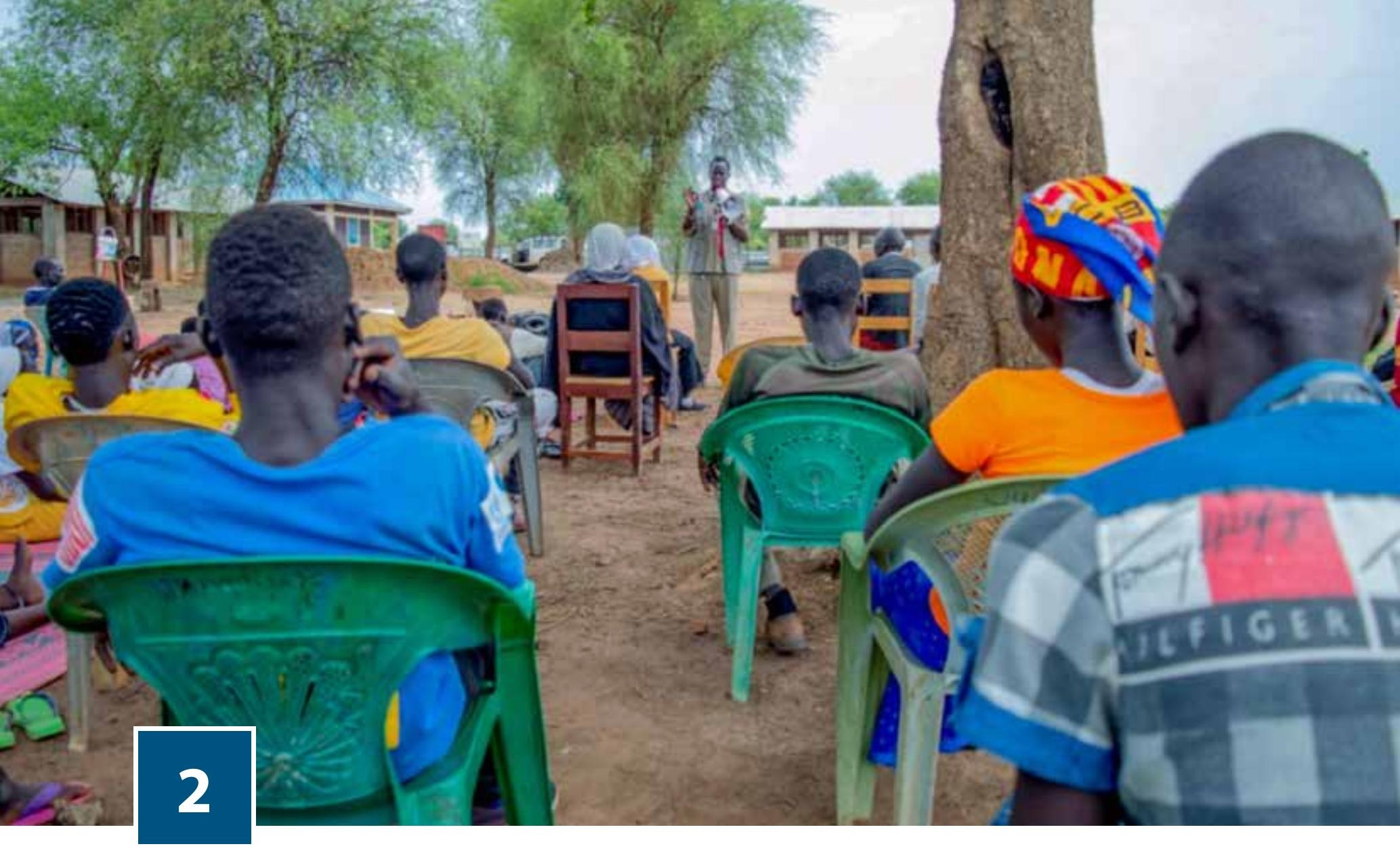

\section{الحماية الهجتمعية}

ممارسة ناشئة من جيبوتي: مساهمة المجتمعات في اكتشاف حالات السل بين اللاجئين

تهدف هذه المهارسة إلى تحسين اكتشاف حالات السل في مناطق اللاجئين وتعزيز البدء المبكر للعلاج من خلال أنشطة المشاركة المجتمعية. كما تسعى إلى تعزيز الماتئ

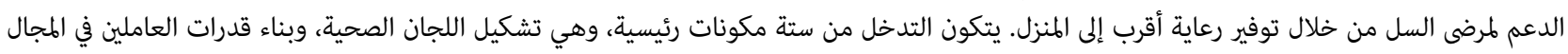

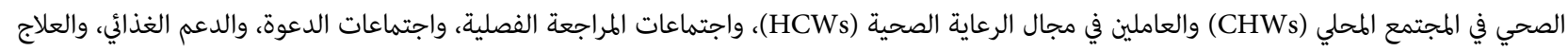
بالقرب من المجتمع. وفيما يلي تفصيل هذه المكونات:

o o

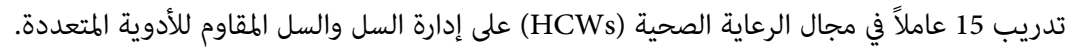

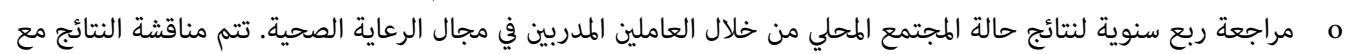

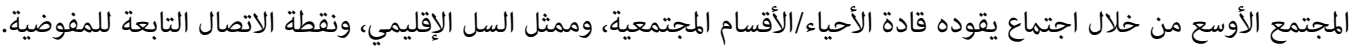

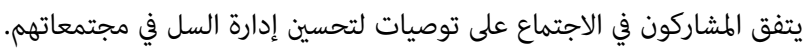
o o o يسمح برنامج العلاج الوطني الآن لمرضى السل بتلقي العلاج على مستوى المخيم، وبالتالي الاستفادة من دعم مجتمعاتهم.

النتائج

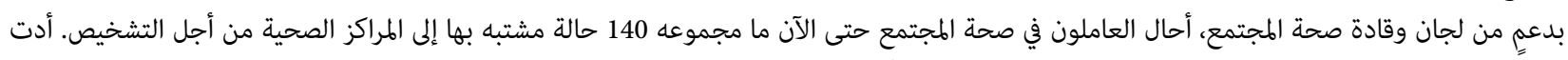

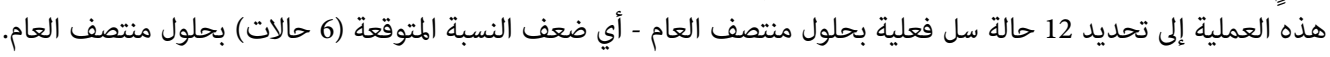

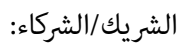
الهيئة الحكومية للتنمية وزارة الصحة الجيبوتية 


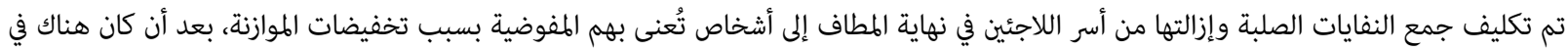

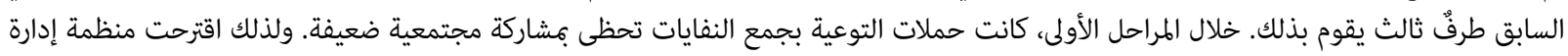

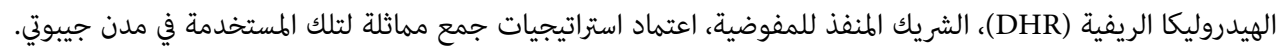

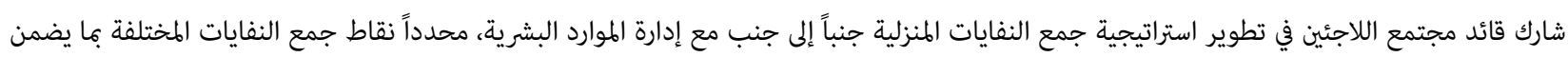

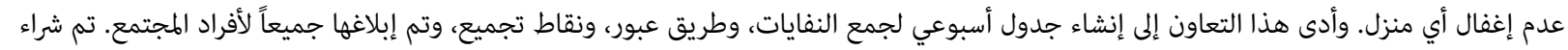

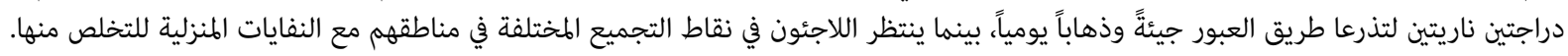

ولضمان جودة خدمات جمع النفايات المنزلية وإدارتها، قامت إدارة الموارد البشرية بتجنيد اللاجئين كمروجين للنظافة. ويستفيد هؤلاء من جلسات بناء القدرات لضمان الحفاظ على بيئة معيشية صحية في مجتمعاتهم المحلية.

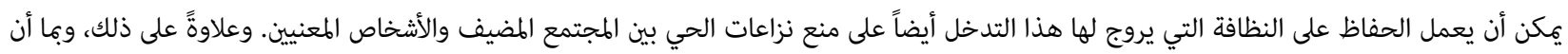

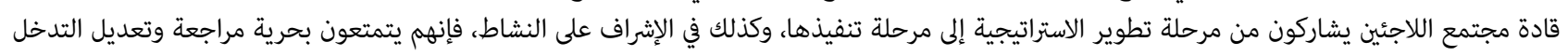
حسب الحاجة. الشريك/الشركاء: منظمة Direction de l'Hydraulique Rurale المكتب الوطني لساعدة اللاجئين والمنكوبين لمزيدٍ من المعلومات، يرجى الاتصال بـ: مصطفى حسن أحمد: mhaktulli@gmail.com abkalay@yahoo.fr عبده علي كيادن

ممارسة ناشئة من إثيوبيا: تنظيم انتخاب ممثلي اللاجئين بما يتماشى مع اعتبارات السن ونوع الجنس والتنوع (AGD)

بعد المخاوف الأمنية الناشئة عن الاشتباكات العرقية التي أودت بحياة لاجئين في مخيم كول للاجئين، قامت وكالة شؤون اللاجئين والعائدين (ARRA)، وكالة إدارة

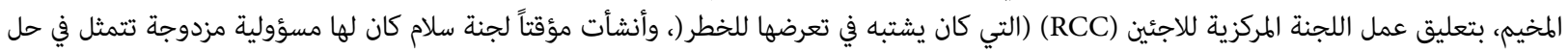

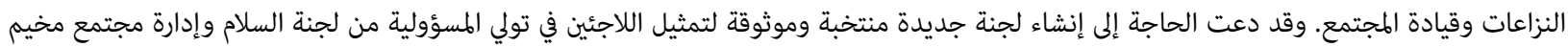
كولي للاجئين.

تضمّن التدخل ذو الشقين تطوير مبادئ توجيهية للانتخابات وفرت فهماً مشتركاً بين جميع أصحاب المصلحة وعززت النزاهة والشفافية والمساءلة في العملية

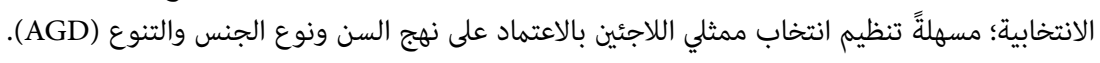

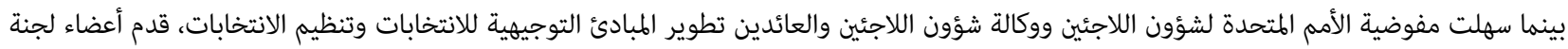

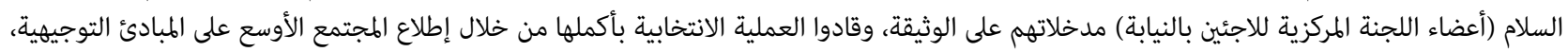

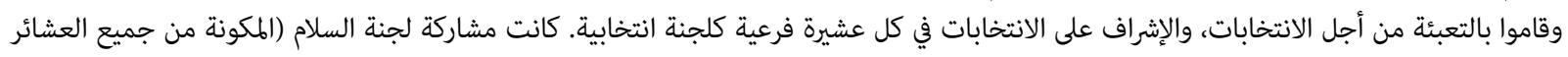

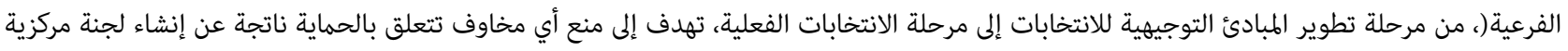

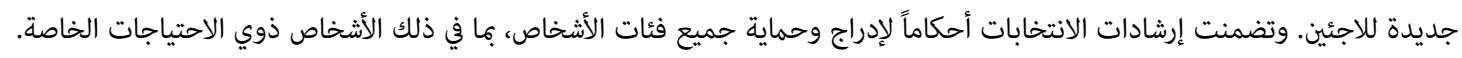

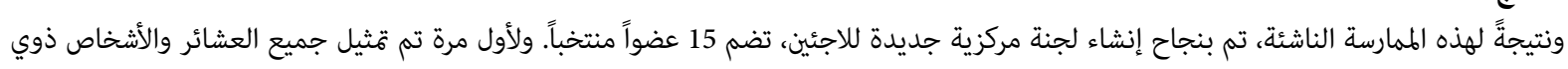
الاحتياجات الخاصة في هيكل القيادة. كما زاد عدد النساء في هذا الهيكة النيكل القيادي من 1 إلى 5.

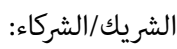
وكالة شؤون اللاجئين والعائدين 
تم تطوير المبادئ التوجيهية لتمكين المجتمع بشكلٍ تعاوني من قبل قادة مجتمع اللاجئين الإرتيريين والمفوضية ووكالة شؤون اللاجئين والعائدين (ARRA)

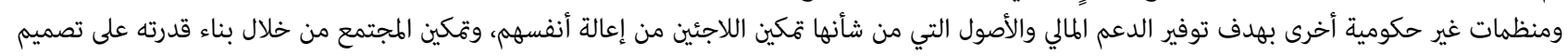
وإدارة أنشطة الحماية في مخيمات اللاجئين.

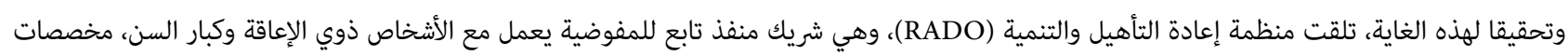

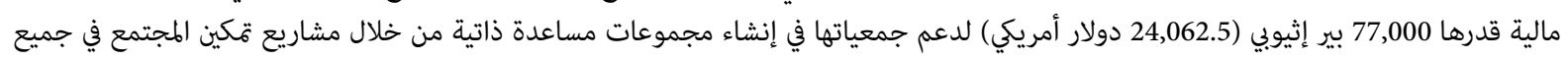

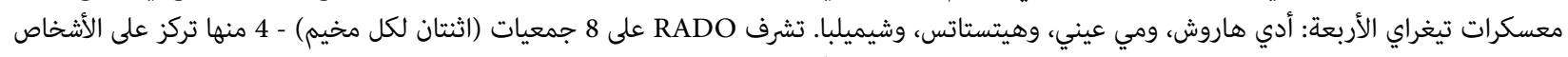

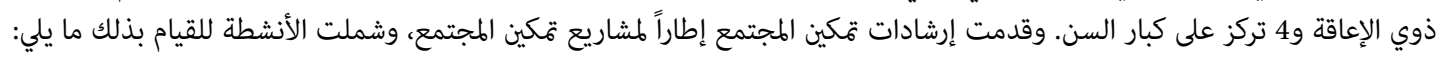

o ت توعية المستفيدين (في هذه الحالة جمعيات RADO) بالمبادئ التوجيهية من خلال عقد اجتماع مع كل جمعية، مع تقديم المفوضية التوجيه عند الحاجة.

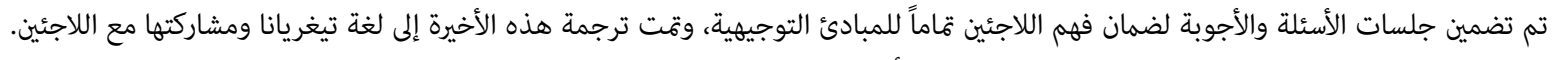

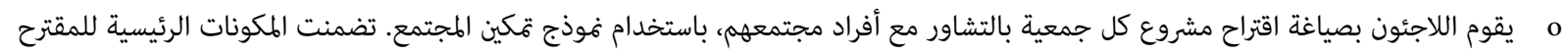
احتياجات وأهداف وخطط إدارة المشروع.

o القديم دعم إضافي لتطوير الاقتراح للجمعيات التي تحتاج إليه. وقد تكفل ذلك بتقديم المقترحات في الوقت المناسب وشمل أيضاً التدريب على تخطيط الموازنة والأنشطة.

o

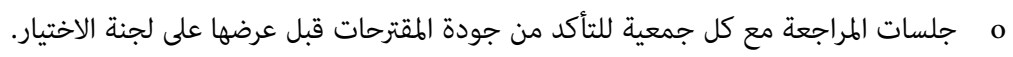

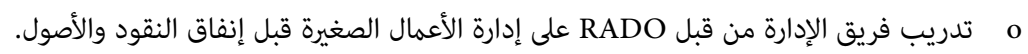

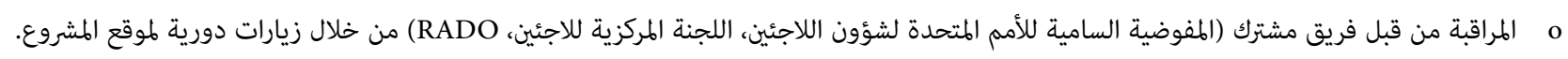
o

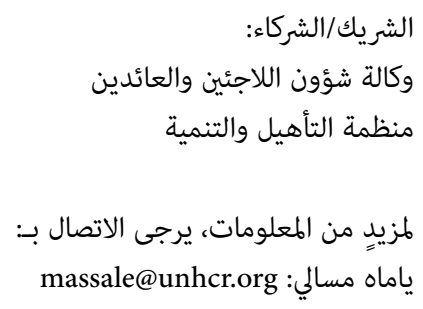


لعبت الرياضة دوراً مهماً في تعزيز حماية النساء والرجال والفتيات والفتيان في مختلف القطاعات مثل التعليم والصحة والتعايش السلمي في مخيم كاكوما للاجئين

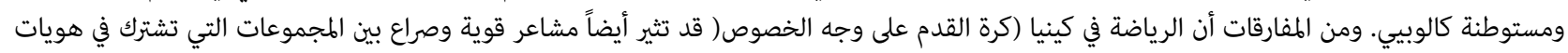
عرقية وثقافية متشابهة.

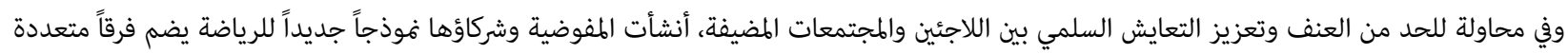

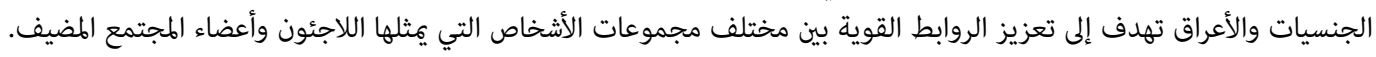

يشجع النموذج الجديد على تغيير السلوك بين الفتيات والفتيان والشباب والشابات، إلى جانب مبادئ "عدم الإضرار" من خلال عدد من الأنشطة الرئيسية: o إنشاء دوريات كرة قدم للذكور ('Kakuma Premier') والإناث ('Diva League'): ويشترط أن تكون الفرق المشاركة متعددة الأعراق ومتعددة الجنسيات. o قرارات حكام خاطئة متصورة.

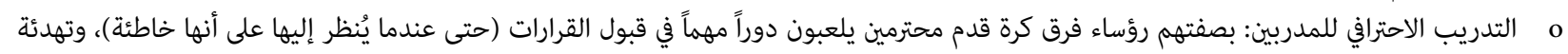

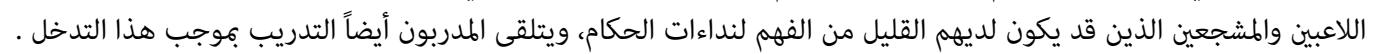

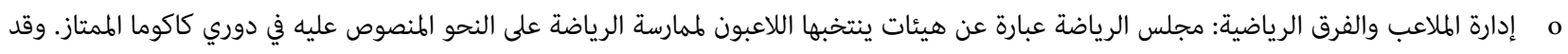

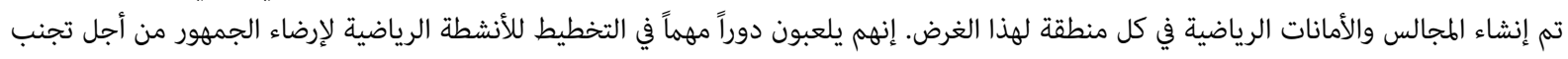

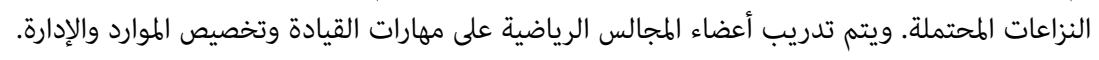

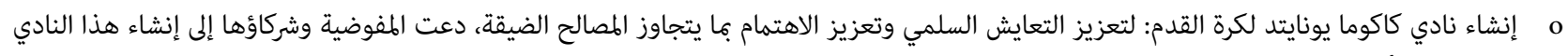

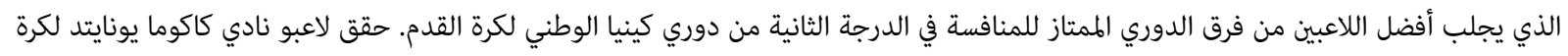

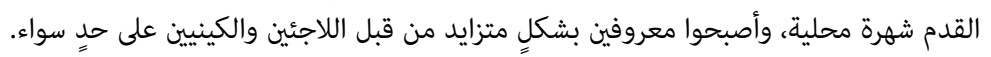

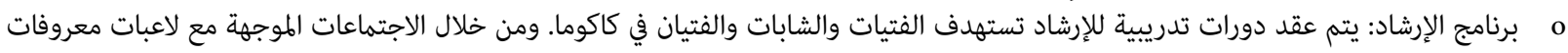

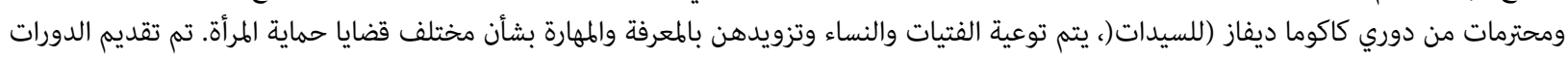

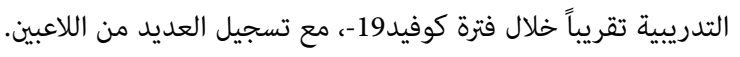

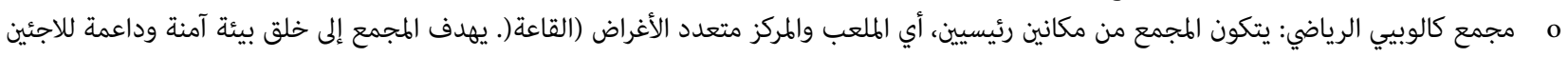

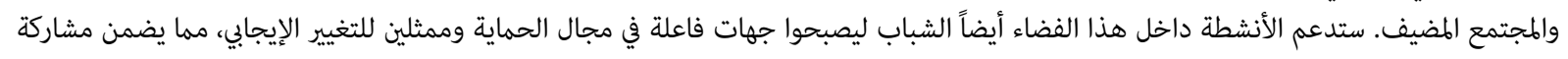

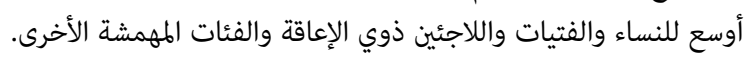

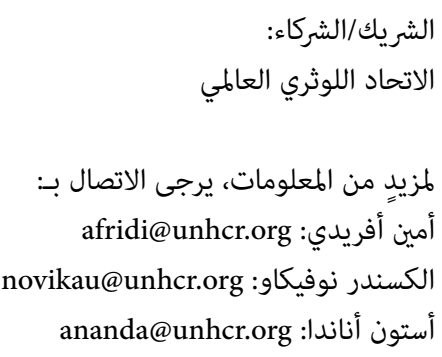


ممارسة ناشئة من كينيا: ترتيبات الرعاية المجتمعية للبالغين غير المصحوبين بذويهم (بها في ذلك كبار السن) الذين يعيشون مع أشكال شديدة من الإعاقة وأمراض الصحة العقلية نمئيات الرعاية

يهدف هذا التدخل إلى: تحديد وتقييم البالغين غير المصحوبين بذويهم الذين يعانون من أشكال حادة من الإعاقة وأمراض الصحة العقلية (بما في ذلك كبار السن)

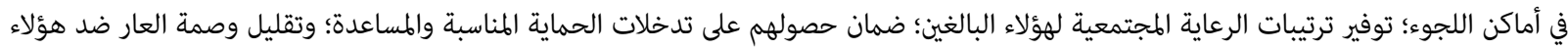

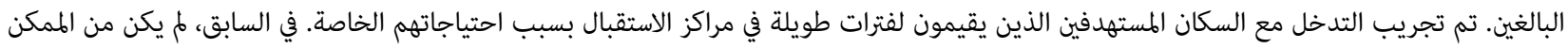
نقل هؤلاء السكان إلى المجتمع لأنهم كانوا بحاجة إلى دعم مجتمعي إضافئ.

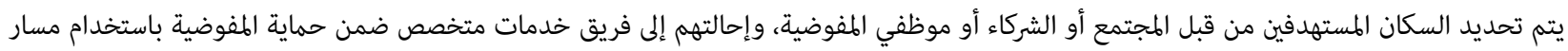

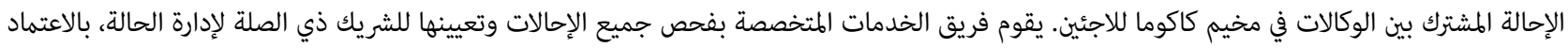

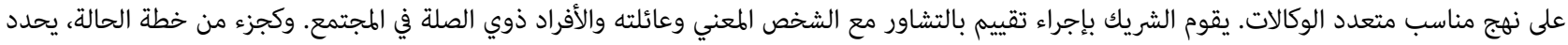

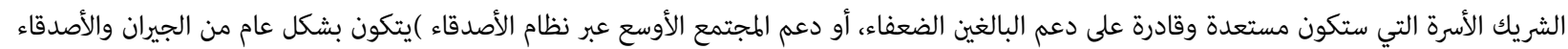

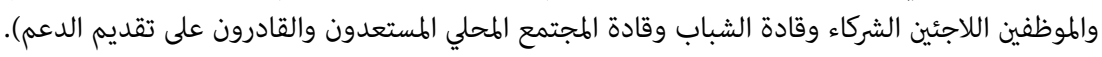

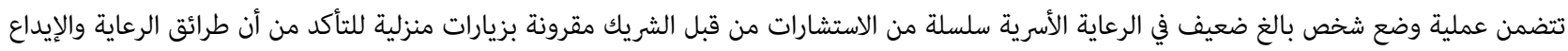

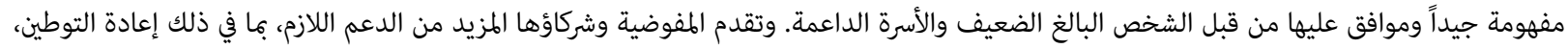

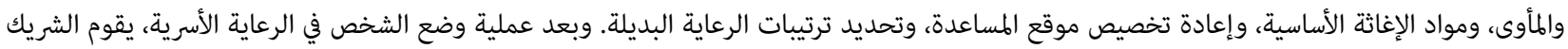

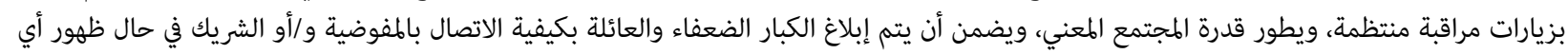

مشاكل.

وباختصار، فيما يلي الخطوات التي اتخذت خلال هذا التدخل: o

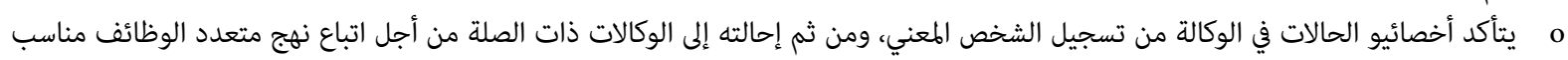
o o

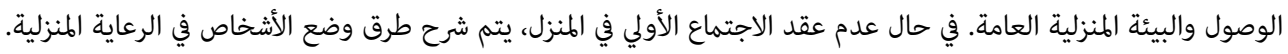
o التموينية، والحطب، وغير ذلك.

o o

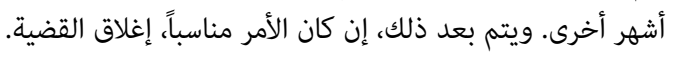

النتائج

في الشهر الأول من ترتيب الرعاية المرتكز على المجتمع المحلي هذا، تم تحديد ما مجموعه 9 بالغين غير مصحوبين بذويهم يعانون من إعاقة شديدة أو أمراض نفسية، بما في ذلك كبار السن، وربطهم بالدعم المقدم في إطار البرنامج.

الشنيسة الأفريقية الداخلية

منظمة Humanity and Inclusion

لجنة الإنقاذ الدولية

منظمة Jesuit Refugee Service

لمزيدٍ من المعلومات، يرجى الاتصال بـ: ليانا بوديسزفا: podeszfa@unhcr.org الكسندر نوفيكاو: novikau@unhcr.org

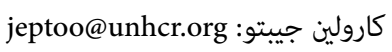
أستون أناندا: ananda@unhcr.org 
دراسة حالة من كينيا: تجنب تلوث المياه بخيوط غطاء لأغطية الجراكن

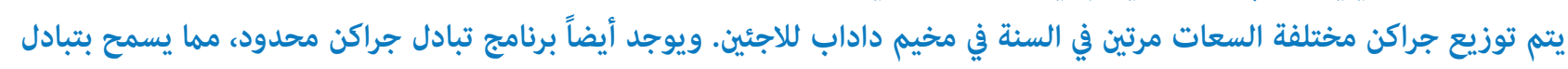
الجراكن المكسورة، اعتماداً على توفر المخزون.

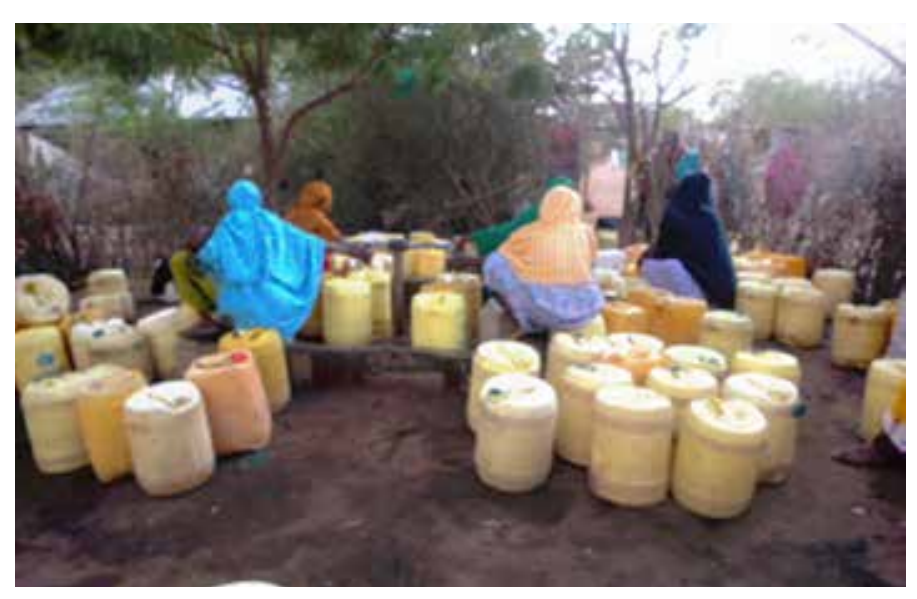

كثيراً ما تُنقل الجراكن من منصات الحصول على الماء إلى المنازل

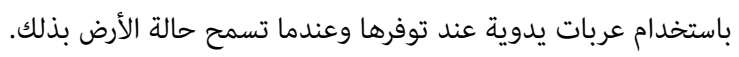

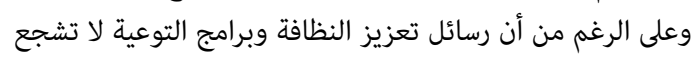

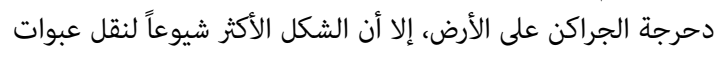

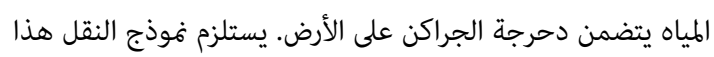

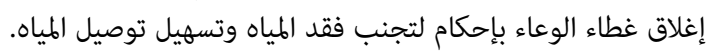

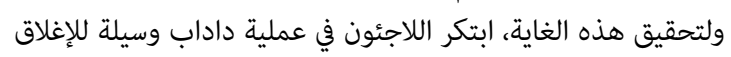

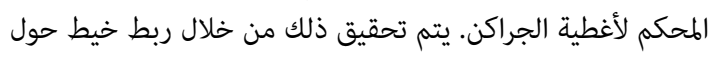

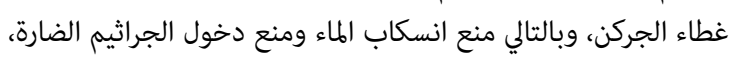
على الرغم من التصاق الرمل والطين الذي تسببه دحرجة الجركن.

الشريك/الشركاء: المعلومات غير متوفرة

كليدٍ من المعلومات، يرجى الاتصال بـ:

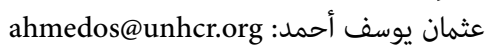

دراسة حالة من كينيا: لجان المياه في السوق

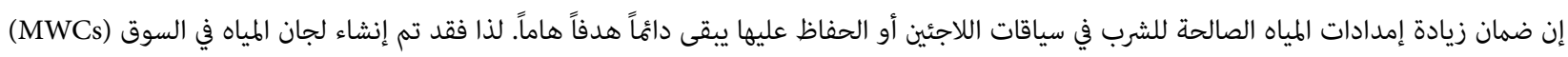

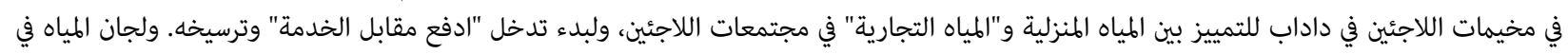

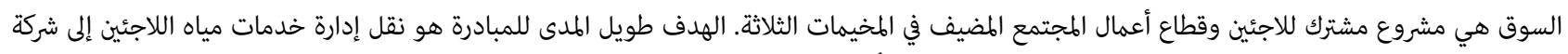

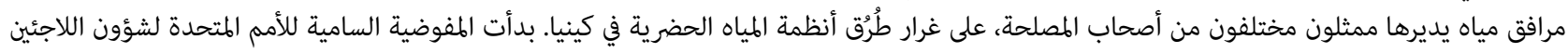

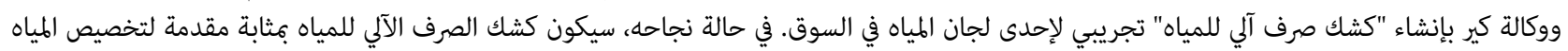

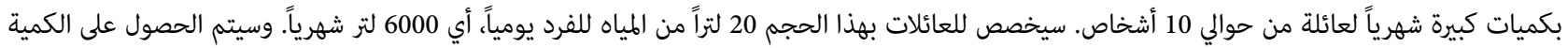

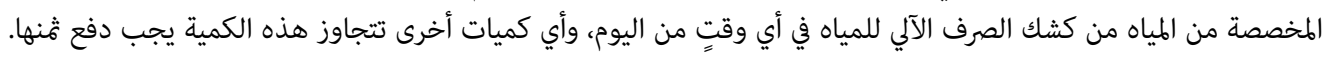

الشريك/الشركاء:

وكالة CARE

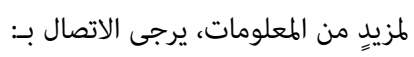

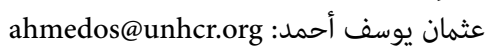




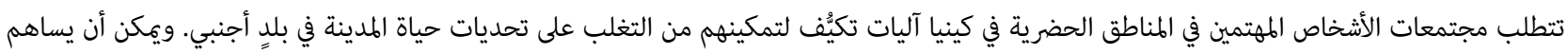

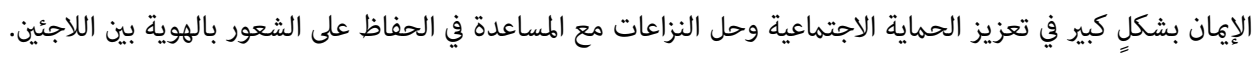

في نيروبي، أقام بعض اللاجئين أماكن عبادة خاصة بهم. وتم تصميم مراكز العبادة هذه بشكلٍ أساسي لتلبية الاحتياجات الروحية للاجئين، مع تكرار تجربة إنية الكنيسة

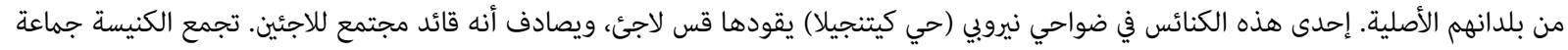

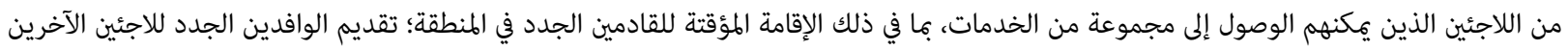

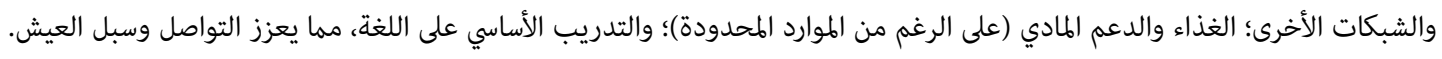

كما أن الكنيسة هي عضوٌ في "زمالة قسّيسي كيتنجيلا"، وهو منتدى يوفر فرص التواصل مع كنائس المجتمع المضيف، تم من خلاله حل بعض النزاعات بين اللاجئين ومضيفيهم.

النتائج

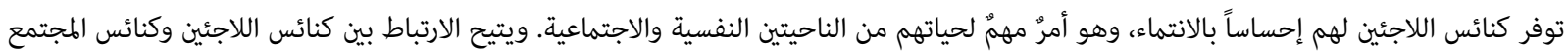

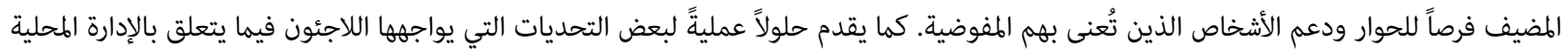

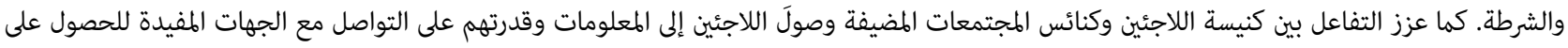

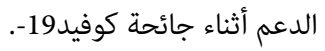

\author{
الشريك/الشركاء:

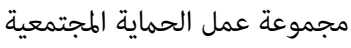 \\ أمانة شؤون اللاجئين \\ مزيدٍ من المعلومات، يرجى الاتصال بـ:
}

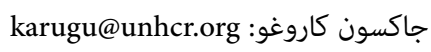

دراسة حالة من كينيا: لجان المياه وخدمات الصرف الصحي والنظافة الصحية المجتمعية

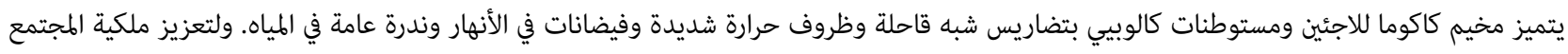

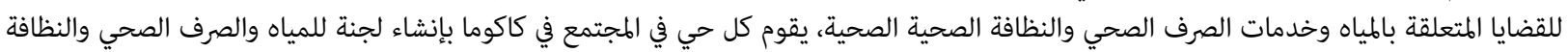

الصحية WASH

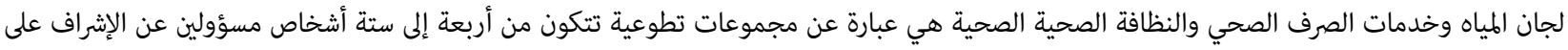

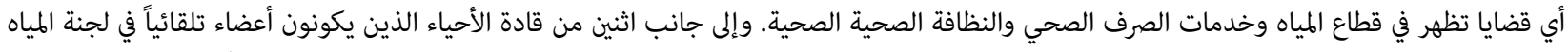

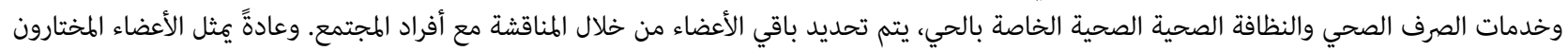

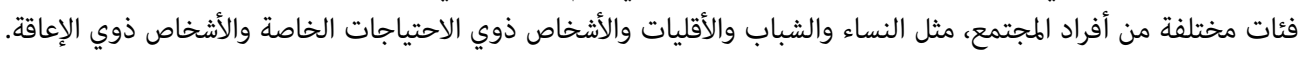

في كاكوما وكالوبيي، يتم توفير المياه عبر 19 بئراً من خلال شبكة من الخزانات الفولاذية المرتفعة وشبكة توزيع تصل إلى منصات الصنابير في المجتمع. يتم تشغيل الآبار إلى حدٍ كبير بواسطة المولدات، ولكن أيضاً بواسطة الألواح الشمسية، عند توفرها.

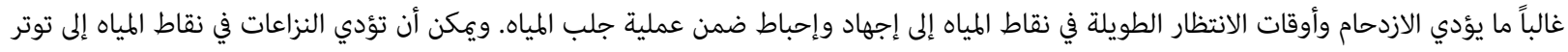

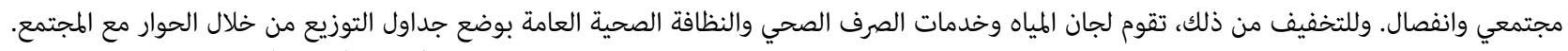

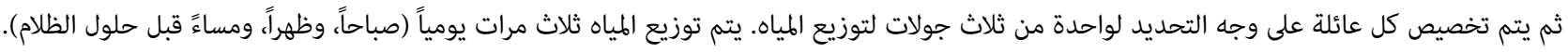

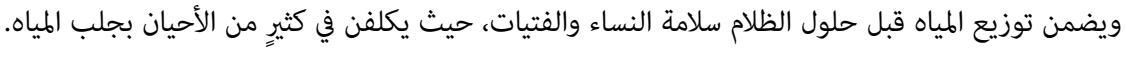

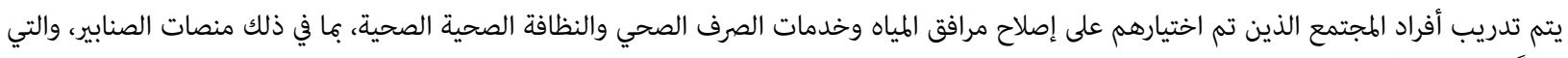

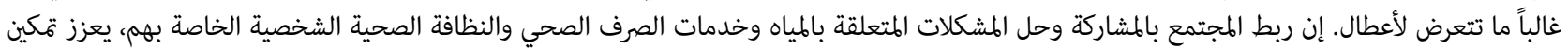

المجتمع وتعزيز القدرات. 


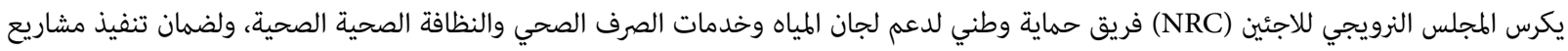

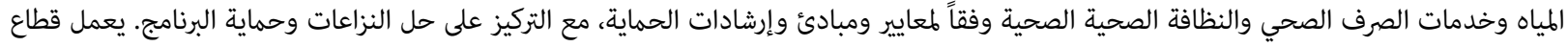

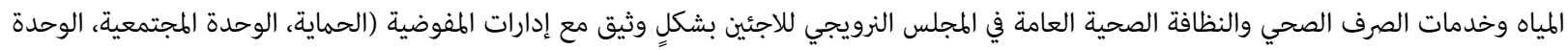

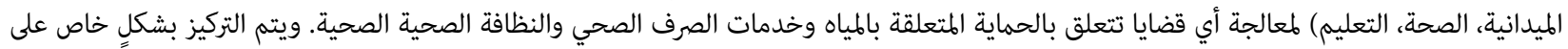

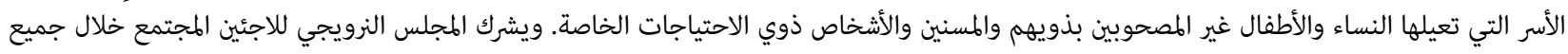

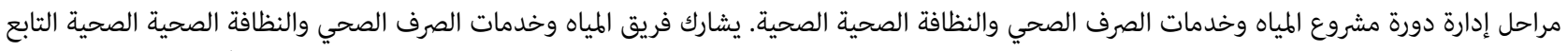

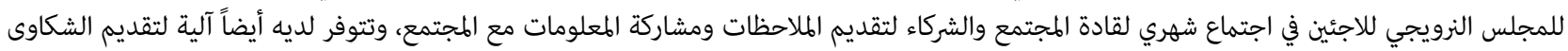
والاستجابة والتغذية الراجعة تشجع الحوار في المجتمع المنماع فهري لفادة المجتي.

\author{
الشريك/الشركاء: \\ المجلس النرويجي للاجئين \\ لمزيدٍ من المعلومات، يرجى الاتصال بـ:

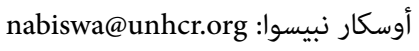 \\ miyahara@unhcr.org مو مياهارار نيسروار \\ دراسة حالة من رواندا: حكام القرى
}

كانت تقارير المفوضية تاريخياً في مخيم ماهاما تتضمن القليل من المعلومات مها يرويه اللاجئون، حيث اعتمدت في المقام الأول على تقرير الشريك والمراقبة

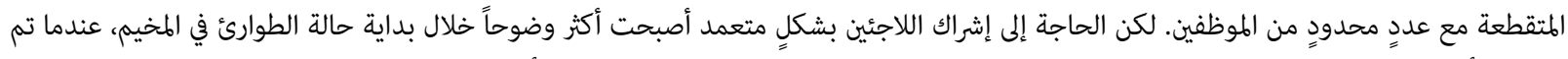

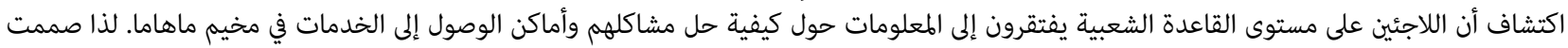

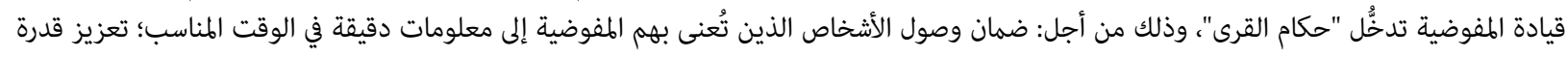

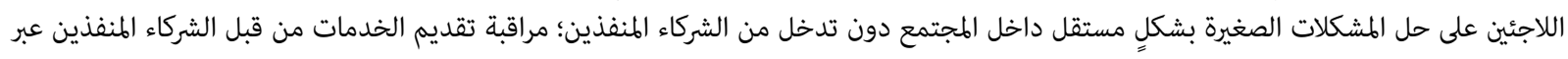

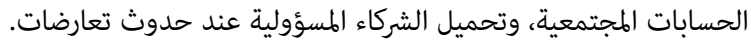

تتضمن مبادرة "حكام القرى" تخصيص موظف من المفوضية للإشراف على كل قرية من قرى مخيم ماهاما للاجئين التي يتم اختيارها، والتي تستوعب ما يقات يقرب

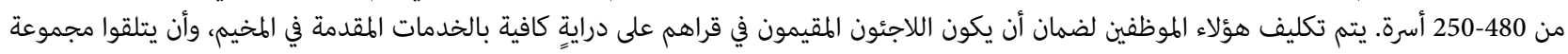

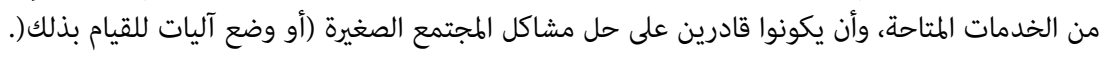

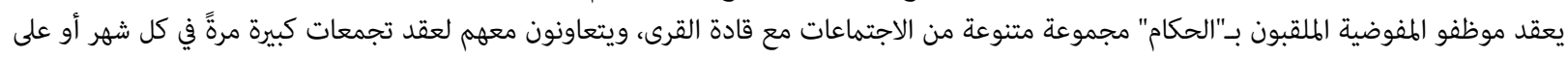

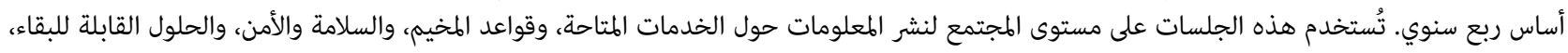

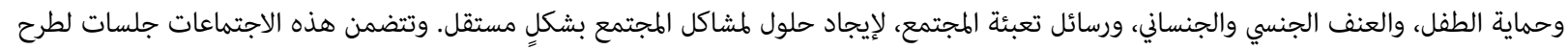
الأسئلة والإجابة عليها.

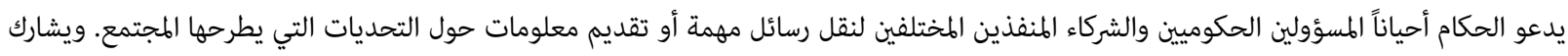

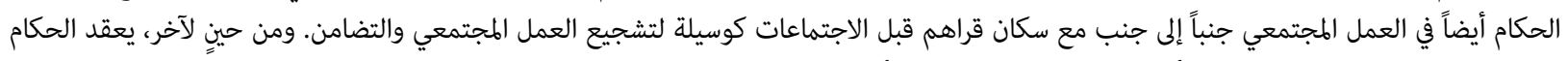

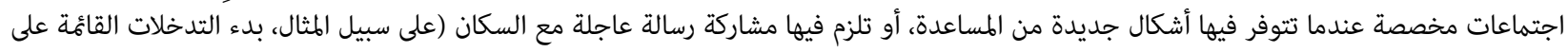

النقود، وتوزيع الغاز، ومعلومات تمارين التحقق). يتم تبادل تقارير هذه الاجتماعات مع فريق إدارة المفوضية، مما يساعد في تحديد أفاط مماثلة، واستخلاص الدروس الهامة، وتقديم التدخلات حسب الحاجة.

الشريك/الشركاء: المعلومات غير متوفرة

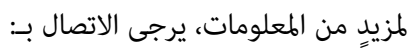

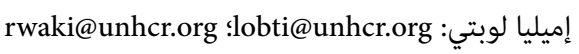


كشفت اجتماعات التنسيق الأسبوعية بين المفوضية والشركاء المنفذين في مخيم ماهاما للاجئين (لغرض تنسيق جميع أنشطة الحماية( عن الحاجة إلى قضاء المزيد

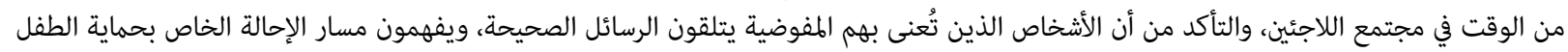

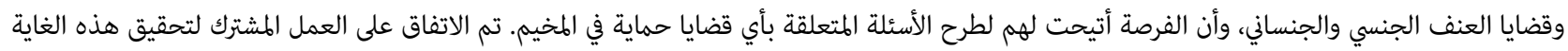

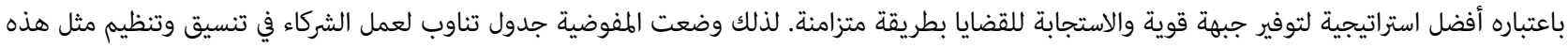

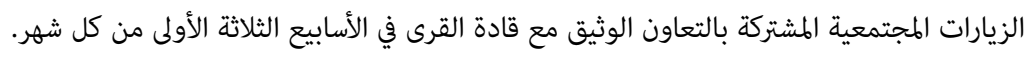

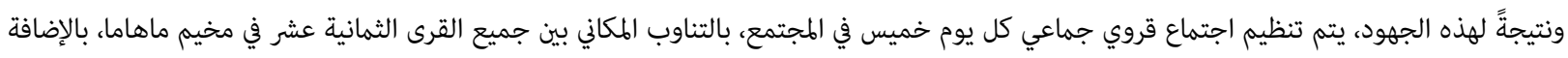

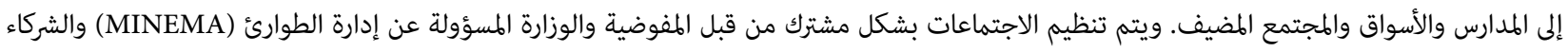

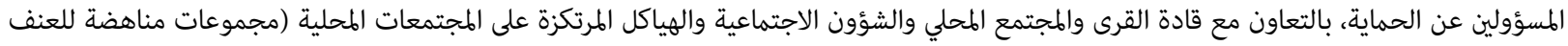

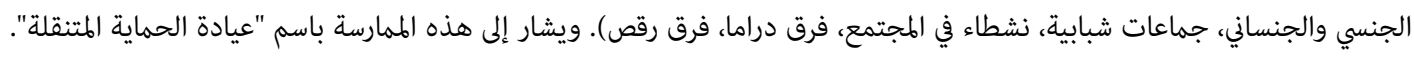

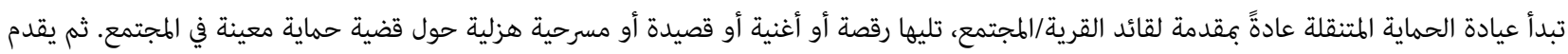

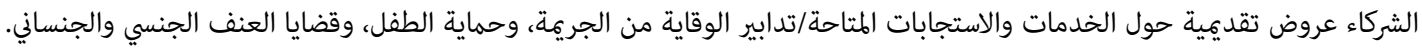

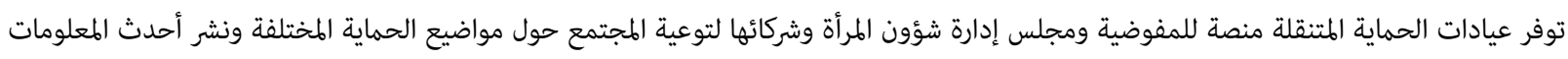
والإعلانات. ويتم تضمين جلسة للأسئلة والشكاوى والتعليقات من المجتمع في التدخل، جنباً إلى جنب مع المعائل ردود الشركاء.

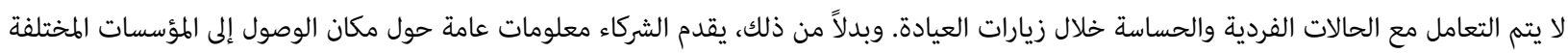

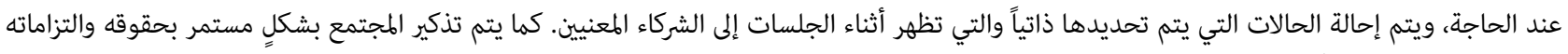
وبضرورة احترام قواعد وأنظمة المخيم.

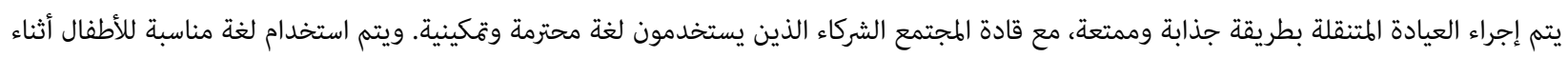

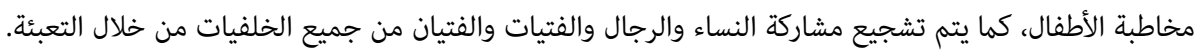

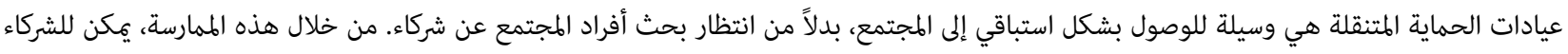

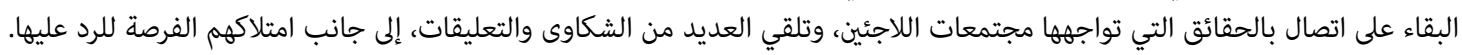

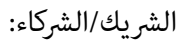

$$
\begin{aligned}
& \text { الوزارة المسؤولة عن إدارة الطوارئ } \\
& \text { المنظمة الدولية لإنقاذ الطفولة إلطوارة } \\
& \text { منظمة Alight } \\
& \text { الوكالة السبتية للتنمية والإغاثة } \\
& \text { لجنة الصليب الأحمر الدولية } \\
& \text { منتدى المساعدة القانونية } \\
& \text { زمالة السجن في رواندا } \\
& \text { لمزيٍٍ من المعلومات، يرجى الاتصال بـ: } \\
& \text { إميليا لوبتي: lobti@unhcr.org }
\end{aligned}
$$


بعد المشاورات مع قادة المجتمع واللاجئين ذوي الإعاقة وأسرهم في مخيمات اللاجئين البورونديين، أصبحت التحديات التي يواجهها اللاجئون ذور الإعاقة وإقة واضحة.

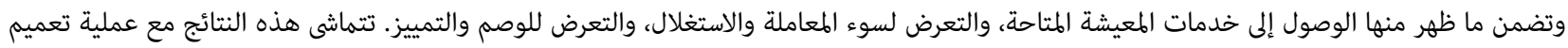

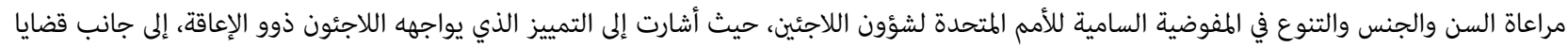

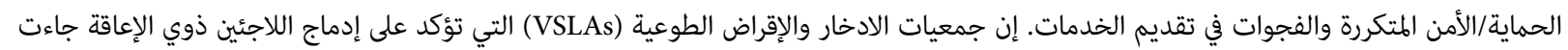

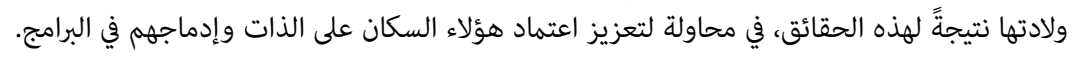

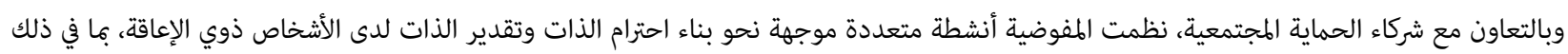

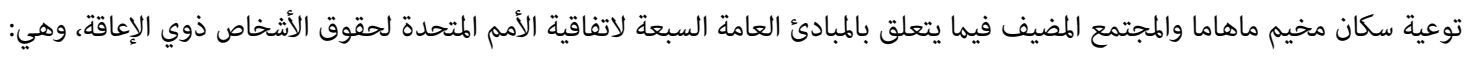

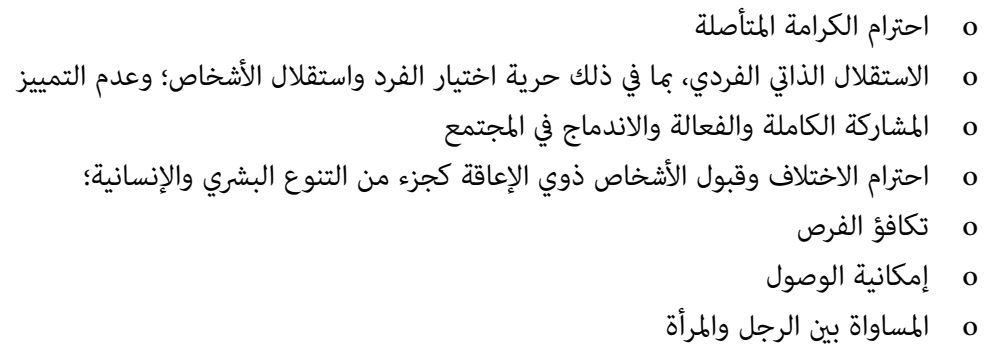

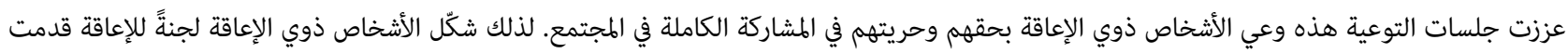

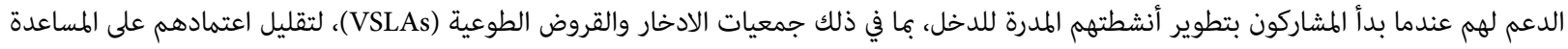
وزيادة مشاركتهم الاجتماعية والاقتصادية.

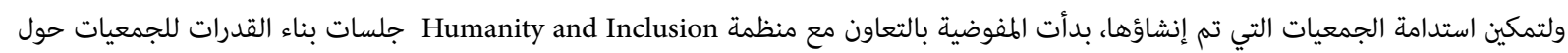

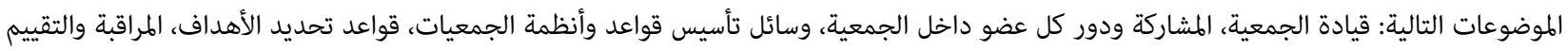

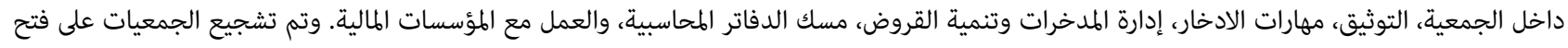

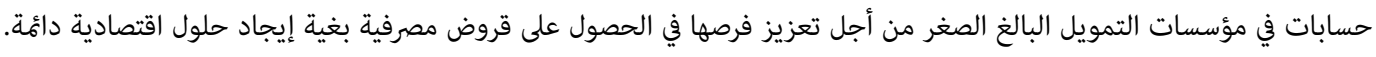

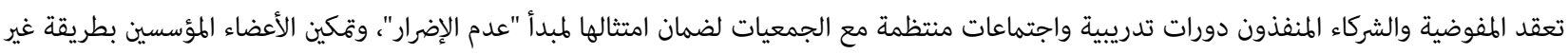

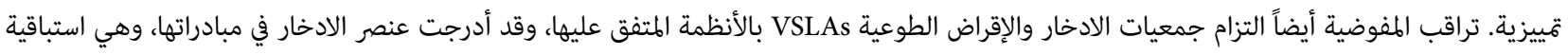

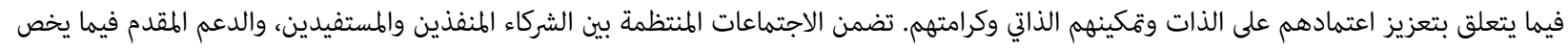
مسك الدفاتر المحاسبية، بالإضافة إلى الاستراتيجيات الأخرى، أن يكون لدى الجمعيات النيات نظام مراقبة ومساءلة مطبق لتحقيق الشفافية.

النتائج

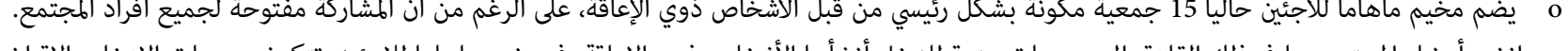
o

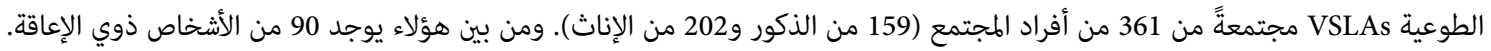

o

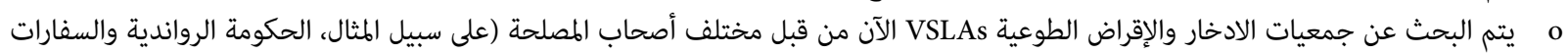

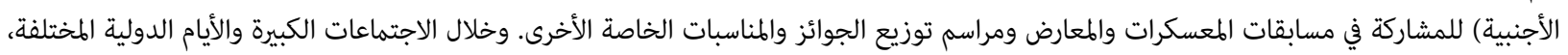

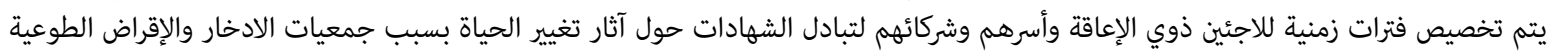

VSLAs

o

الشريك/الشركاء:

منظمة Humanity and Inclusion

لمزيدٍ من المعلومات، يرجى الاتصال بـ:

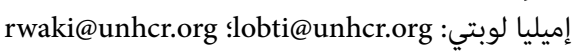




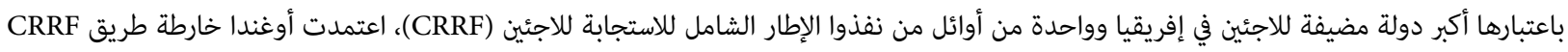

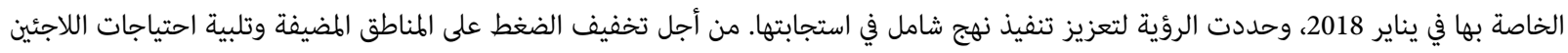

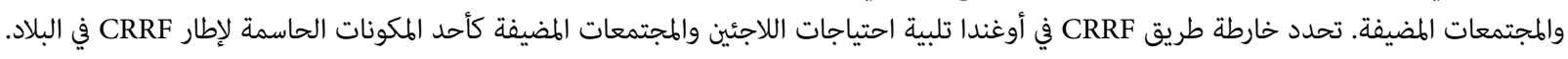

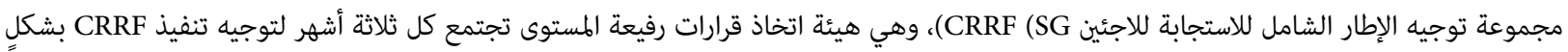

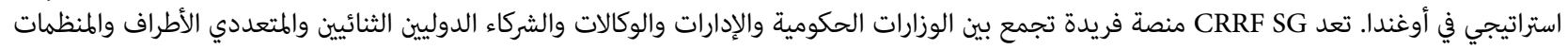

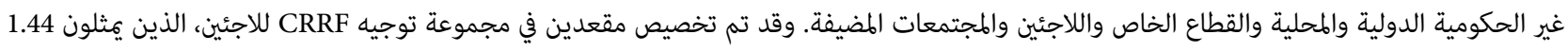
مليون لاجئ في البلاد.

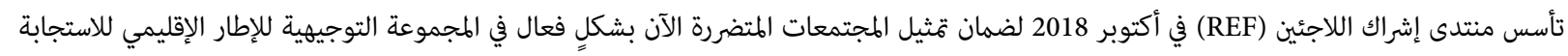

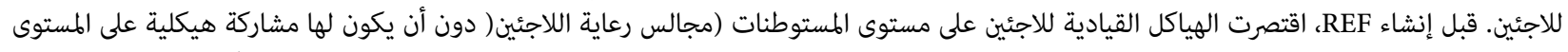

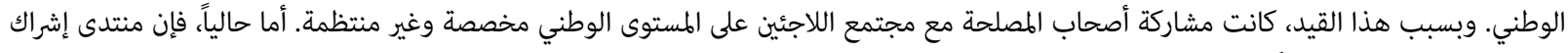

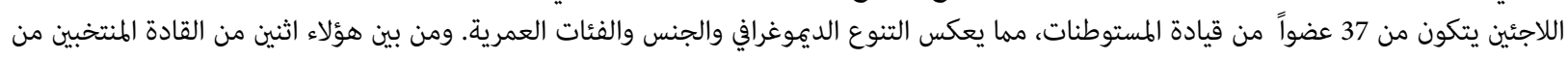

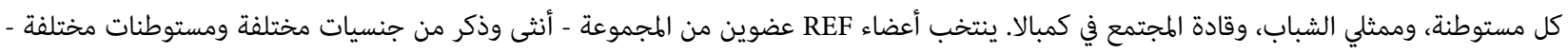

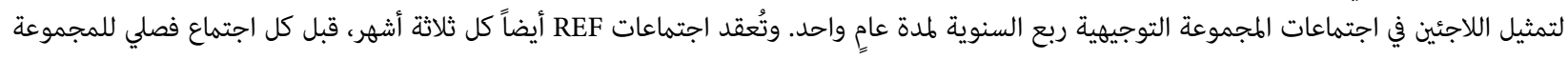

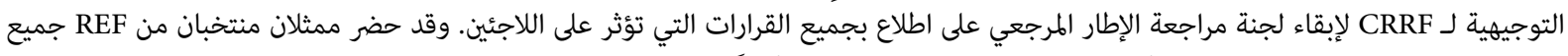

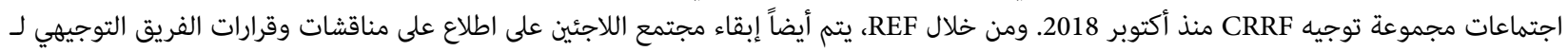

.CRRF

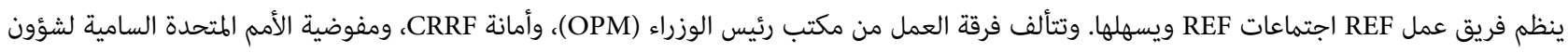

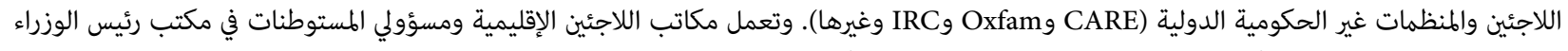

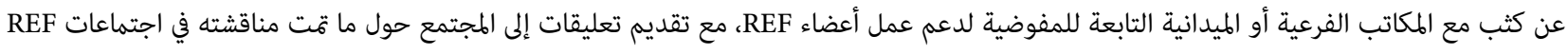

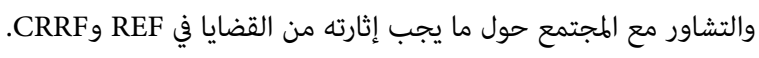

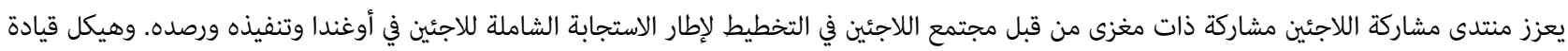

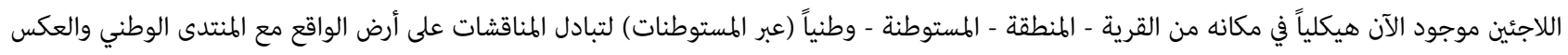

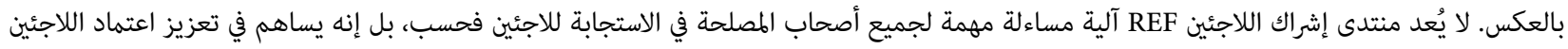

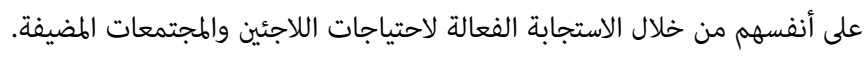

وقد قام اثنان من ممثلي اللاجئين من REF بحضور وGAD و و ومؤتمر طوكيو الدولي الرابع المعني بتنمية أفريقيا TICAD وغيرها من المشاركات الدولية لتبادل خبراتهم ومعارفهم ومناقشة القضايا من ممثي التي تؤثر على مجنى مجتمعهم.

الشريك/الشركاء: متعددون

كليدٍ من المعلومات، يرجى الاتصال بـ:

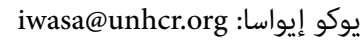
ليزلي فيليز: velez@unhcr.org

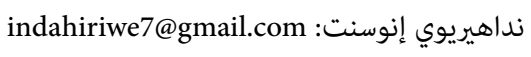
ريك بارتولدوس: Rick.Bartoldus@rescue.org أنيت كيامبادّي: ريك بارتوس: Annet.Kyambadde@care.org 


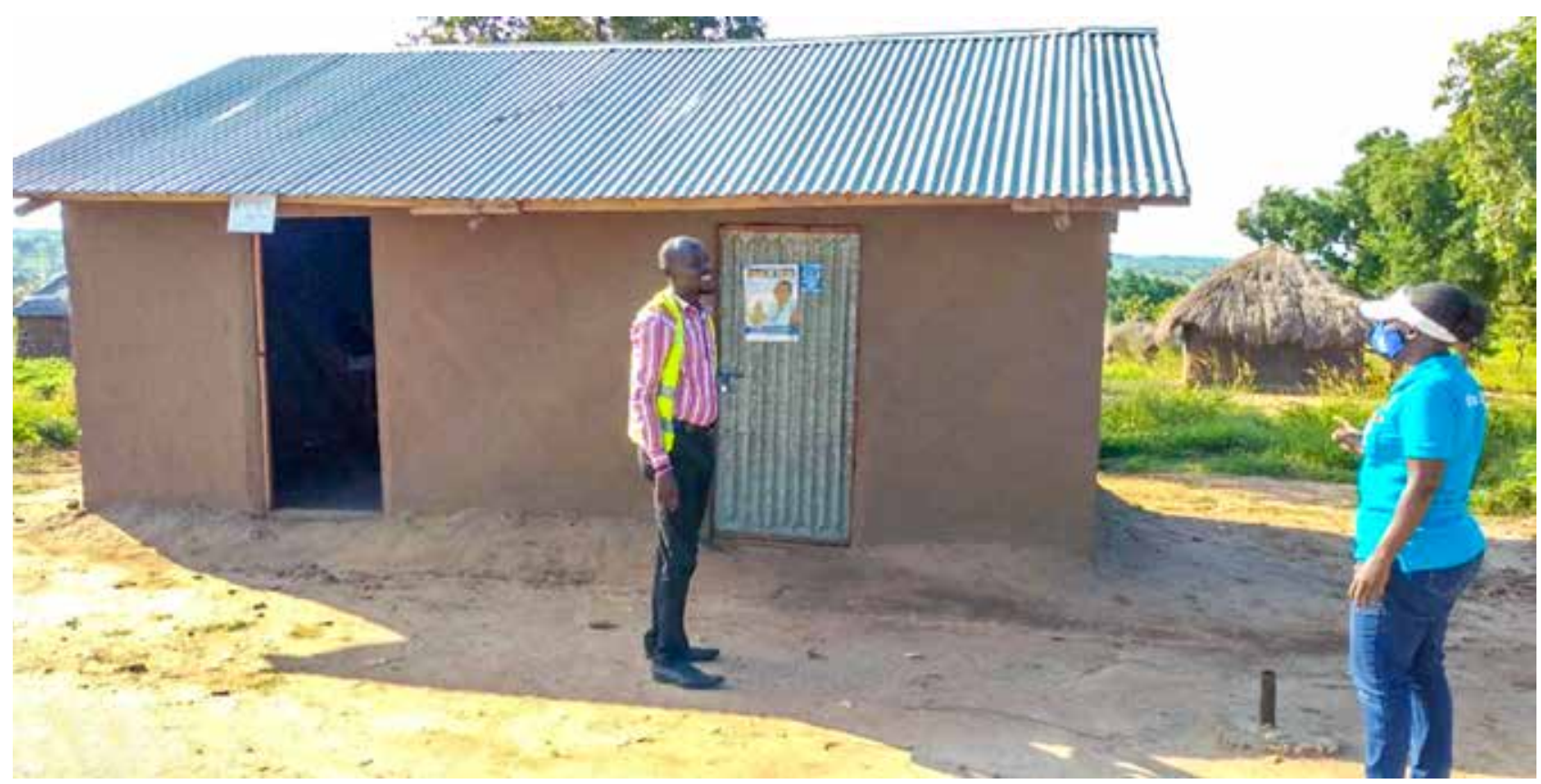

كان إنشاء مساحات شبه دائمة لمجلس رعاية اللاجئين (RWC) في منطقة أوفوا مبادرة مجتمعية بحتة بقيادة قيادة مجلس رعاية اللاجئين موجهة نحو تعزيز

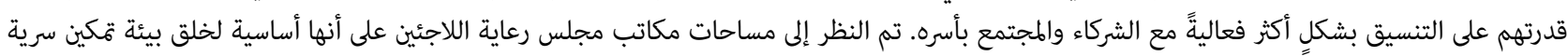

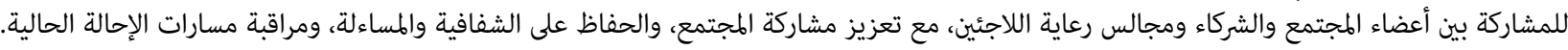

تم إنشاء مساحات مكاتب مجلس رعاية اللاجئين في 6 قرى في منطقة أوفوا. تسهل هذه المساحات على اللاجئين والشركاء التواصل مع قادة مجلس رعاية اللاجئين

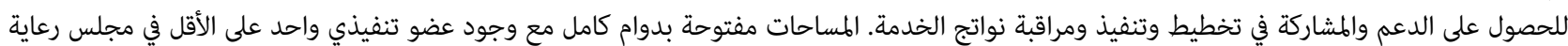
اللاجئين لحل المشكلات، بما في ذلك الشكاوى أو المخاوف الفردية، ومشاركة الملاحظات، والحاجة إلى مساحة اجتماع.

بالإضافة إلى ذلك، أنشأ الأشخاص ذوو الاحتياجات الخاصة (PSN) في منطقة أوفوا ست مجموعات دعم وظيفي (واحدة لكل قرية)، مع مجموعة سابعة إضافية

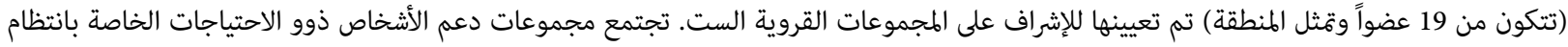

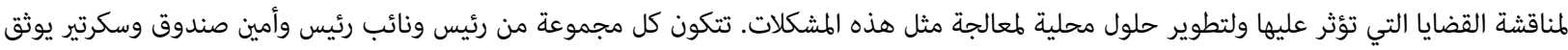

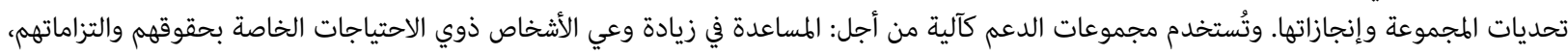

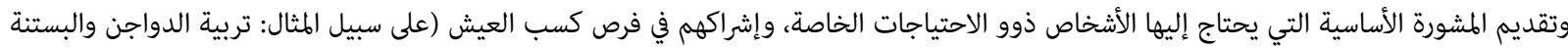
لأغراض المطبخ)، وعلى نطاقٍ صغير تجارة التجزئة والمدخرات.

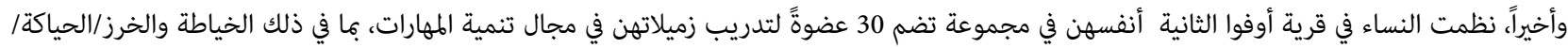

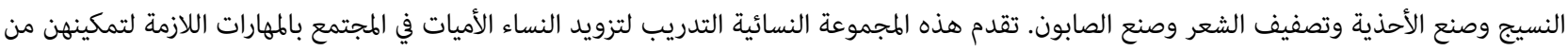

o ميثق الأشخاص المعنيون بقيادتهم ويواصلون عرض مخاوفهم من خلال الهياكل القائمة. وهناك مشاركة ملحوظة من قبل قادة اللاجئين في عمليات اتخاذ القرار

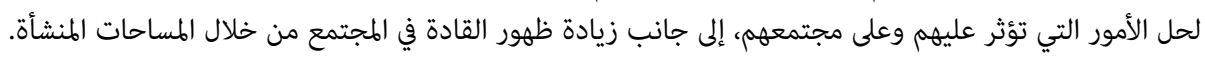

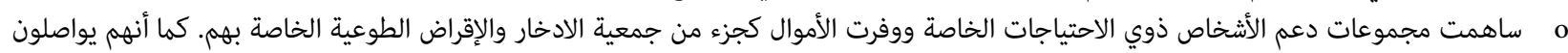

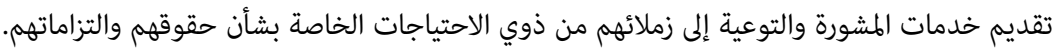
o

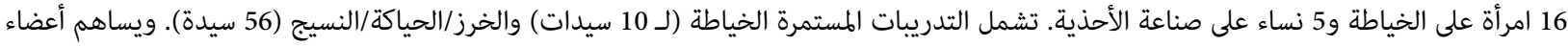
المجموعة مَا يعادل 20,000 شلن أوغندي للعضوية و500 شلن أوغندي للتسجيل و1,000 شلن أوغندي أسبوعياً. وتقرر المجموعة بشكلٍ

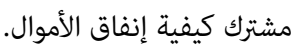




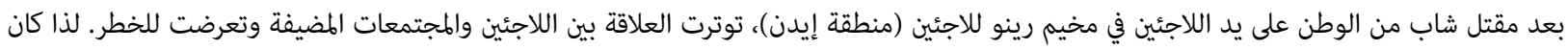

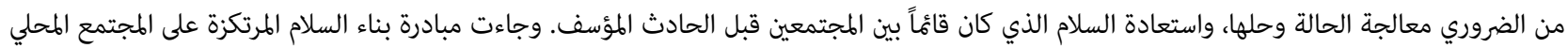
وليدةً لهذه الظروف.

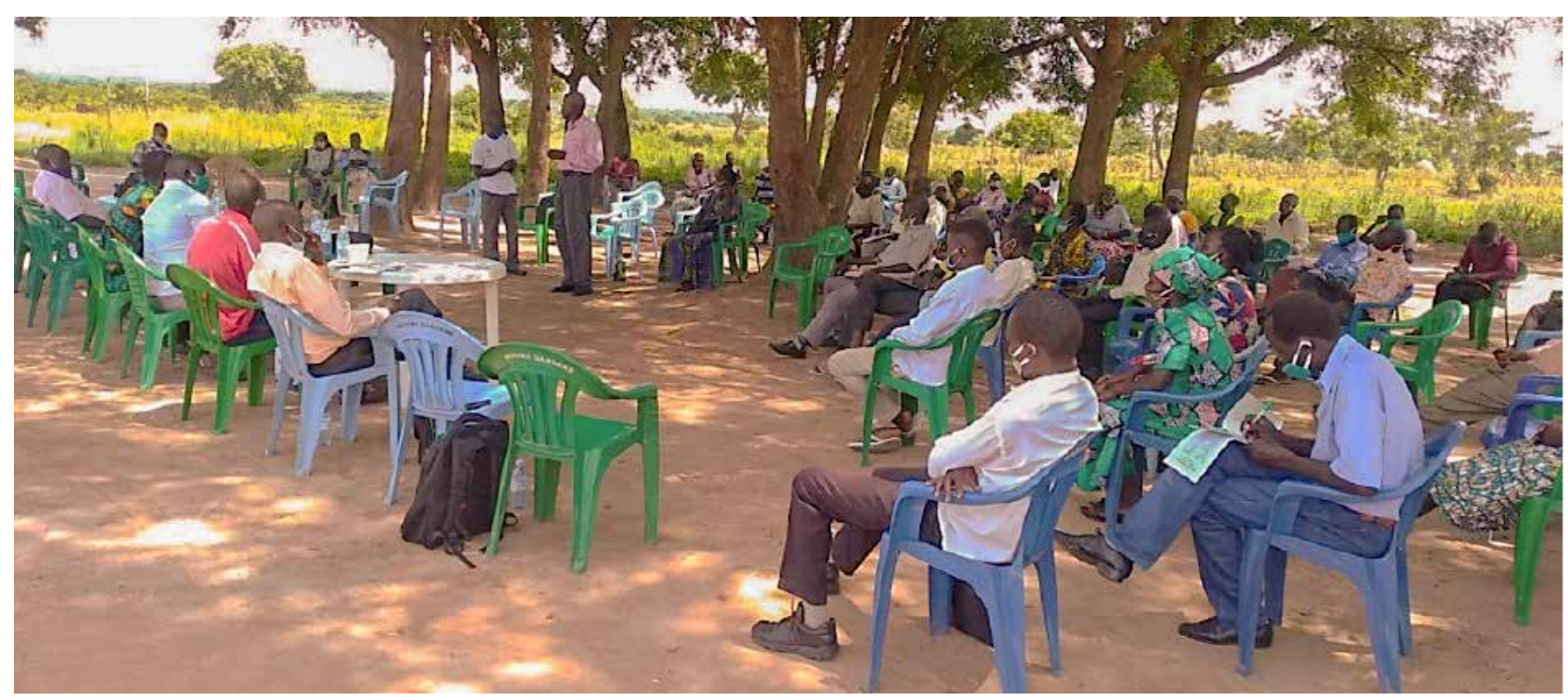

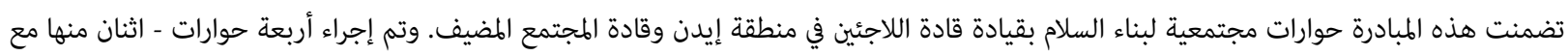

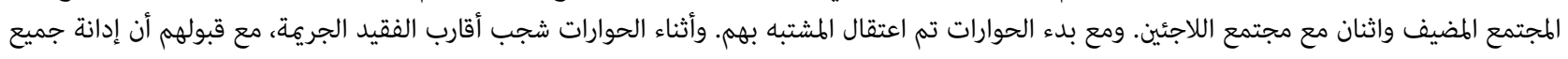
اللاجئين ستكون غير عادلة، وحذروا المواطنين من الانتقام.

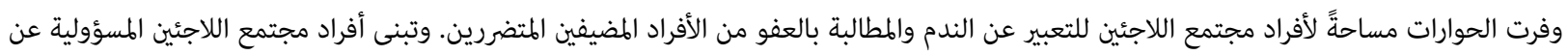

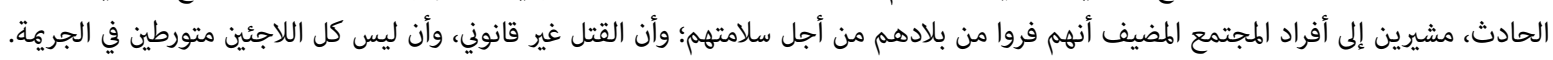

وقد تقرر أن يتعايش اللاجئون والمواطنون، وأن يستمروا في تقاسم الموارد المتاحة. تم تشجيع اللاجئين الذين حصلوا على الأرض أو استأجروها على استئناف

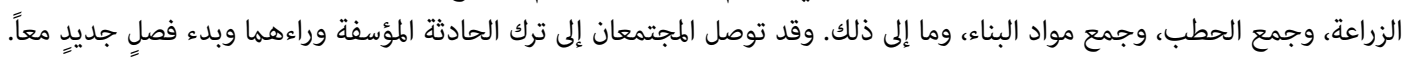

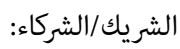

$$
\begin{aligned}
& \text { شبكة قكين تكنولوجيا المجتمع المجراء } \\
& \text { المجلس الدافركي للاجئين }
\end{aligned}
$$

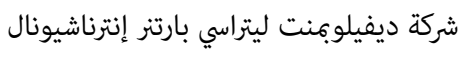

$$
\begin{aligned}
& \text { المجلس النرويجي للاجئين }
\end{aligned}
$$

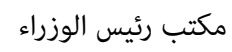

$$
\begin{aligned}
& \text { لمزيدٍ من المعلومات، يرجى الاتصال بـ: } \\
& \text { جايل تشونج: chunge@unhcr.org } \\
& \text { إجوي جيفري باكولي: ejoyi@unhcr.org }
\end{aligned}
$$


لا يزال الأشخاص ذوو الاحتياجات الخاصة في مخيم بيديبيدي للاجئين يواجهون تحديات في الوصول إلى الغذاء بسبب الموقع البعيد لنقاط توزيع الأغذية (FDP)

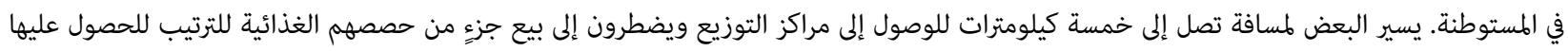

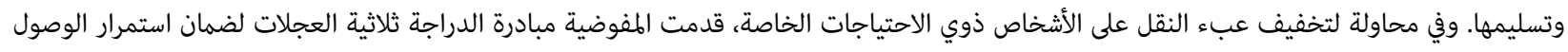

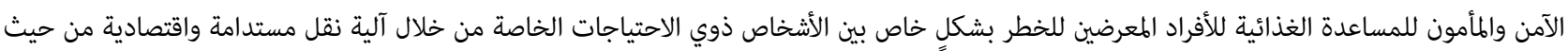

التكلفة.

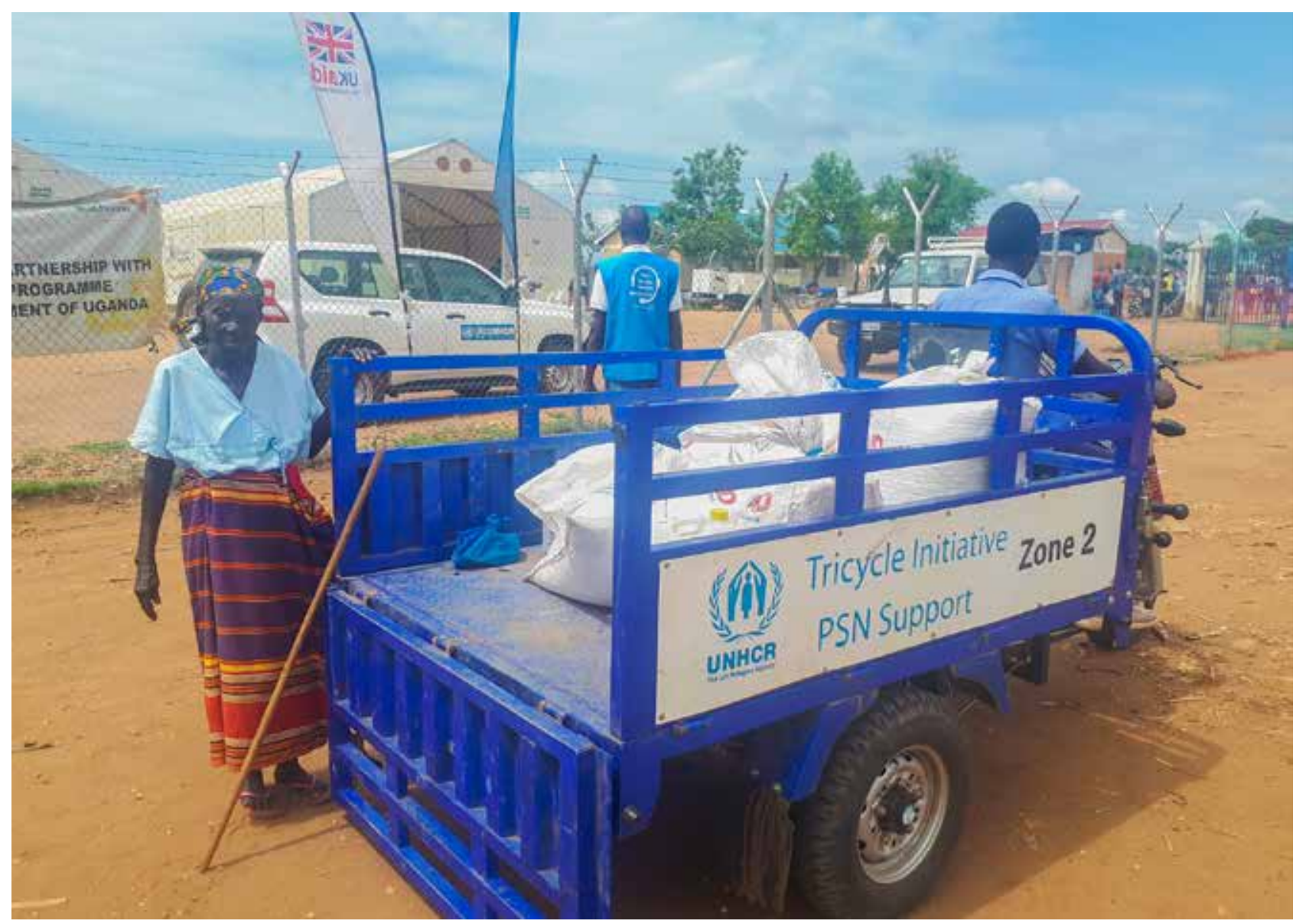

هذا المشروع له هدف ذو شقين: 1) تسهيل خدمات النقل المجانية بطريقة آمنة للأسر الضعيفة بشكلٍ خاص من نقاط التنمية الطارئة إلى مساكنهم داخل

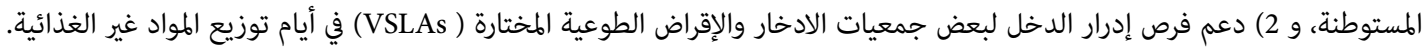

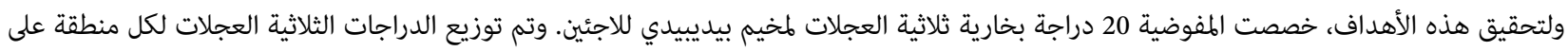

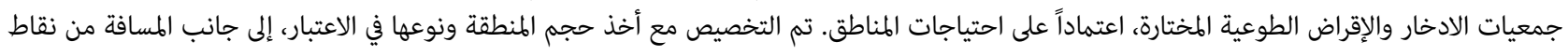

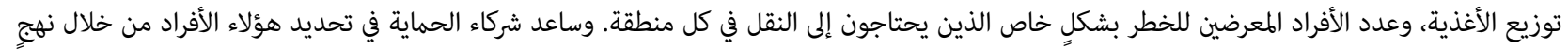

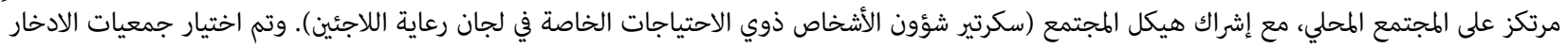

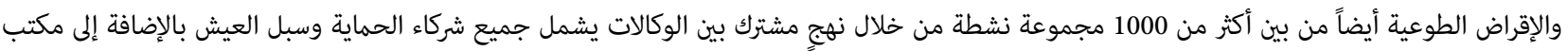

رئيس الوزراء.

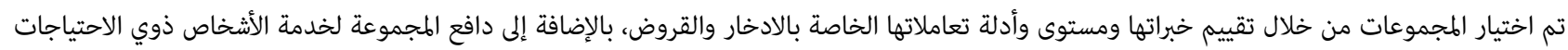

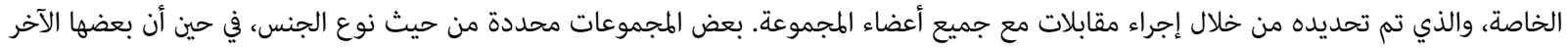

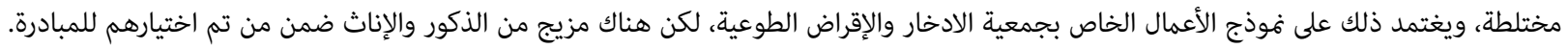

تم تدريب جمعيات الادخار والإقراض الطوعية المختارة على تشغيل الدراجات ثلاثية العجلات وتم تزويد عضوين من كل مجموعة بتصاريح ركوب. تم تسهيل

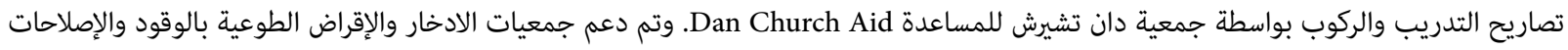

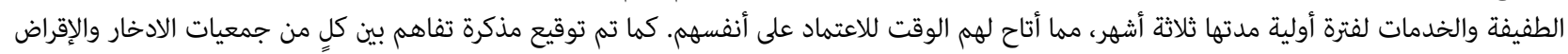

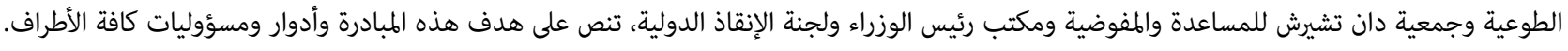




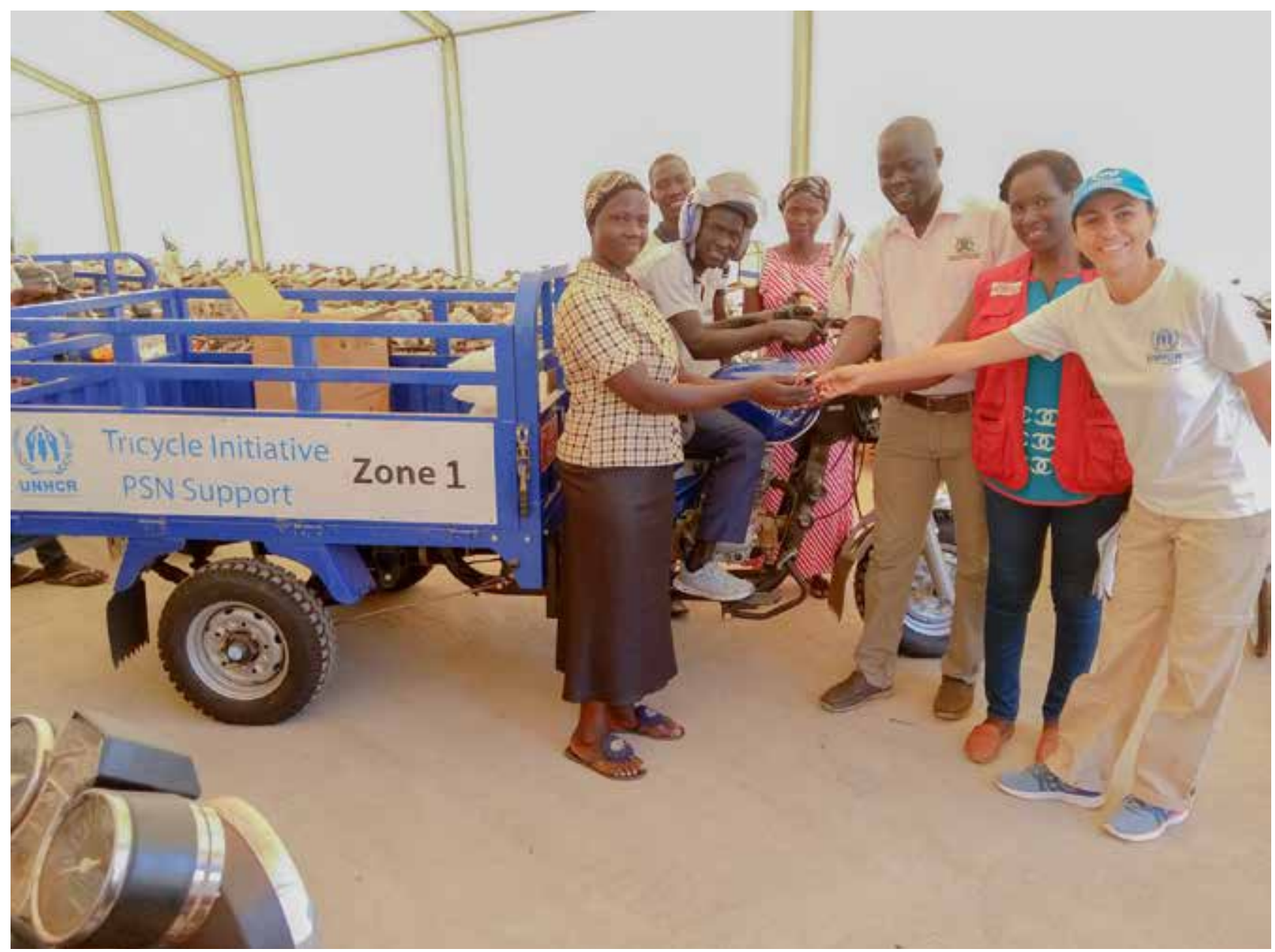

تم تسليم 20 دراجة ثلاثية العجلات للمجموعات في مناطق مختلفة من مستوطنة بيديبيدي. وهم يستخدمونها بشكلٍ جيد، ويدعمون الأفراد المعرضين للخطر

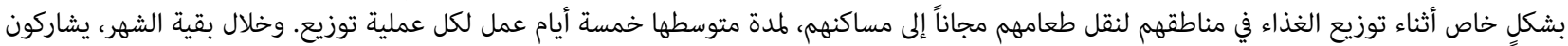

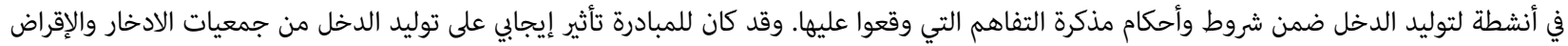

الطوعية.

النتائج

يلخص الاقتباس التالي من عضو إحدى جمعيات الادخار والإقراض الطوعية النتائج التي حصلت عليها المبادرة حتى الآن: "عندما بدأنا باعتهاد الدراجات ثلاثية

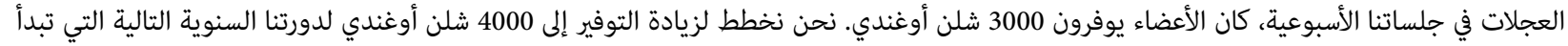

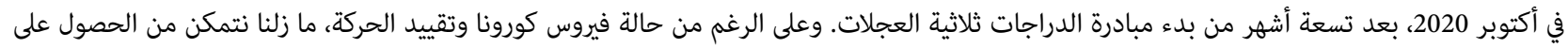

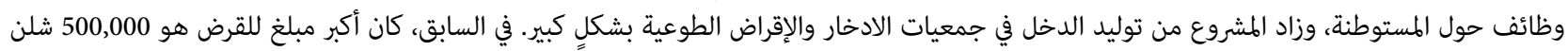
أوغندي، أما الآن فيمكننا منح قروض تصل وراد المشوع من توليد 1,000,000 شلن. وسيساعد ذلك الأعضاء على التفكير في مشاريع أكبر وزيادة إمكانياتهم بشكلٍ كبير.

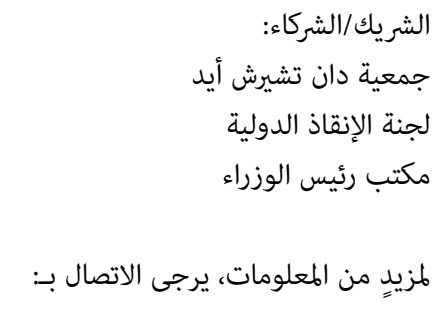

الهام البغدادي: baghdad@unhcr.org

فنسنت بوكينيا: bukenyav@unhcr.org الهغي: 


\section{دراسة حالة من جنوب السودان: شبكة حماية للأشخاص المشردين داخلياً مرتكزة على المجتمع المحلي}

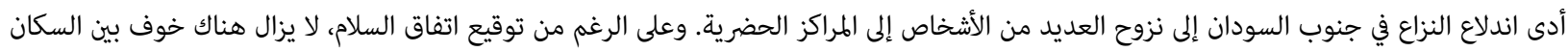

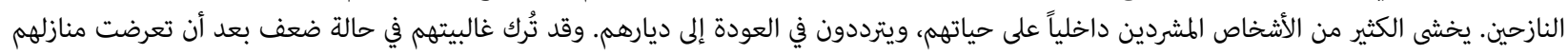
للتخريب وتعطلت سبل عيشهم نتيجة النزاع المسلح.

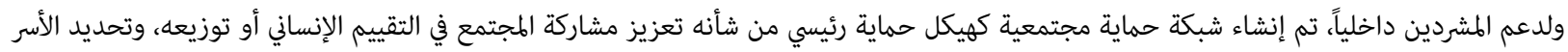

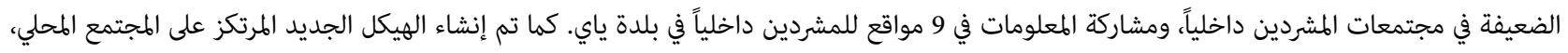

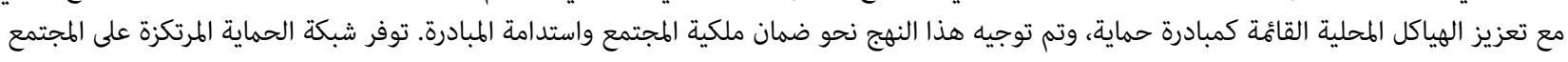

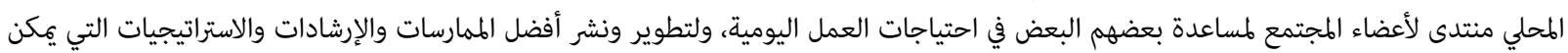

للأعضاء استخدامها.

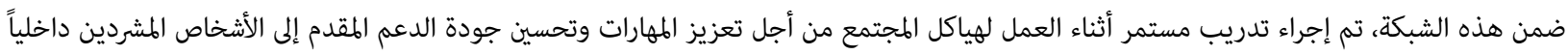

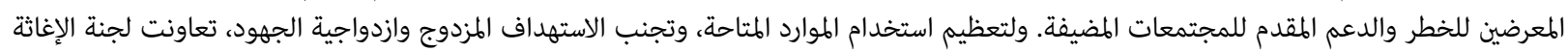

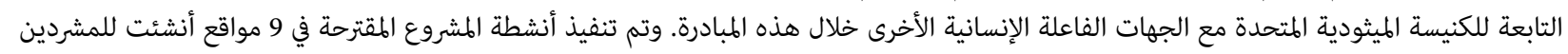

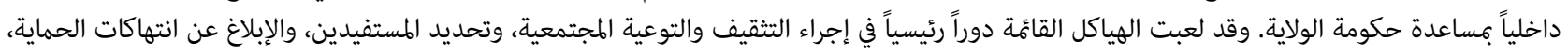

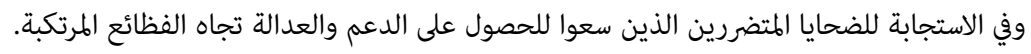

أدى إنشاء وعمل الشبكة المرتكزة على المجتمع المحلي إلى ما يلي:

o

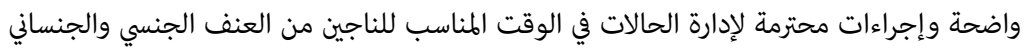
o o

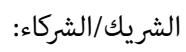

اللجنة الميثودية المتحدة للإغاثة بعثة تخفيف المعاناة في جنوب السودان

لززيدٍ من المعلومات، يرجى الاتصال بـ:

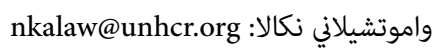




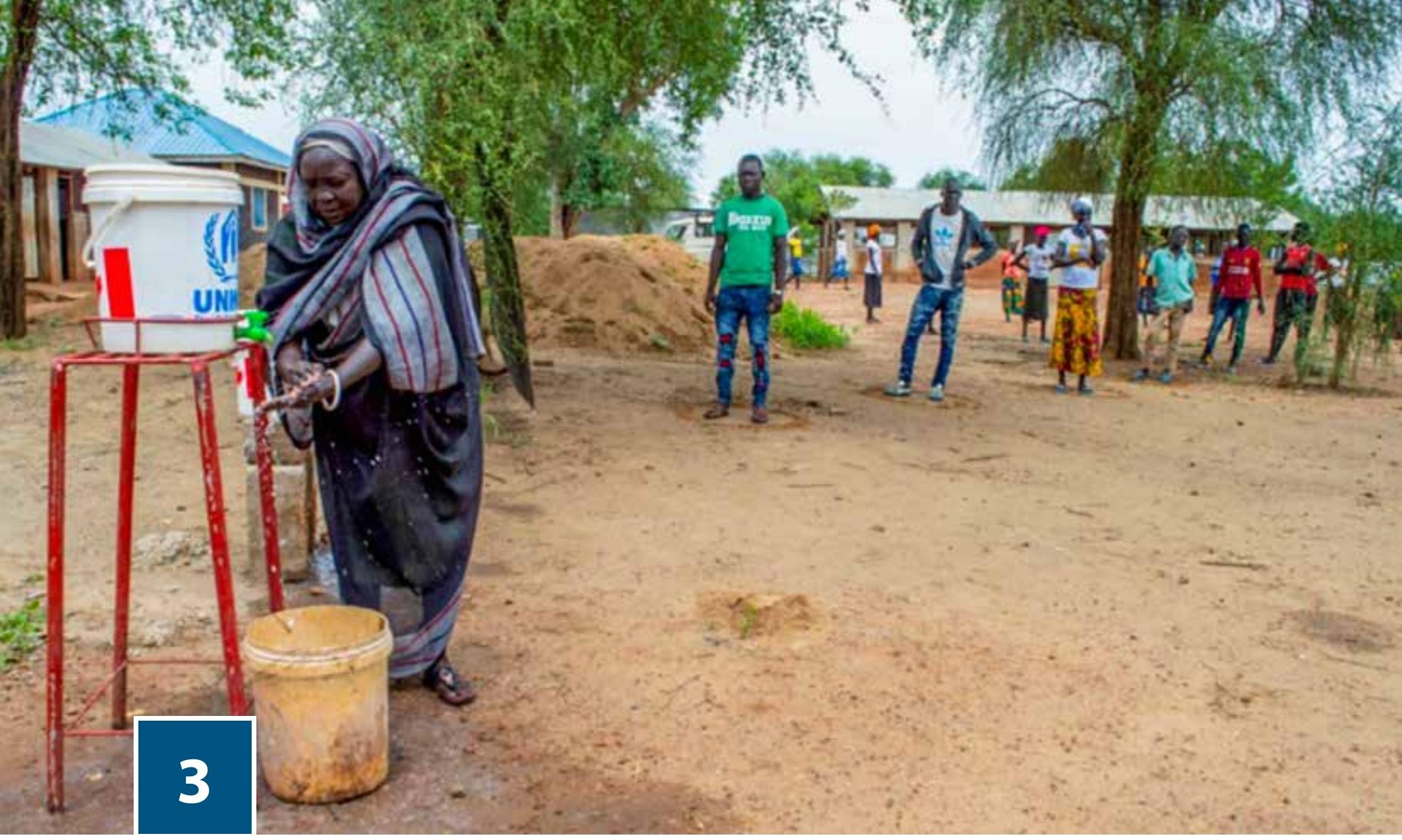

\section{المساواة بين الجنسين}

ممارسة واعدة من إثيوبيا: متطوعو الوصول إلى اللاجئين في أديس أبابا

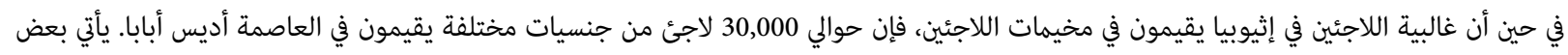

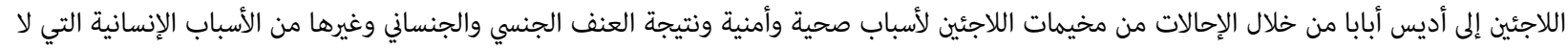

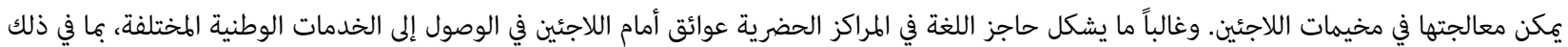

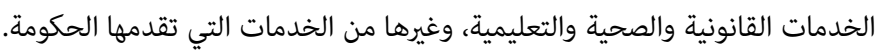

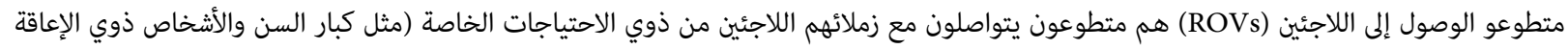

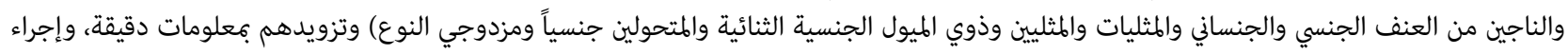

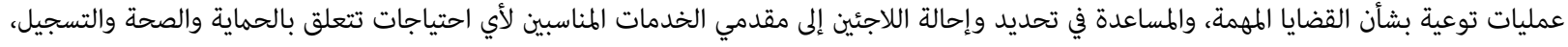

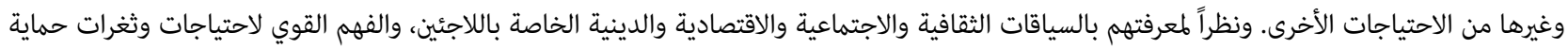

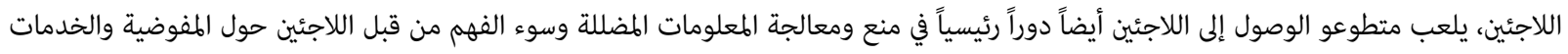
الشريكة.

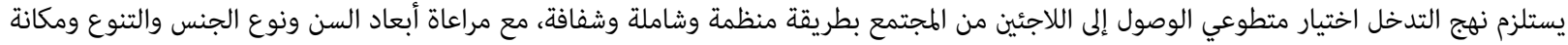

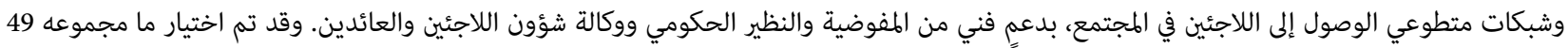

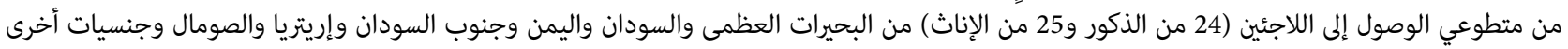
تعيش في أديس أبابا.

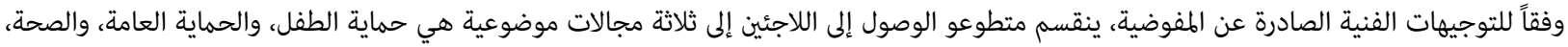

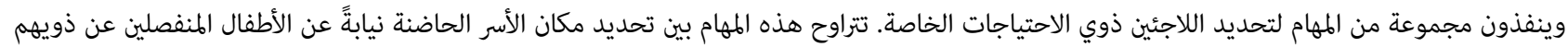

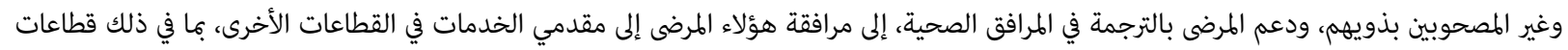
الشرطة والقطاع القانوني، حسب الحاجة. 


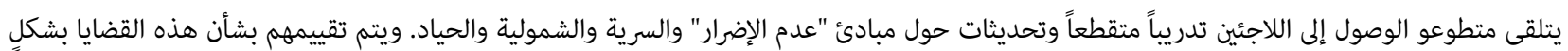

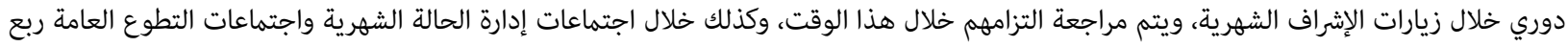

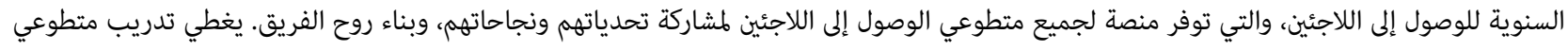

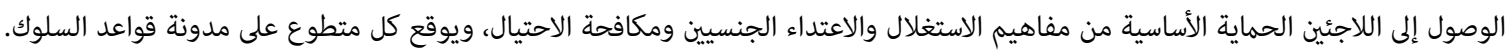

يتم إعطاء متطوعي الوصول إلى اللاجئين مهمات لتحديد أربع حالات شهرياً تتكون من أشخاص ذوي احتياجات خاصة تتطلب اهتمام المفوضية أو الشريك المنفذ.

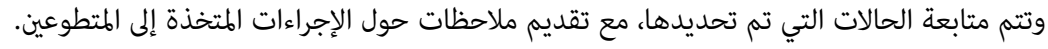

النتائج

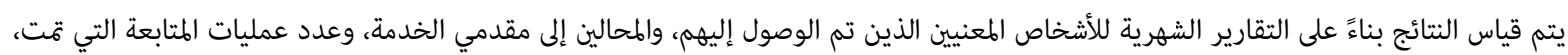

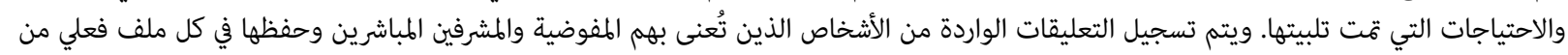

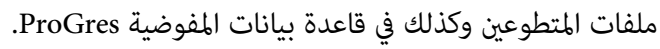

$$
\begin{aligned}
& \text { الشريك/الشركاء: } \\
& \text { وكالة شؤون اللاجئين والعائدين الثناء } \\
& \text { لجنة التنمية والمساعدة بين الكنائس } \\
& \text { منظمة Jesuit Refugee Service } \\
& \text { لمزيدٍ من المعلومات، يرجى الاتصال بـ: } \\
& \text { نونو علي: aliyi@unhcr.org }
\end{aligned}
$$

دراسة حالة من كينيا: المساواة بين الجنسين في توفير المياه وخدمات الصرف الصحي والنظافة الصحية الصحية

يتم تنظيم خدمات المياه وخدمات الصرف الصحي والنظافة الصحية الصحية في مخيم كاكوما للاجئين ومستوطنة كالوبيي خصيصاً لتقديها إلى جميع الأشخاص

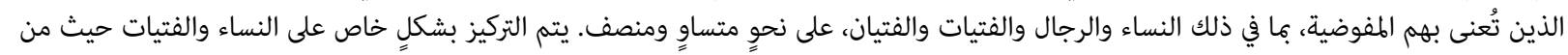

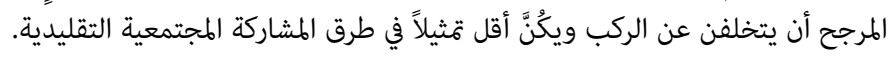

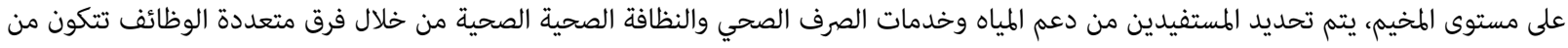
مفوضية الأمم المتحدة لشؤون اللاجئين، وأمانة شؤون اللاجئين، والشركاء المنفذين للصحة، ومجموعة من الشركاء الآخرين. ويتم إعطاء الأولوية للأسر التي تعولها

على مستوى الأحياء، يتم تدريب لجان المياه وخدمات الصرف الصحي والنظافة الصحية الصحية (الهياكل التمثيلية الخاصة بالمياه وخدمات الصرف الصحي الصحي

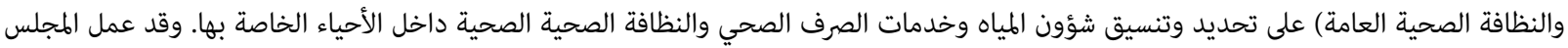

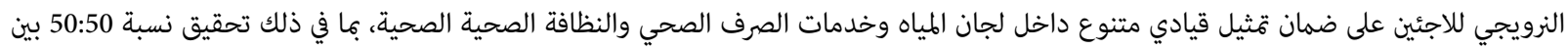

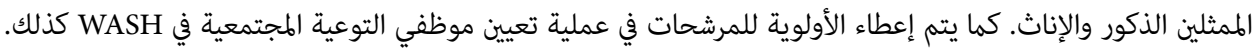

$$
\text { الشريك/الشركاء: }
$$

للمزيد من المعلومات الرجاء الاتصال: معار ماراء

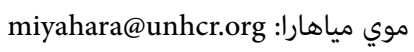
أوسكار نابيسوا: nوي ماها : nabiswa@unhcr.org جurtonj@unhcr.org جاغاتشا بيرتون نايسوا: 


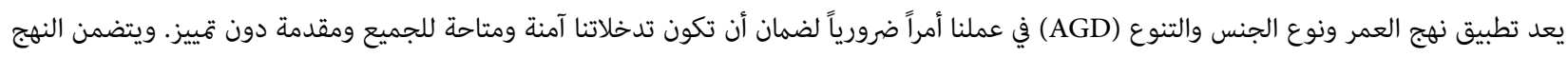

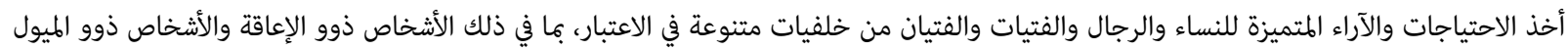
الجنسية والهويات الجنسية المتنوعة والأقليات العرقية والدينية واللغوية أو مجموعات السكات النيان الأصليين، في التقييم والتخطيط وعمليات التنفيذ والمراقبة.

ومن أجل التأكد من أن جميع الزملاء في المفوضية والقطاعات يطبقون نهج مراعاة السن ونوع الجنس والتنوع في عملهم، طورت فرق الحماية المجتمعية (CBP)

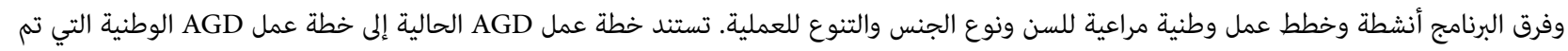

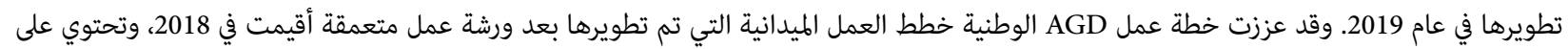

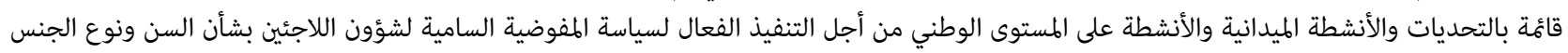
والتنوع. وتم تطوير خطة العمل هذه بشكلٍ أكبر من خلال المشاورات مع قادة القطان القطاعات في كمبالا وموظفي الحماية الميدانيين والشركاء.

استندت خطة عمل AGD إلى خطة أنشطة AGD، لكنها تشبه جدول المؤشرات، حيث تقدم مؤشرات على مستوى النتائج والمخرجات، وخطوط الأساس

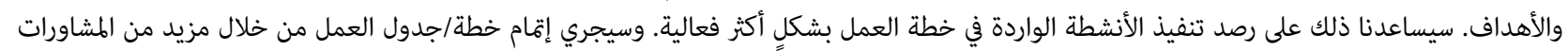

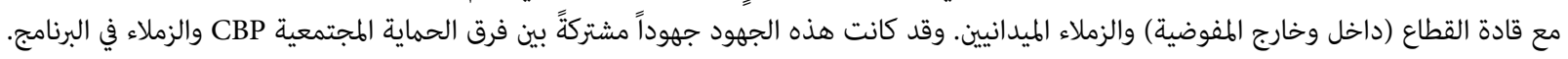

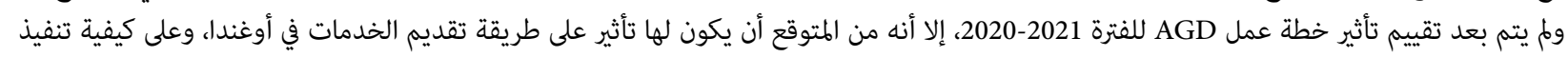
سياسة المفوضية الخاصة بالعمالة والتنوع العمراني. إن التطبيق الفعال لنهج النهات للجميع ويمكّن الفئات المهمشة والمحرومة من الحصول على الحقوق.

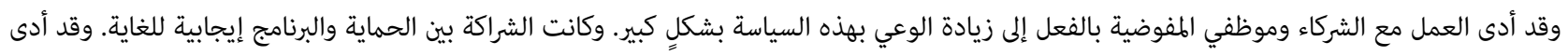
اشتراك كبير موظفي البرامج إلى جعل هذه المبادرة مبادرة من المفوضية، لا مبادرة حماية.

الشريك/الشركاء: متعددون

لمزيدٍ من المعلومات، يرجى الاتصال بـ: سام مصلاي: mosallai@unhcr.org يوكو إيواسا: iwasa@unhcr.org كلير أسكيو: askew@unhcr.org

دراسة حالة من أوغندا: خطط عمل مراعية للسن ونوع الجنس والتنوع للشركاء المنفذين

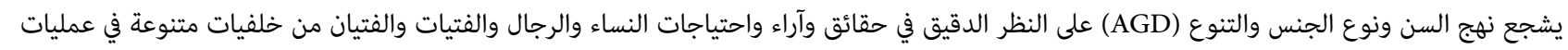

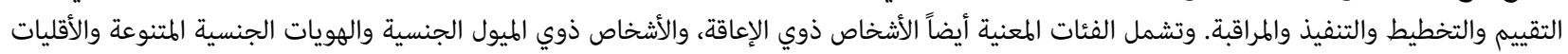
العرقية والدينية واللغوية أو مجموعات السكان الأصليين.

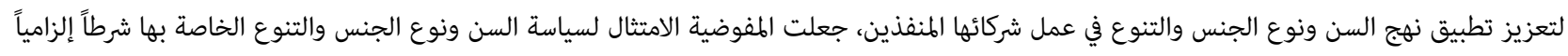

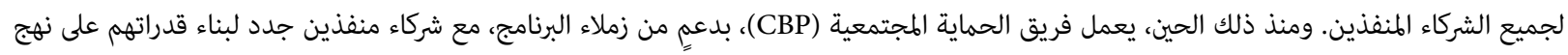

.AGD

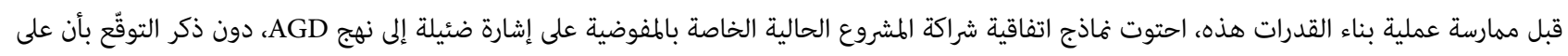
الشركاء المنفذين الالتزام بسياسة AGD الخاصة بالمفوضية. وبالتالي، م يكن الشركاء علثماء على علمٍ بهذه السياسة.

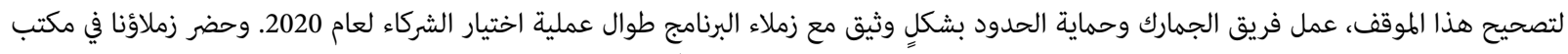

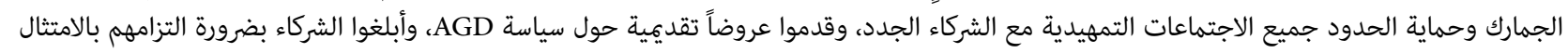

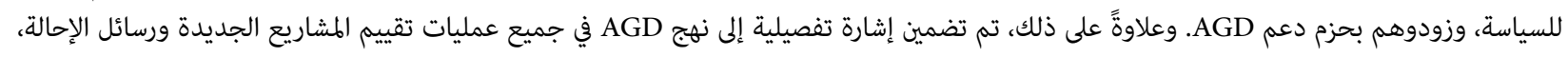

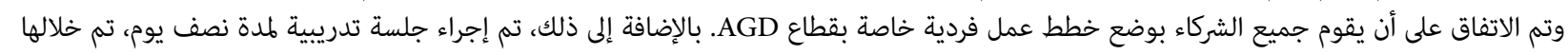

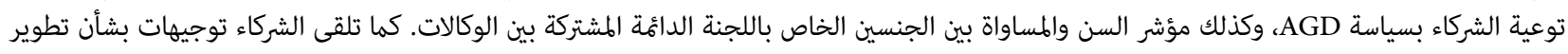

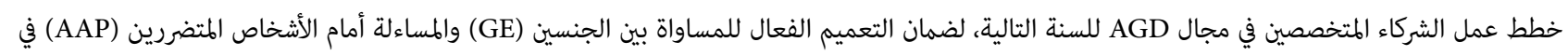


جميع أنشطة الشركاء. تحتوي خطط العمل هذه على الأنشطة والمؤشرات والمنسقين والمواعيد النهائية. وسيجري رصد التقدم المحرز في تنفيذ خطط العمل خلال استعراضات أداء منتصف العام ونهايته.

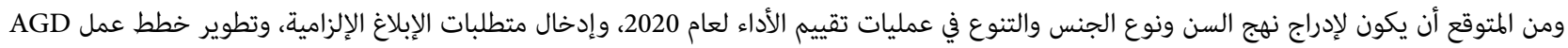

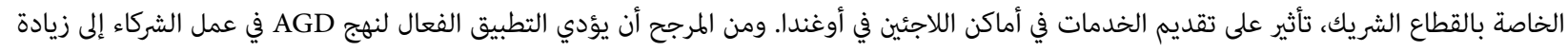

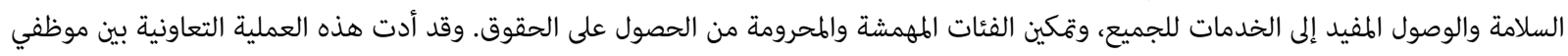

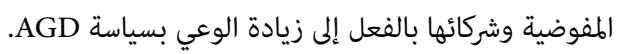

الشريك/الشركاء: متنوعون

لمزيدٍ من المعلومات، يرجى الاتصال بـ:

سام مصلاي: mosallai@unhcr.org يوكو إيواسا: iwasa@unhcr.org 


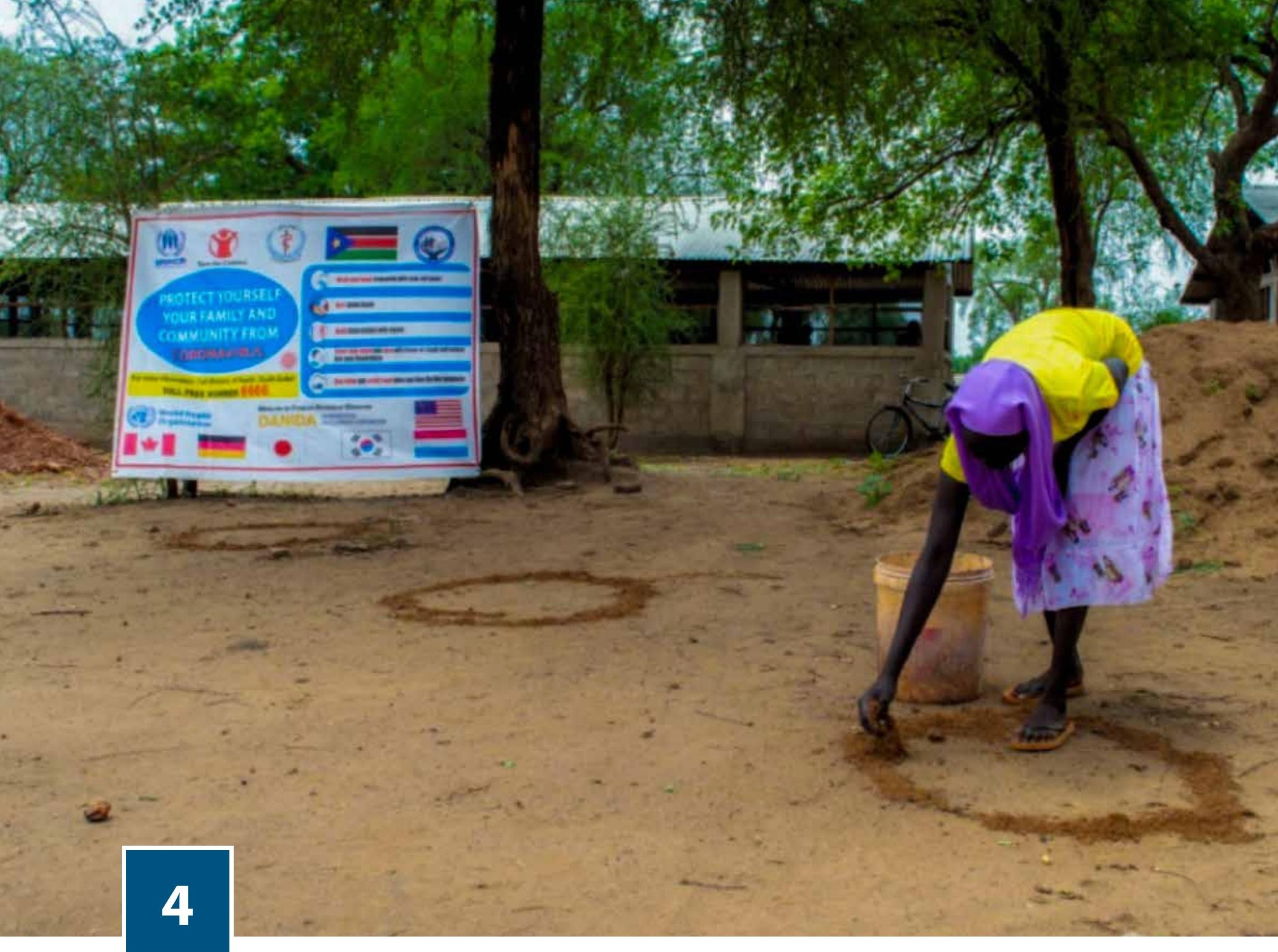

\section{العنف الجنسي والجنساني/التخفيف من المخاطر/الاستجابة}

ممارسة ناشئة من إثيوبيا: مطحنة مملوكة للمجتمع تديرها جمعية نسائية

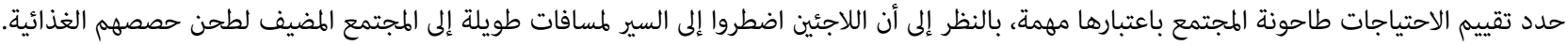

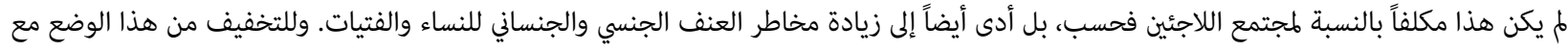

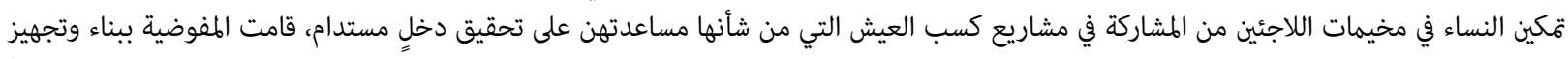

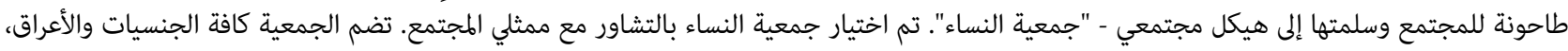
وتعمل في وئام وتعزز التعايش السلمي.

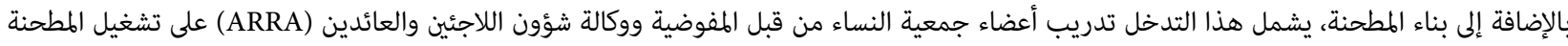

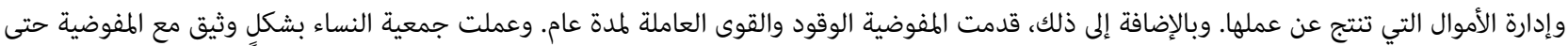

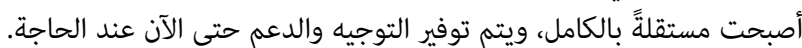

النتائج

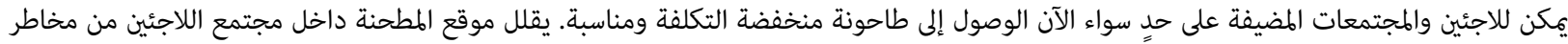

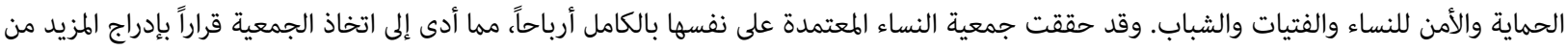

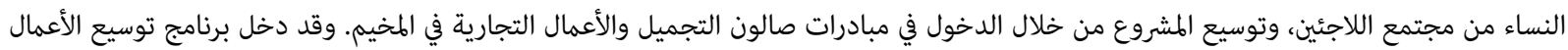

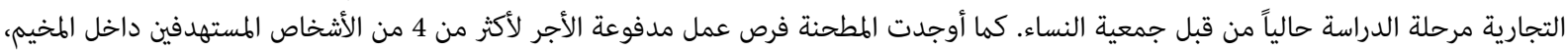


وحسّنت النساء المشاركات في المشروع سبل عيشهن وأصبحن يساهمن مالياً في احتياجات مساكنهن وأسرهن. وحظي المشروع باهتمام المزيد من النساء اللواتي

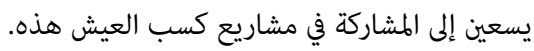
الشريك/الشركاء: وكالة شؤون اللاجئين والعائدين

لمزيدٍ من المعلومات، يرجى الاتصال بـ: rajbansh@unhcr.org أليسون راجبانشي من المعات

دراسة حالة من كينيا: استراتيجيات المياه وخدمات الصرف الصحي والنظافة الصحية الصحية المراعية للنوع الاجتماعي كإجراء للوقاية من العنف الجنسي والجنساني

لردع مرتكبي العنف الجنسي والجنساني في مخيمات اللاجئين، يتم إنشاء نقاط المياه عمداً في أماكن مفتوحة وفي متناول أفراد المجتمع. وعلاوةً على ذلك، يتم

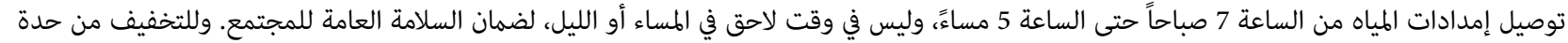

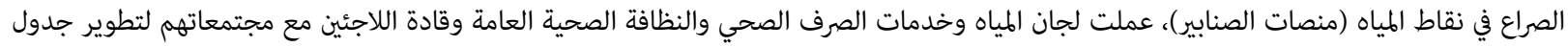
مجتمعي لجلب المياه يتم تنظيمه في فترات الصباح والظهيرة والطساء.

وبالإضافة إلى ذلك، تم تصميم المراحيض المشتركة للاجئين الوافدين الجدد مع مصاريع داخلية لحماية الخصوصية والكرامة. كما تم توعية أفراد المجتمع بضرورة مرافقة القصَّر والنساء إلى المراحيض ليلاً.

$$
\begin{aligned}
& \text { الشريك/الشركاء: - الشجري } \\
& \text { المجلس النرويجي للاجئين } \\
& \text { لزيدٍ من المعلومات، يرجى الاتصال بـ: }
\end{aligned}
$$

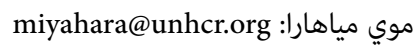

$$
\begin{aligned}
& \text { أوسكار نابيسوا: موي ماهارا: nabiswa@unhcr.org } \\
& \text { جون ناغاتشا بيرتون: burtonj@unhcr.org }
\end{aligned}
$$

ممارسة ناشئة من كينيا: منازل آمنة يديرها المجتمع

لدى المفوضية وشركاؤها مجموعة من المتطوعين المدربين من مجتمع اللاجئين فتحوا منازلهم لتوفير مساحات آمنة للناجين من العنف الجنسي والجنساني الذين

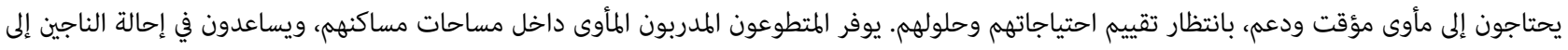

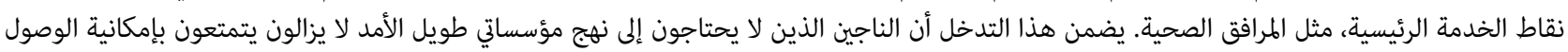

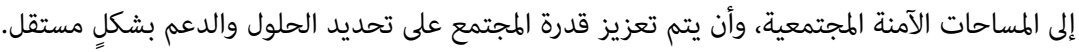

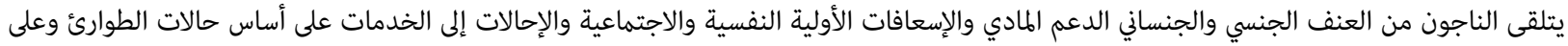

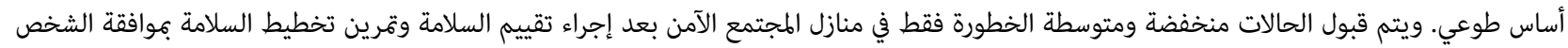

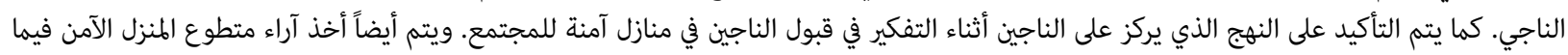

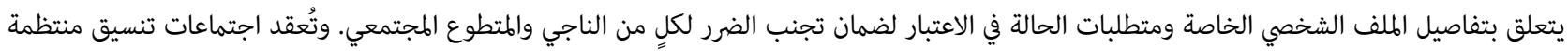
بين الوكالات ومؤتمرات حالة مخصصة لتحديد خطط الحالة وتتبع التقدم خلال عملية القبول.

النتائج

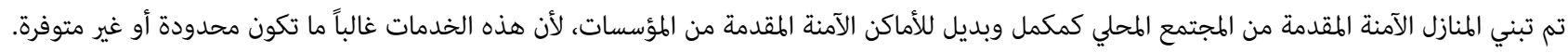

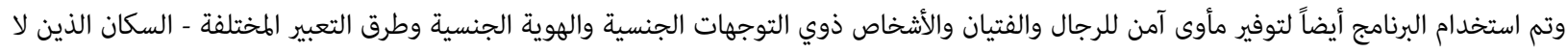

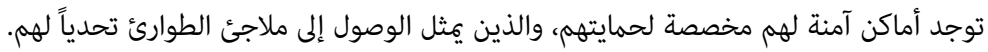

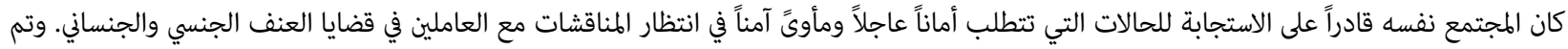

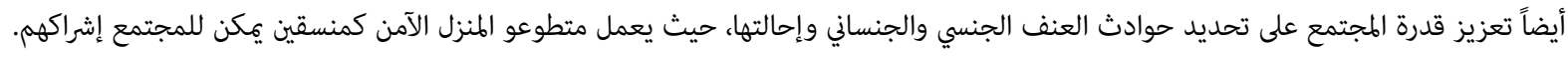


ممارسة ناشئة من كينيا: مقدمو الرعاية المجتمعية - ملاجئ حضرية آمنة مؤقتة للناجين من العنف الجنسي والجنساني عملت المفوضية السامية للأمم المتحدة لشؤون اللاجئين والجمعية العبرية لساعدة المهاجرين (HIAS) مع الهياكل المجتمعية في مناطق اللاجئين الحضرية لرعاية

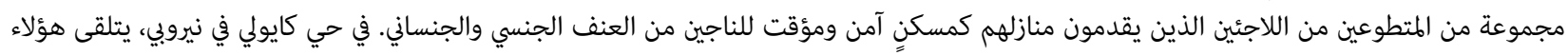

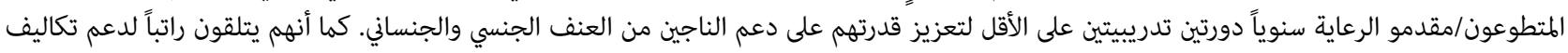

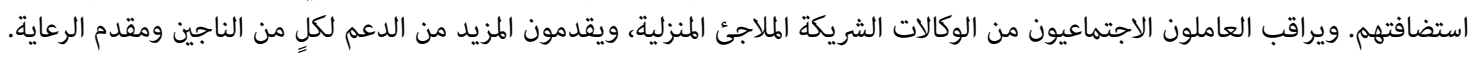

تتم توعية لجان المجتمع بمبادرة مقدم الرعاية المجتمعية، وتعمل هذه اللجان كمنصة لتحديد وفحص مقدمي الرعاية المجتمعية قبل تسجيلهم في البرنامج. وفي حالة عدم توفر مقدم رعاية مجتمعي لاستقبال أحد الناجين، تستخدم الهياكل المجتمعية الأخرى (مثل الكنائس( كملاذٍ آمنٍ للناجين.

هذه المهارسة هي حل مجتمعي يؤكد حقيقة أن المجتمعات يمكن أن تدعم الناجين من العنف الجنسي والجنساني خارج مسار الإحالة التقليدي للشركاء، والذي

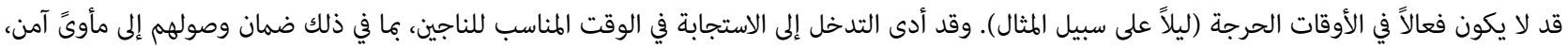
وإلى المرافق الصحية ومراكز الشرطة، فضلاً عن الاستشارة الفورية.

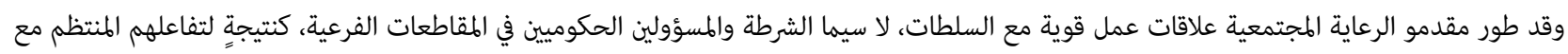

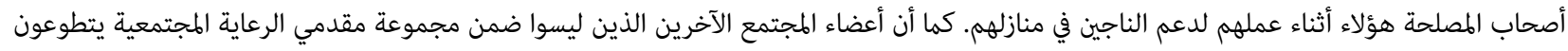

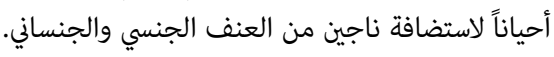

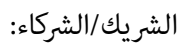

$$
\begin{aligned}
& \text { جمعية مساعدة المهاجرين العبرية } \\
& \text { أمانة شؤون اللاجئين } \\
& \text { مجموعة عمل العنف القائم على النوع الاجتماعي }
\end{aligned}
$$

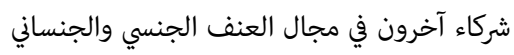

$$
\begin{aligned}
& \text { لمزيدٍ من المعلومات، يرجى الاتصال بـ: } \\
& \text { جاكسون كاروغو: karugu@unhcr.org } \\
& \text { دانيال موريثي: mureithi@unhcr.org }
\end{aligned}
$$

ممارسة ناشئة من رواندا: مبادرة حمل المراهقات والتسرب من المدرسة

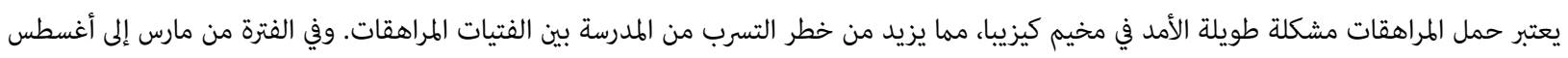

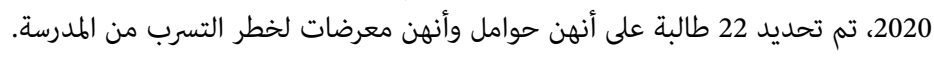

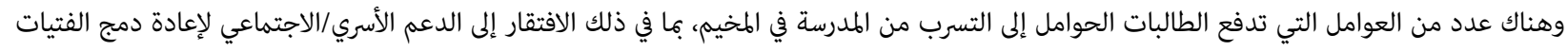

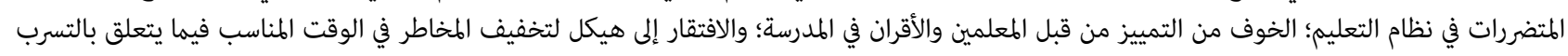

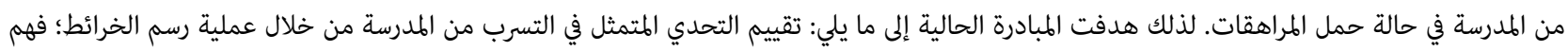

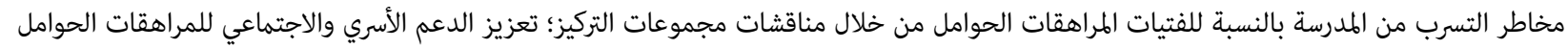

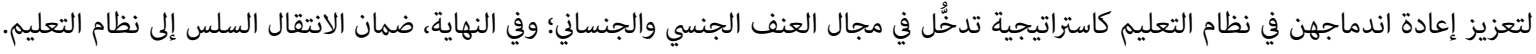
تألفت المهارسة من المكونات التالية:

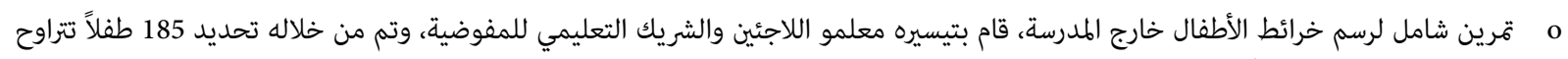

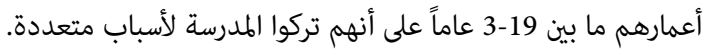

o 
الفتيات أنهن شعرن بأن حياتهن انتهت بَجرد أن اكتشفن أنهن حاملات، وشعر آباؤهن بالخجل من السماح لهن بالعودة إلى المدرسة، وكانت الفتيات قلقات من احتمال تعرضهن للتمييز في المدرسة. o

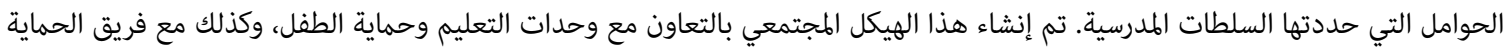
المرتكزة على المجتمع المحلي في كارونجي. هو د دورات تدريبية وشيكة للمعلمين وممثلي إدارة السلوك الاجتماعي (بقيادة الشريك في المجال المال الصحي والشريك في مجال العنف الجنسي والجنساني) لتعزيز المعرفة والقدرة على الاتصال بهدف التخفيف من ومنئ المخاطر.

النتائج بجهدٍ متواصل في عام بدء التدخل، عادت 15 فتاة مراهقة إلى المدرسة، ممن كنّ قد تسرّبن من المدرسة بسبب الحمل، وكان أداء بعضهن ممتازاً في الامتحانات الوطنية.

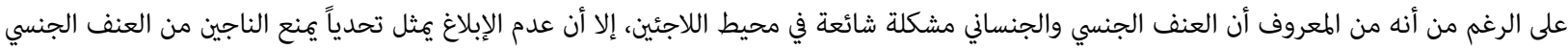

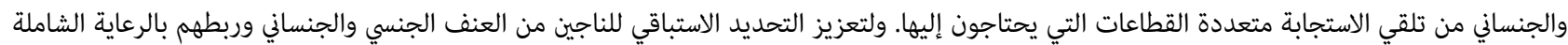

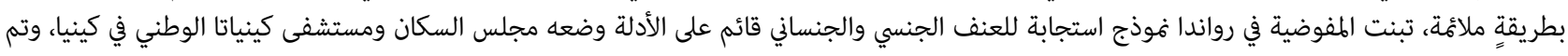
تقييمه في محيط اللاجئين في أوغندا بالتعاون مع المفوضية.

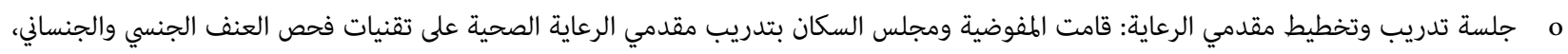

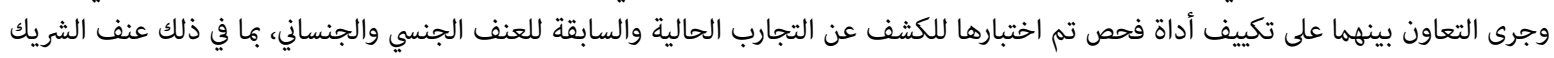

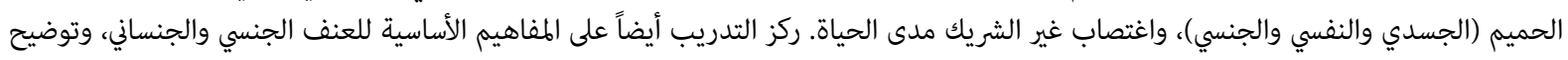

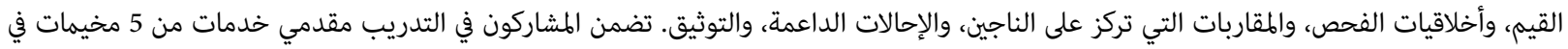

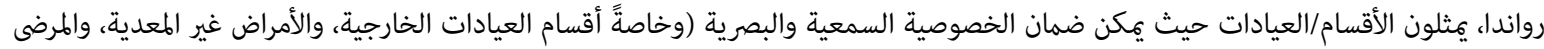

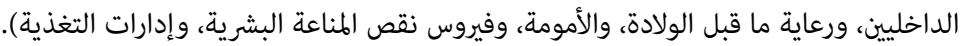
o

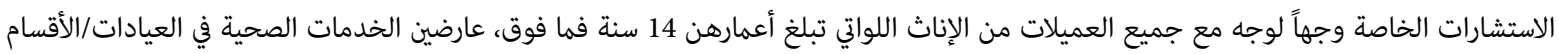

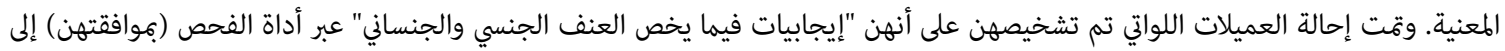

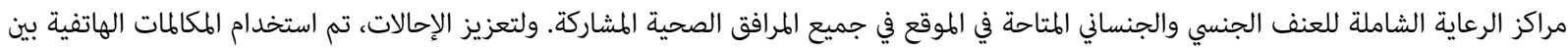

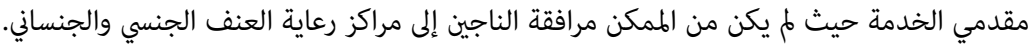

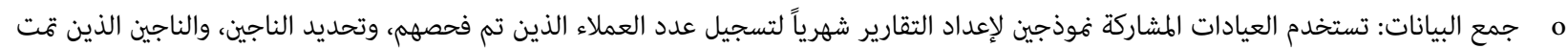

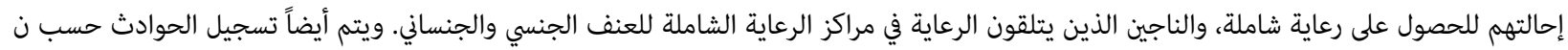

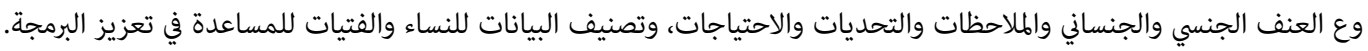

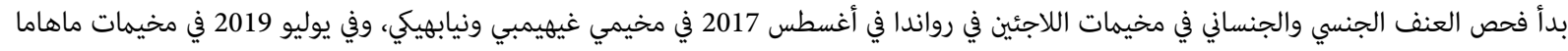

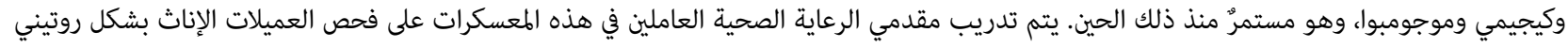
لاكتشاف أكبر عدد ممكن من الناجين في أقرب وقتٍ ممكن.

النتائج

o في عام 2017، شهدت المرافق الصحية المشاركة في مخيمَين في رواندا زيادة بنسبة 300\% في نسبة الناجين الذين تم تحديدهم وربطهم بالرعاية الشاملة

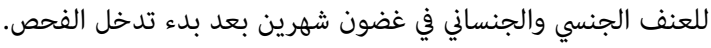

o 


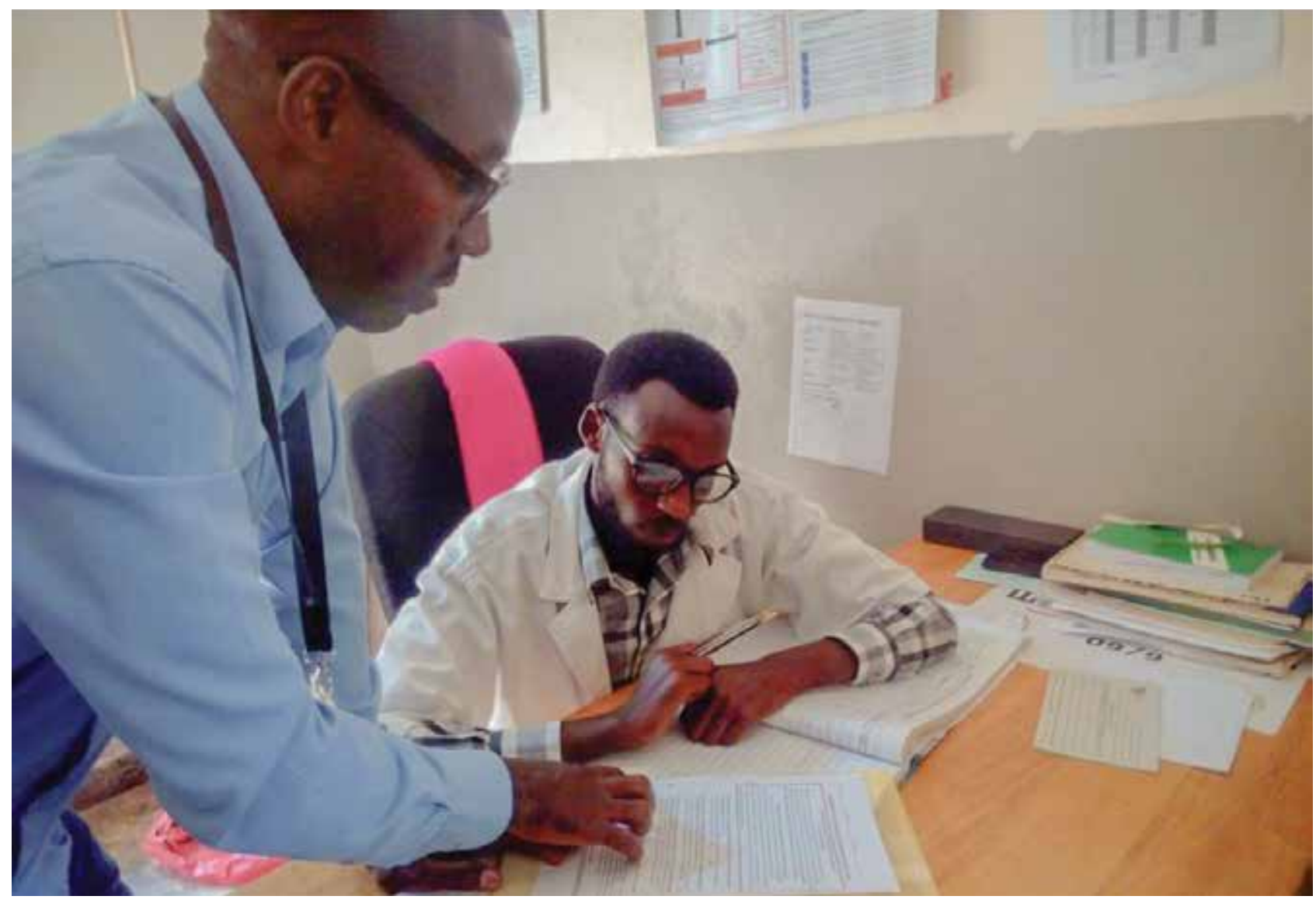

الفحص، وتمت إحالة 276 إلى خدمات الاستجابة للعنف الجنسي والجنساني.

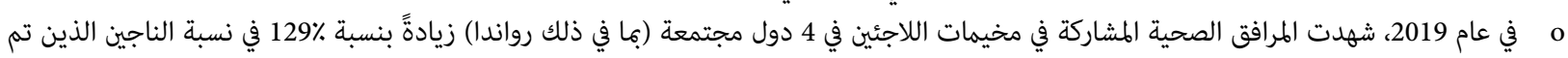

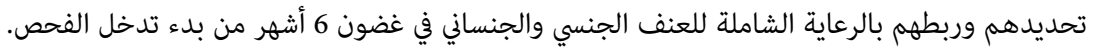
o

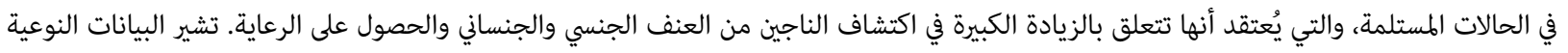

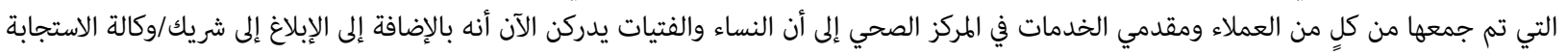

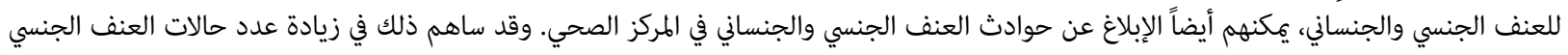
والجنساني المكتشفة.

o

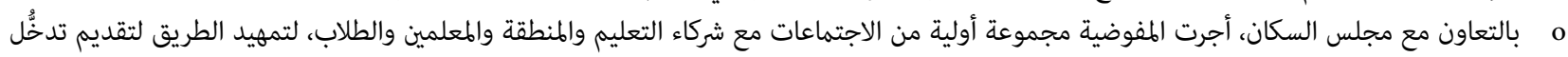

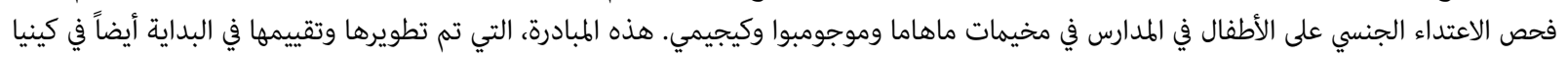

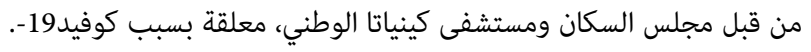

الشريك/الشركاء: منظمة العمل الإنساني في أفريقيا

منظمة منظمة اعمل

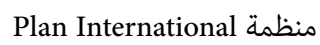
مجلس السكان

المنظمة الدولية لإنقاذ الطفولة المجان

لمزيدٍ من المعلومات، يرجى الاتصال بـ: زهرة ميجراني: mirghani@unhcr.org 


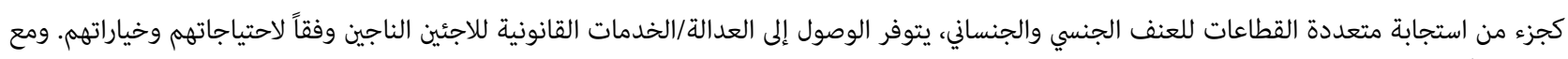

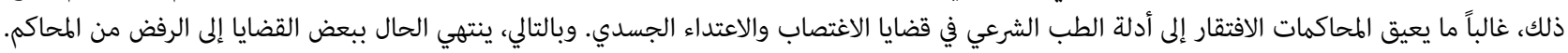

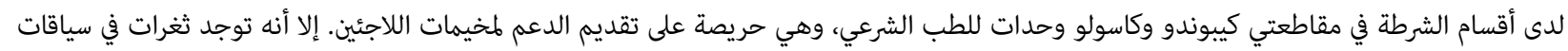

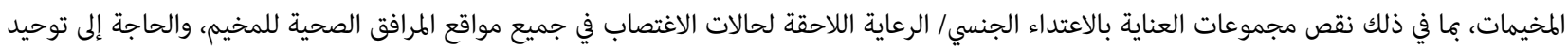

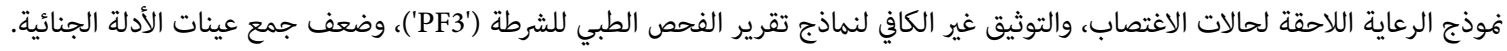

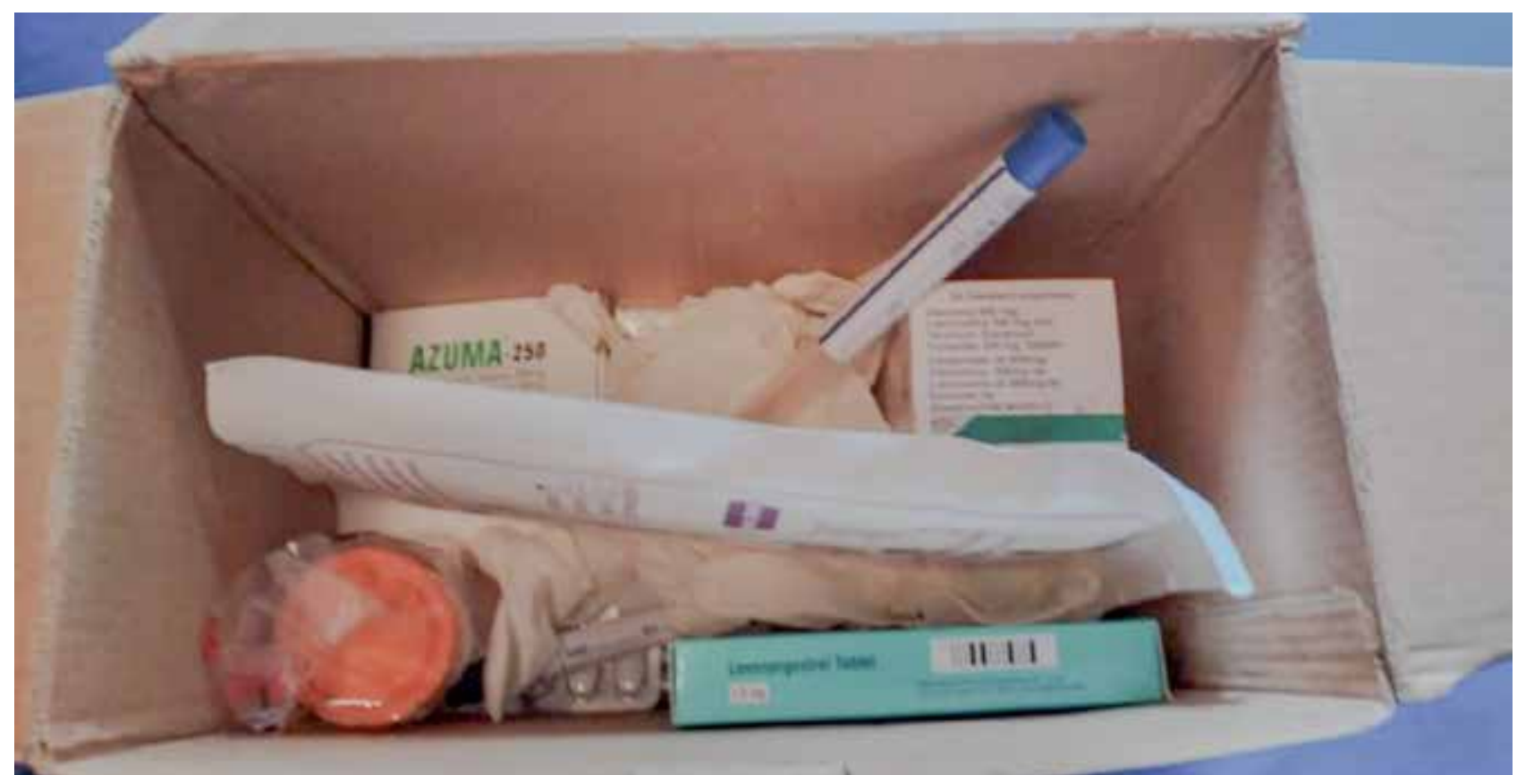

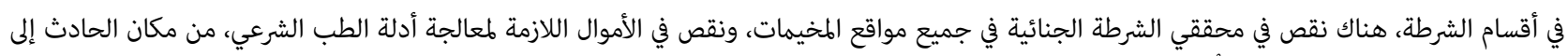

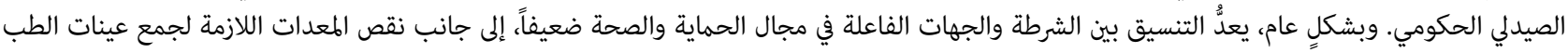

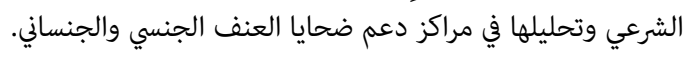

واستجابةً لهذه الحقائق، يهدف التدخل الحالي إلى تعزيز إدارة سلسلة جمع الأدلة الجنائية من خلال بناء قدرة مقدمي الرعاية الصحية اللاحقة للاغتصاب

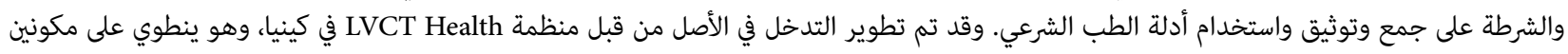

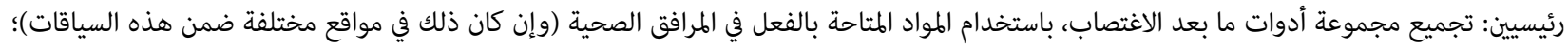

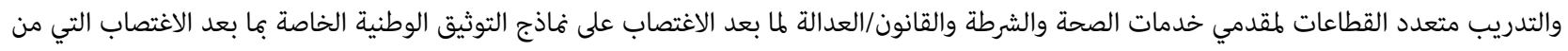

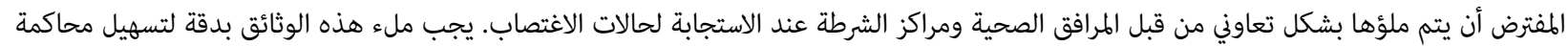
قضايا الاغتصاب في المحكمة.

في سياقات اللاجئين التنزانيين، يتم تفعيل هذا التدخل على النحو التالي: o o o o

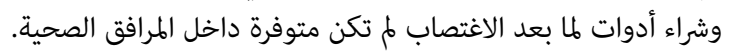
o

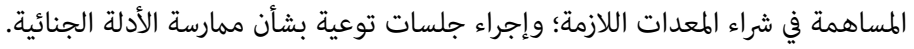

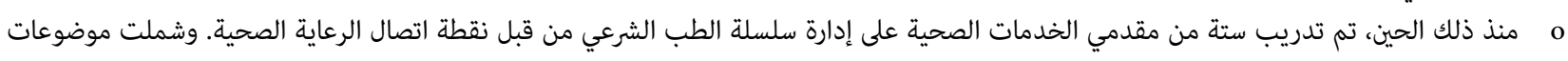

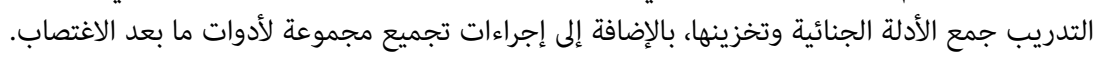

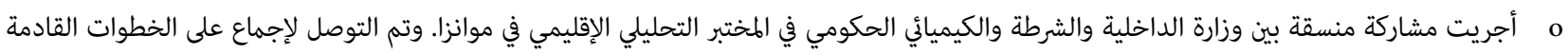

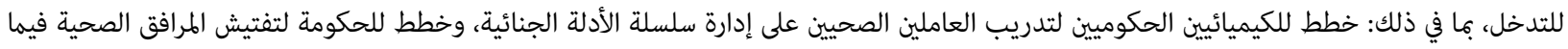
يخص استعدادها لإدارة سلسلة الطب الشرعي (أدوات الجمع، التخزين، وغير ذلك). 


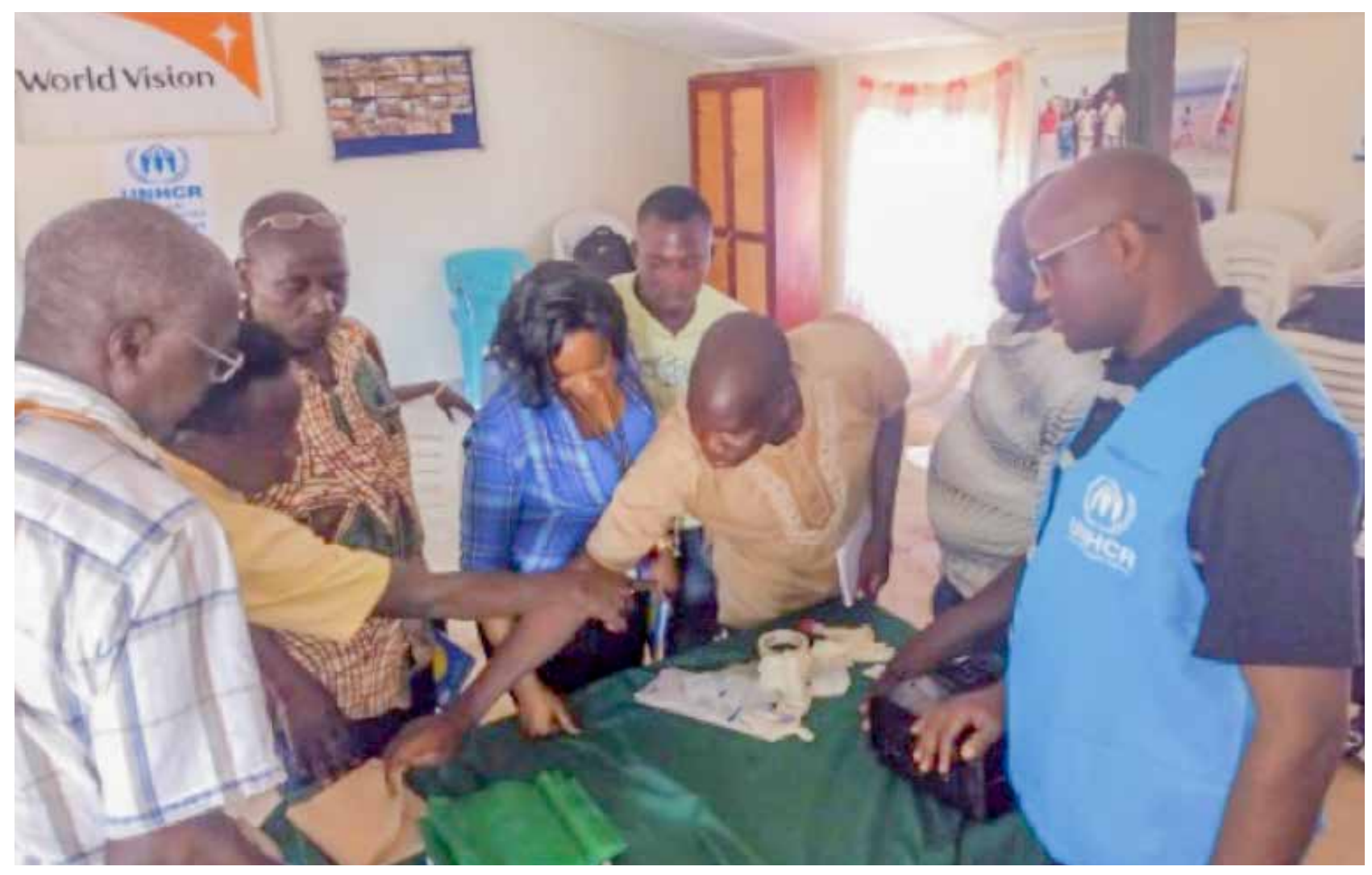

منذ بدء التدخل، كان هناك تحسن في ملء استمارات PF3 من قبل الشرطة، وعلى الرغم من ذلك يوصى بإجراء دورات تدريبية دورية لتجديد المعلومات بسبب التبات

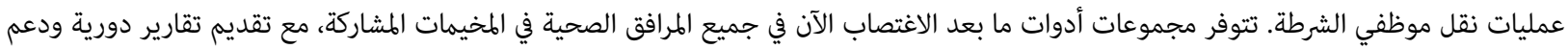

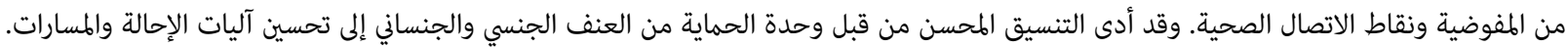

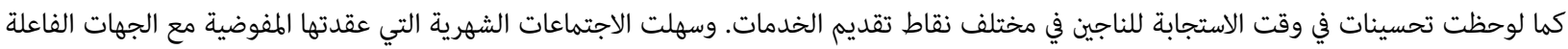

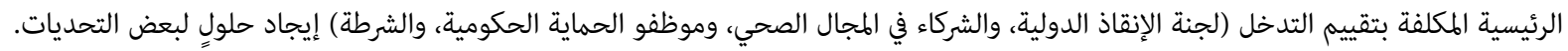

$$
\text { الشريك/الشركاء: - (الشنة }
$$

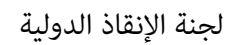

منظمة LVCT Health

منظمة منظمة منظمة أطباء بلا حدود

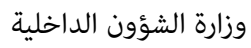

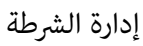

الشريك المنفذ فيما يخص العنف الجنسي والجنساني منظمة الصليب الأحمر التنزاني

لمزيدٍ من المعلومات، يرجى الاتصال بـ:

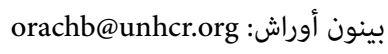

رحيمة كاتيغا: رينون أوراش الدكتور يوئيل ماشيمبا: رحيمة كاتيا: مياتا توبي جونسون: johnsonm@unhcr.org الدكورئ مانيما مايكل غيثو: Michael.Gaitho@lvcthealth.org 


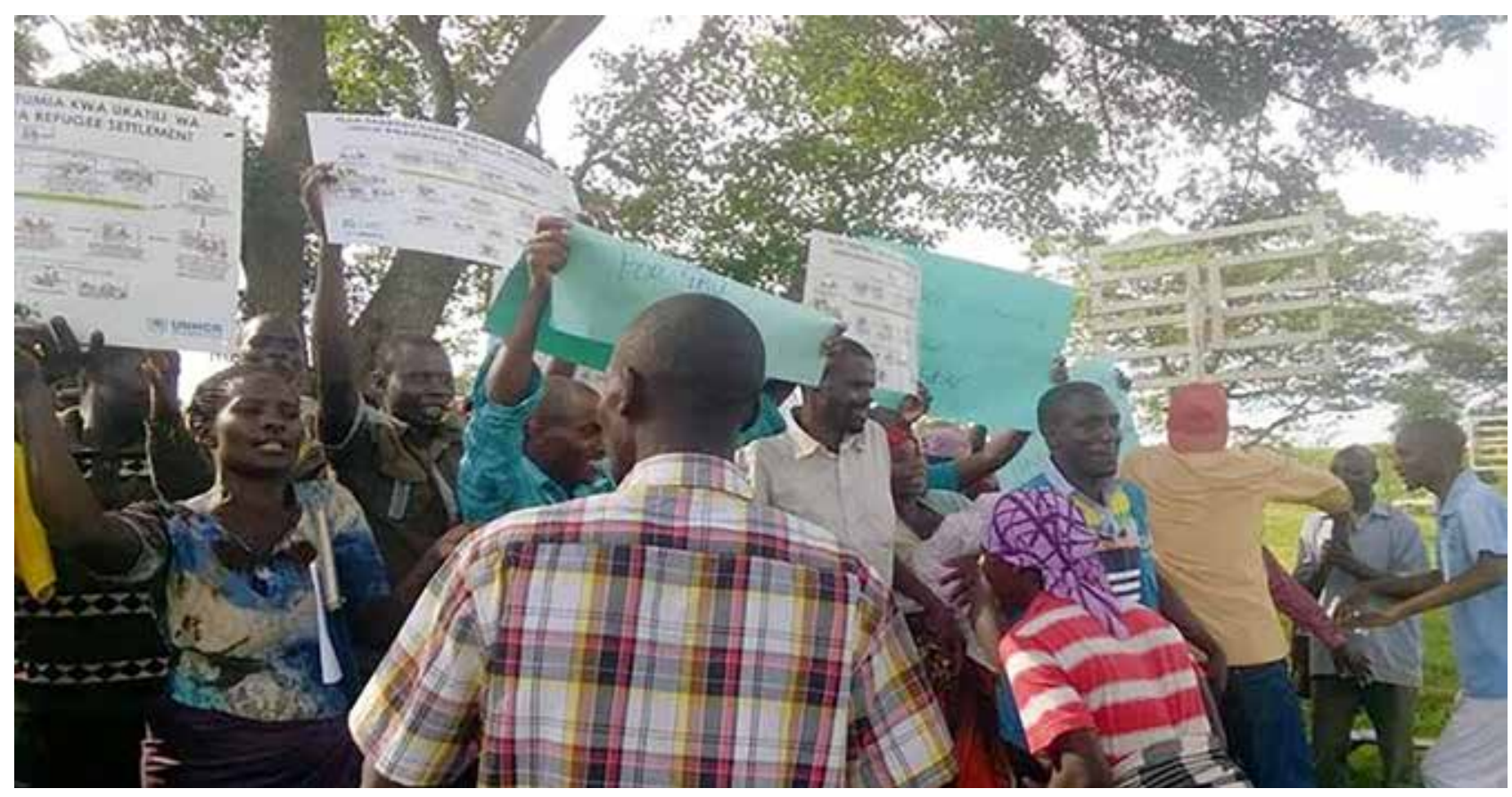

إن "تحالف القرى لعدم التسامح مطلقاً" هو تدخل مجتمعي للوقاية من العنف الجنسي والجنساني تم تطويره للبيئات الريفية في جنوب إفريقيا بواسطة برنامج

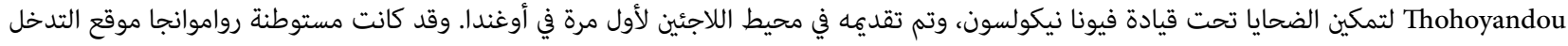

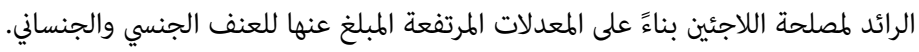

يتضمن التدخل المكونات التالية:

رسم الخرائط والحوارات المجتمعية: لتحديد جميع الهياكل والوكالات التي يمكن استهدافها للمشاركة، بما في ذلك تقديم الخدمات الخاصة بالعنف الجنسي

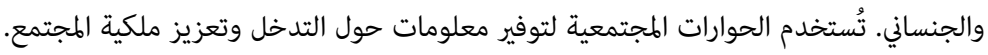

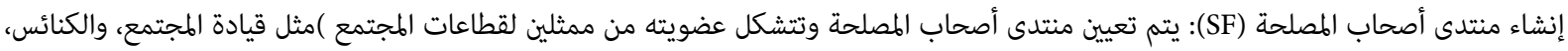

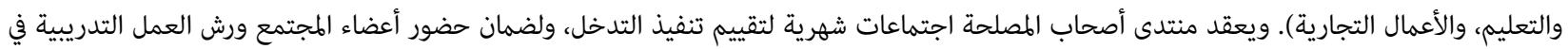
إطار التدخل.

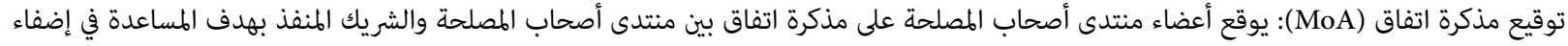

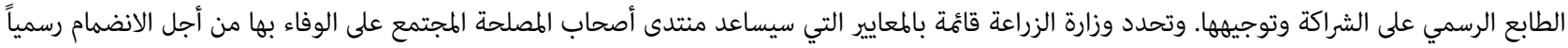

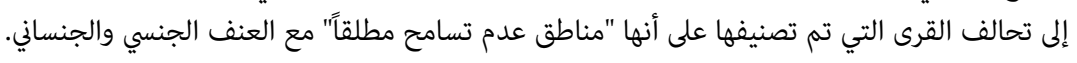

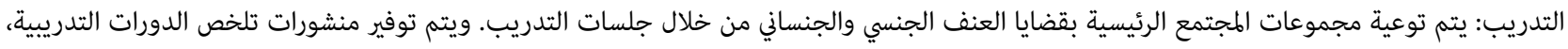

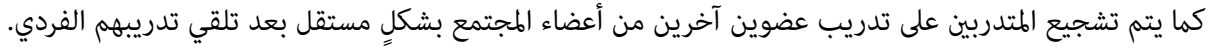

مراسم أخذ التعهدات: بمجرد تحقيق القرية للتوقعات المحددة من قبل وزارة الزراعة في مذكرة الاتفاق، تتلقى القرية رعاية لمراسم عامة، يُدعى خلالها رجال

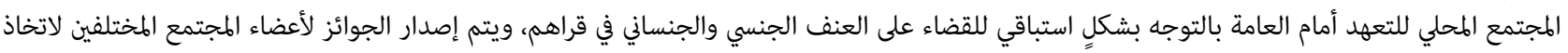
موقف ضد العنف الجنسي والجنساني أو مشاركة شهاداتهم.

تحديد التحالف: تتوج مراسم أخذ التعهدات بإزاحة الستار عن لوحة إعلانية مجتمعية تشير إلى اسم القرية وإعلان حالة "عدم التسامح المطلق" الخاصة بهم

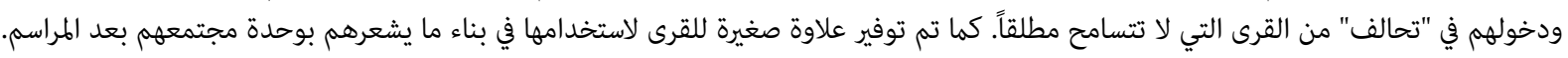

أظهرت نتائج التقييم لهذا التدخل في أوضاع اللاجئين الأوغندية انخفاضاً مهماً من الناحية الإحصائية في حدوث: العنف الجسدي من الشريك الحميم (للرجال

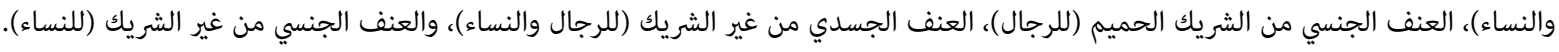

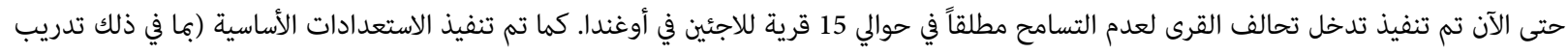


الشركاء المنفذين، وتوعية قادة المجتمع، و/أو إنشاء منتديات أصحاب المصلحة، وما إلى ذلك) لتقديم التدخل في محيط اللاجئين في جيبوتي وإثيوبيا وزامبيا.

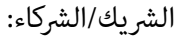

$$
\begin{aligned}
& \text { الاتحاد اللوثري العالمي الشي }
\end{aligned}
$$

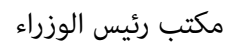

$$
\begin{aligned}
& \text { لزيدٍ من المعلومات، يرجى الاتصال بـ: } \\
& \text { ouma@unhcr.org ميلدريد أومان المعاك، برجيد } \\
& \text { مونيكا روتون: monicah.rwotmon@lutheranworld.org } \\
& \text { فيونا نيكولسون: nicholsonfiona27@gmail.com }
\end{aligned}
$$

دراسة حالة من جنوب السودان: نُهُج في الحماية مرتكزة على المجتمع المحلي (الوقاية من العنف الجنسي والجنساني، وتخفيف المخاطر، وحماية الطفل، ومشاركة الشباب)

يقيم اللاجئون في ولاية أعالي النيل في أربعة مخيمات في مقاطعة مابان، ويعتمدون اعتماداً كبيراً على الوكالات الإنسانية لتوفير الخدمات الأساسية المنقذة للحياة.

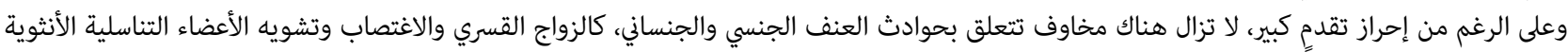

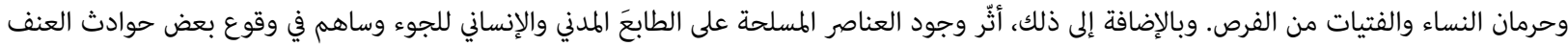

$$
\text { الجنسي والجنساني. }
$$

لذلك تم تطوير تدخل متعدد الأوجه بهدف: ضمان سلامة الناجين من العنف الجنسي والجنساني في مخيمات مابان للاجئين )بما في ذلك، على سبيل المثال لا

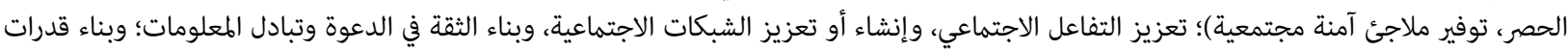

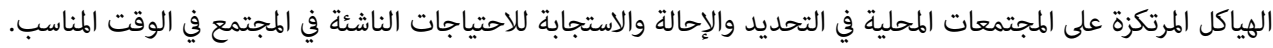

ولإثراك الهياكل المجتمعية بفاعلية في تحقيق هذه الأهداف، واصلت المفوضية، جنباً إلى جنب مع شركاء حماية الطفل والشباب والعنف الجنسي والجنساني، والهن

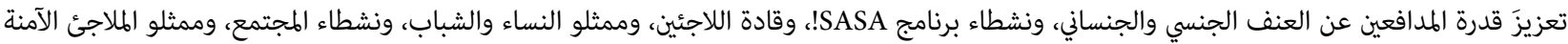

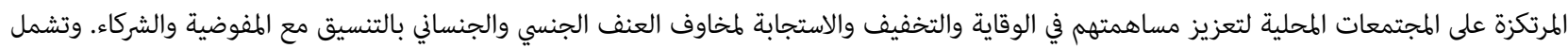

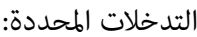

o o

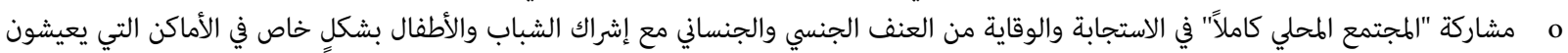
ويلعبون ويعملون ويتعلمون فيها.

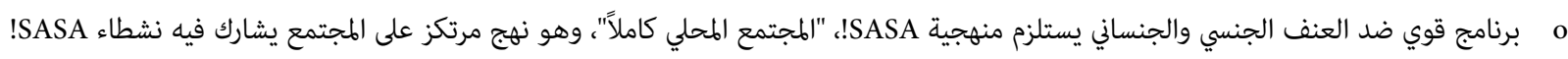

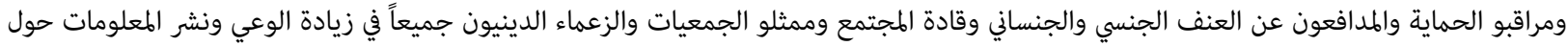
العنف الجنسي والجنساني على مستوى القرية. o المشاركة المتعمدة للفتيان والرجال في برنامج العنف الجنسي والجنساني كمحفزات للتغيير السلوكي الإيجابي.

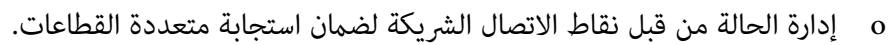
o

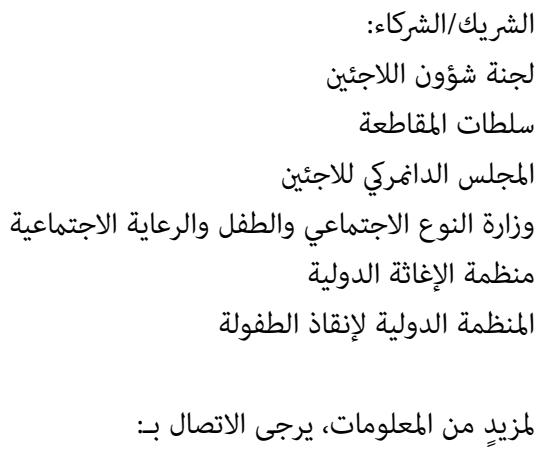

SO Bunj AoR 
